\title{
State-of-the-art of Surface Integrity in Machining of Metal Matrix Composites
}

\author{
Zhirong Liao ${ }^{\mathrm{a}}$, Ali Abdelhafeez ${ }^{\mathrm{a}}$, Haonan Li ${ }^{\mathrm{b}}$, Yue Yang ${ }^{\mathrm{b}}$, Oriol Gavalda Diaz ${ }^{\mathrm{a}}$, Dragos \\ Axinte ${ }^{a, b, *}$ \\ a Machining and Condition Monitoring Group, Faculty of Engineering, University of Nottingham, NG7 2RD, UK \\ b Department of Mechanical, Materials and Manufacturing Engineering, The University of Nottingham Ningbo, China
}

\begin{abstract}
Metal matrix composites (MMCs), as advanced substitutes of monolithic metallic materials, are currently getting an increasing trend of research focus as well as industrial applications for demanding applications such as aerospace, nuclear and automotive because of their enhanced mechanical properties and relative lightweight. Nevertheless, machining of MMC materials remains a challenging task as a result of their structural heterogeneity which leads to deterioration of the machined surface integrity and rapid tool wear. While prior review papers have concentrated on the other machining aspects (e.g. process modelling and tool wear) of MMCs, none of them has addressed the subject of reviewing workpiece surface integrity aspects in details. This paper presents a detailed literature survey on the conventional and nonconventional machining of metal matrix composites with the primary focus on the aspects related to workpiece surface integrity. The contribution of material mechanical and microstructural properties as well as the material removal mechanism upon the quality of workpiece surfaces/subsurface are discussed along with their influences on the fatigue performance of machined part.
\end{abstract}

Keywords: Metal matrix composites; Machining; Surface integrity; Fatigue

\section{Contents}

1. Introduction

2. Material definition

3. Surface integrity of Metal Matrix Composites

4. Conventional Machining of Metal Matrix Composites

4.1. Orthogonal cutting and turning

4.2. Drilling, milling and grinding

5. Non-Conventional Machining of Metal Matrix Composites

5.1 Laser (assisted) machining

5.1.1 Laser assisted machining

5.1.2 Laser machining

5.3 Abrasive waterjet machining

5.4 Electro-discharge machining

6. Effect of MMCs surface integrity on fatigue performance

7. Summary and Outlook 


\section{Introduction}

With their advantages of lightweight and high specific properties (e.g. strength, stiffness and wear resistance), in recent decades, the Metal Matrix Composites (MMCs) are getting an increased attention from both the research and industrial applications point of views. This drives the development of MMCs for their use in numerous fields such as aerospace, nuclear and ground transportation industries as strong alternative materials. The value of global MMCs market has been reported at USD 460.5 Million in 2016 and this value is projected to reach USD 619.1 Million by 2021 at a CAGR of $6.10 \%$ [1]. Moreover, the growing trend of academic publications started since the 1970s on the research of material synthesis while reports on machining research started to pick-up in the 1980s and increased in an accelerated rate from 2000s (Figure 1).

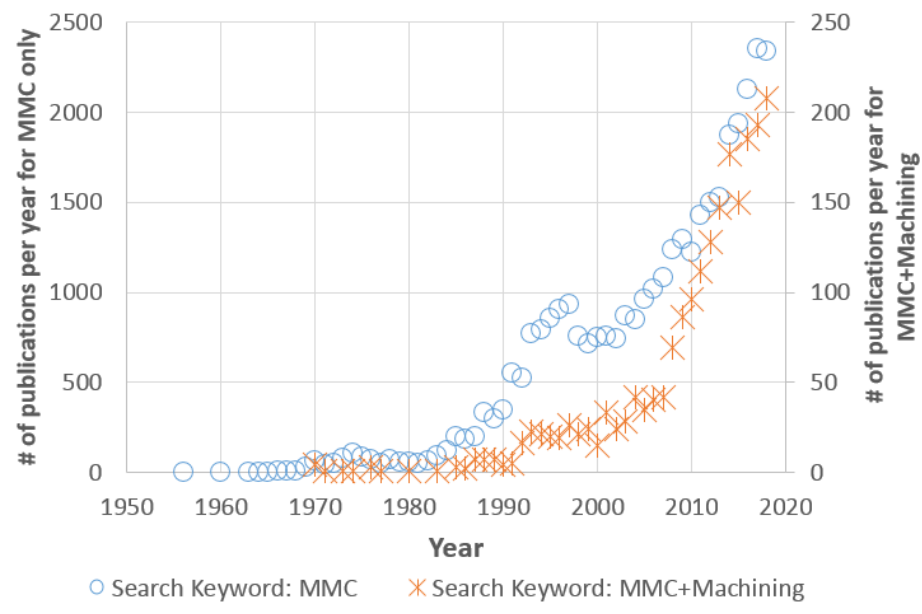

Figure 1 Evolution of the number of academic publications in reference to "Metal matrix composites" and "Metal matrix composites Machining" showing the 'phase shift' between the research in material development and machining technologies [source: Scopus]

Similar to other composites, MMCs are a combination of two or more constituents with a structure constituted from a matrix (metal) and a reinforcement (e.g. mainly particles or continuous/discontinuous fibres). The metal matrix distributes the loading stress and provides the compliant support for the structure while the embedded particles or fibres deliver higher physical and/or mechanical performance (e.g. higher strength, better wear resistance or higher thermal efficiency) in a preferential (fibre reinforced) or non-preferential (particle reinforced) directions within the material bulk [2]. This particular material structure leads to the advantage of achieving higher performance when compared to their equivalent non-reinforced metallic alloys; see Figure 2 where an increased strength of the MMCs compared with the monolithic material is depicted [3-5]. On one hand, this is advantageous when using these materials in demanding applications but, on the other hand, makes the use of conventional machining processes more difficult. Particular hurdles to good machinability of MMC include, heterogeneous structure which leads to anisotropic thermal and mechanical properties thus the variable thermal and mechanical loading on cutting tools, as well as the abrasive nature of the 
reinforcing constituents which highly affects the tool life [6]. Furthermore, the low machinability of MMCs could also lead to severe workpiece surface defects (e.g. micro/macro cracks of the matrix, pull-out of the reinforcement particles), which would further deteriorate the materials performance in their service life. Meanwhile, nonconventional machining methods, such as electro discharge machining-EDM, laser and abrasive waterjet machining, have also been employed for the machining of this type of materials aiming to achieve a high productivity. However, although these methods have a higher potential for MMCs machining over the conventional machining methods [7], different non-conventional machining processes have their own drawbacks in this application, which would lead to low unfavourable workpiece surface integrity.

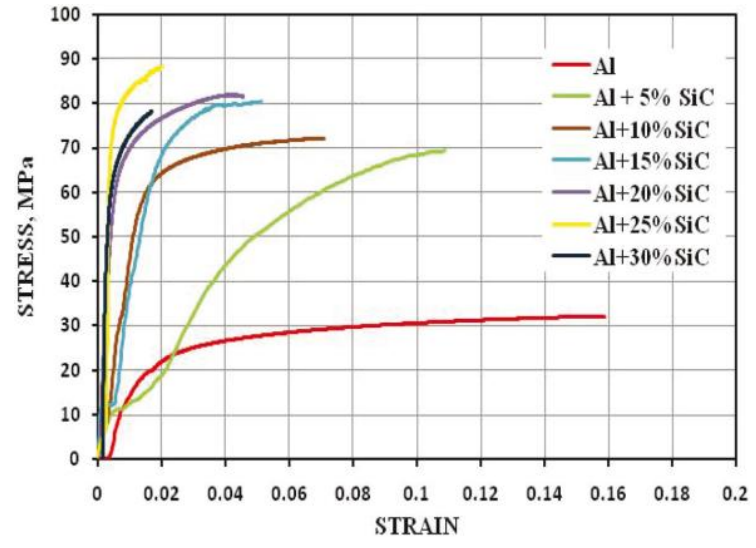

(a)

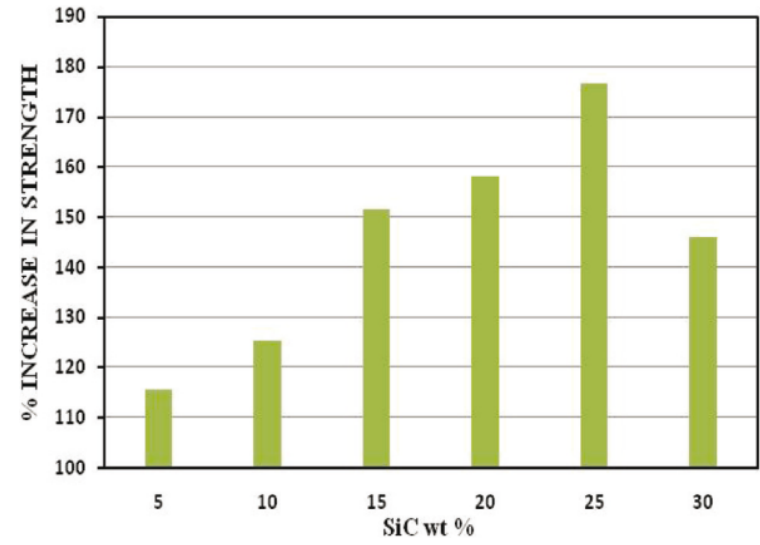

(b)

Figure 2. An example on how variations of wt\% of reinforcement constituent (SiC) influence the strain-stress curves of the Al based MMCs when compared with pure Al matrix (a) and the dependence of tensile strength on SiC wt\% content for Al based composites (b) [3].

The challenges in manufacturing MMCs plus the difficulties in generating complex shapes by machining at low costs and achieving high dimensional/geometrical accuracies as well as acceptable workpiece surface integrity seems to limit the market growth and industrial applications [3]. Recently, a large amount of research reporting on optimising the machining technology of MMCs including several reviews were published [8-11]. However, these surveys mainly focused on the machinability aspects (e.g. tool performance, cutting force) while the surface integrity of these materials, which is of key importance for their functionalities, has been on-the-odd occasions commented. As Fig. 3 indicates, it is evident the scarcity of review articles with nearly unavailable surveys focusing on the surface integrity of machined MMCs (Figure 3). 


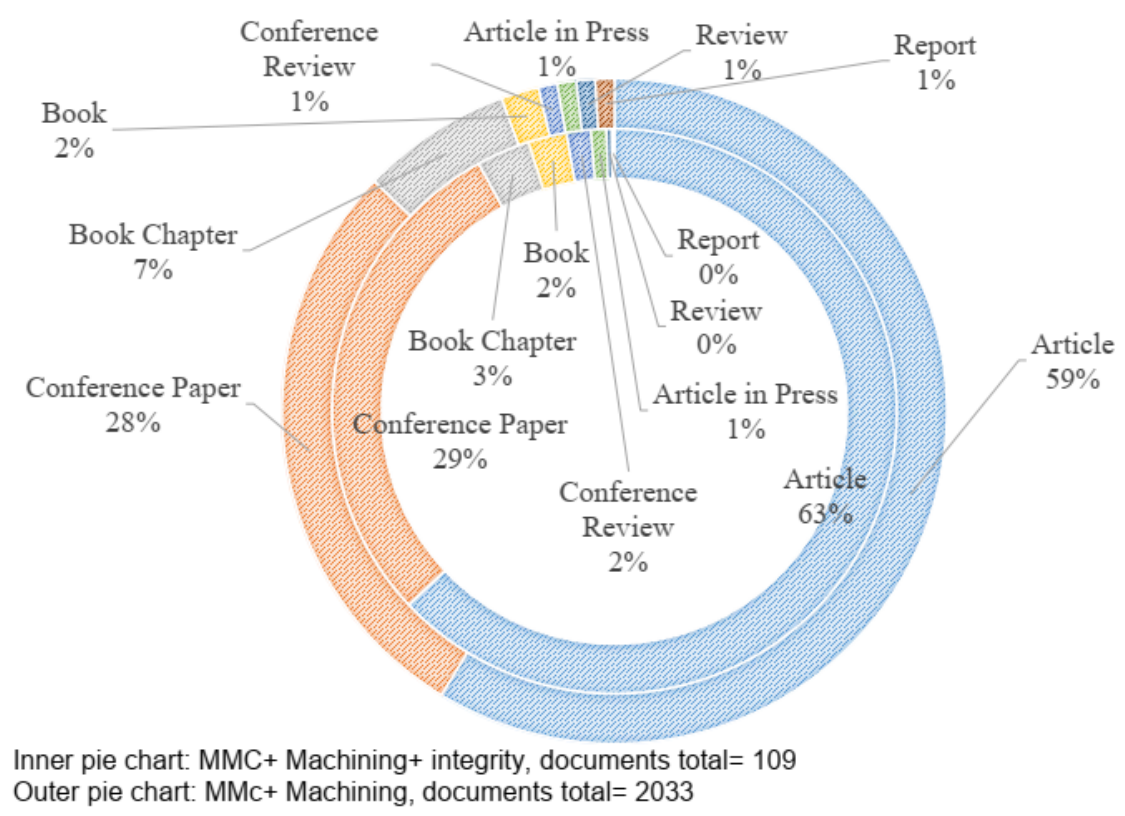

Figure 3 Analysis of research publications on MMCs machining showing the scarcity of review articles focused on surface integrity [Source: Scopus].

Therefore, this article is dedicated to present the current views on the understanding the surface integrity of metal matrix composites following conventional and non-conventional machining operations as well as their effects on the component functional performance. Thorough survey is introduced by starting from the material structure/definition and followed by workpiece surface integrity resulted from conventional processes such as orthogonal cutting, turning, drilling, milling and grinding. Subsequently, a section on non-conventional machining processes including laser, laser-assisted, abrasive waterjet, electro-discharge machining and their effects on surface integrity was introduced. The review concludes with a section focusing on the effect of the surface integrity on the fatigue performance of machined MMC components.

\section{Metal Matrix Composites: Material definition}

As a special type of advanced composites, MMCs have been applied in numerous industrial applications by providing better performance when compared with monolithic metals. MMCs refer to the composites consisting of at least two phases, in which the matrix maintains the shape of the material while the reinforcements provide the desired physical and mechanical properties. As shown in Figure 4, the main constituents used in MMCs are: 


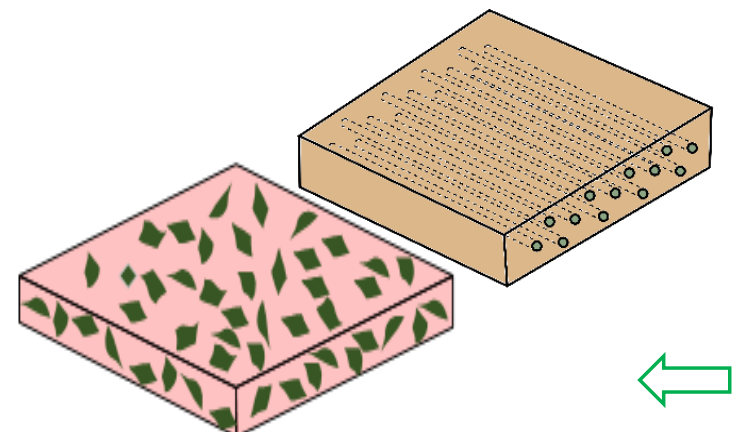

Metallic Matrix Composite

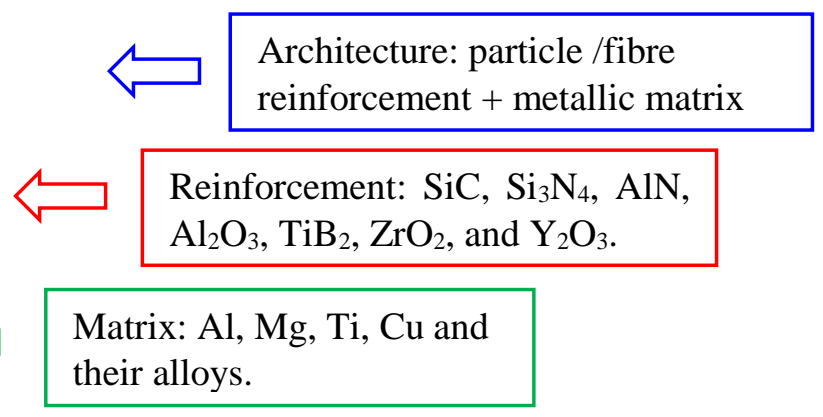

Figure 4 Generic structure of Metal Matrix Composites

(i) Matrix - refers to monolithic metals which provides the compliant support for the reinforcements. The most common matrix materials for MMCs are light-weight metals such as $\mathrm{Al}, \mathrm{Mg}$, $\mathrm{Ti}$ and their alloys.

(ii) Reinforcement - refers to the constituents embedded in the matrix as either discontinuous particles (e.g. $\mathrm{SiC}, \mathrm{Al}_{2} \mathrm{O}_{3}$, NiTi, Fullerene, $\mathrm{TiO}_{2}$, and graphite), monofilament continuous fibres (e.g. SiC, W) or whiskers (e.g. C, SiC, W). The reinforcement is added mainly to change the physical properties such as thermal conductivity and expansion coefficient (CNT particles, $\mathrm{C}$ fibres) and/or to modify the mechanical performance such as yield strength (TiC particles, $\mathrm{SiC}$ fibres), wear resistance ( $\mathrm{SiC}$ particles, W fibres), creep resistance $\left(\mathrm{Al}_{2} \mathrm{O}_{3}\right.$ particles, $\mathrm{C}$ fibres), matrix-reinforcement interfacial bonding strength $\left(\mathrm{B}_{4} \mathrm{C}\right.$ particles, $\mathrm{C}$ whiskers).

In comparison with polymer composites, MMCs, generally, have higher quasi-isotropic stiffness, strength, hardness, and high thermal resistance in addition to, improved creep resistance, fatigue performance, toughness, and electrical properties. This improved performance results in an increased utilisation of MMCs in high value-added industries such as nuclear, defence, automobile, aerospace, marine and electronics, as well as other commercial industries such as sport goods and medical equipment. Figure 5 summarises the most common structure, constituents (i.e. matrix, reinforcement), key properties, and examples of utilisation for the MMCs. 


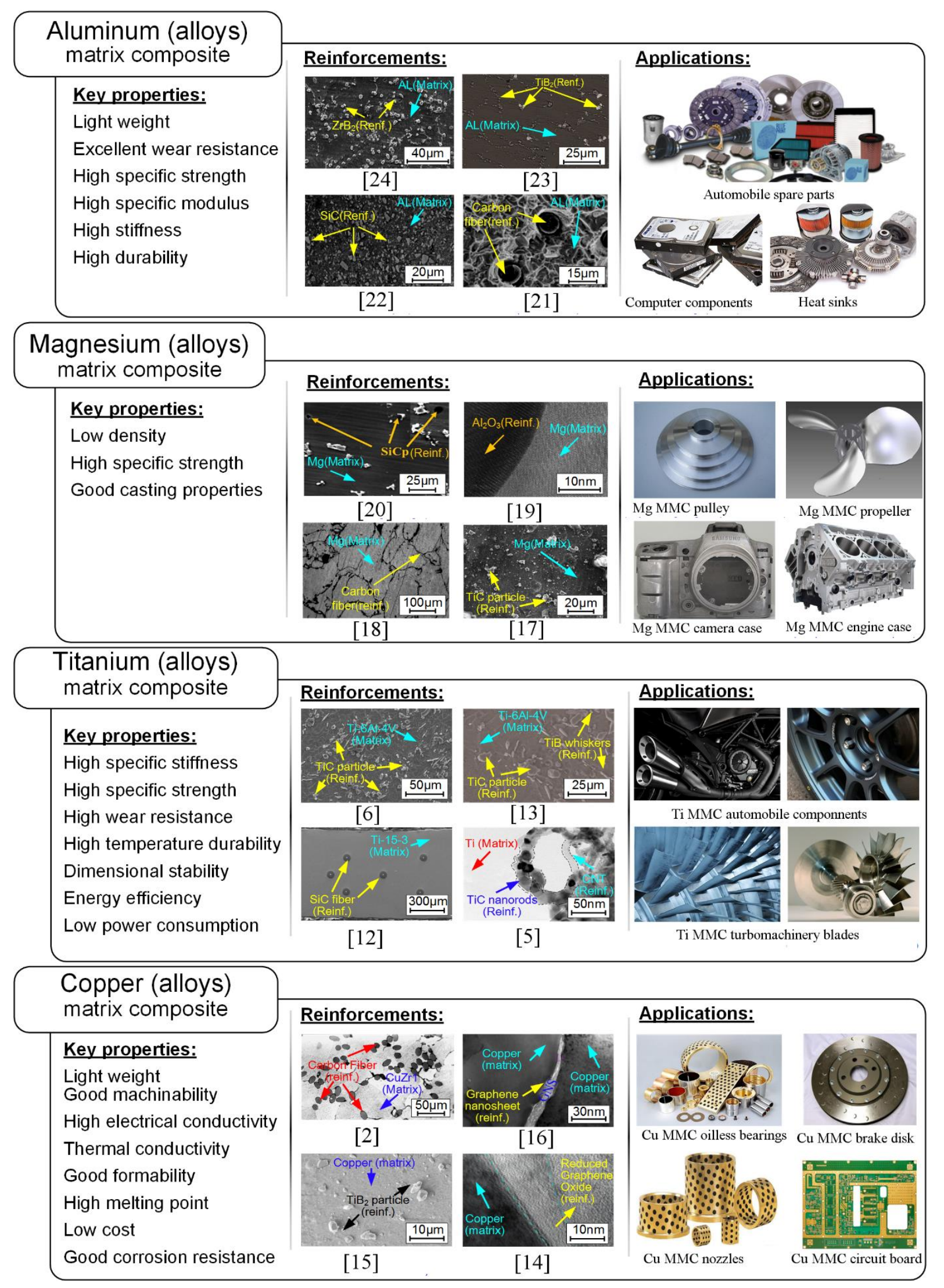

Figure 5 Typical matrix types, reinforcement categories and key properties as well as common applications of $\mathrm{Al}, \mathrm{Mg}$, Ti and Co based MMCs [2,5,6,12-24] 


\section{Surface integrity after machining of Metal Matrix Composites}

MMCs are usually designed to be applied in harsh conditions for various industries (i.e. nuclear, aerospace, and defence) with their main advantages such as light weight, high wear resistance, elevated corrosion resistance, high strength and high stiffness [25-27]. Thus, the workpiece surface integrity of MMCs after machining is a critical aspect which influences the components' functional performance as well as the service life. Nevertheless, with the heterogeneous structure of the MMCs, the material damage generated on both the free surface and superficial layer during the machining needs to be carefully considered to allow an enhanced workpiece performance.

Surface integrity is a comprehensive description for the machined surface quality, including surface topography (e.g. surface roughness and waviness), metallurgical state (e.g. microstructure and microdefects) and mechanical characteristics (e.g. microhardness and residual stresses) below the free surface [28-30]. For MMCs, which are recognised as difficultto-cut materials, it is common that the defects after machining manifest as interface debonding between hard particles and ductile matrix, pulled out of reinforcements (e.g. particles) and microcracks of the matrix; these are heavily influenced by the MMCs' anisotropic structures when interacting with the machining end-effectors (e.g. cutting tools). For instance, some reinforcement particles are inclined to be cut through, pulled out or even pressed into the matrix, which could increase dislocations that lead to surface/subsurface work hardening [911]. Also, both residual stresses and dislocations induced by thermal fields could be generated in MMCs during the machining process due to the difference of thermal expansion between matrix and reinforcements [31,32]. Hence, a careful understanding of the effect of the machining process on the surface of MMCs is of critical relevance for their industrial applications.

Surface topography includes both surface roughness and waviness which could be accessed with contact (stylus/laser profilometers) [33,34] and non-contact (3D interferometry) measurements [35-37]. Due to the nature of the reinforcement in MMCs, it allows more applications for parts undergoing high friction and cycle loading conditions wherein the surface topography is of great concern. Nevertheless, the heterogeneous nature of MMCs could lead to higher surface roughness and waviness during the machining process due to cutting forces variations and probable reinforcement phase pull-out of the matrix. Same as other materials, the surface topography of MMCs is dependent on the machining parameters related to various manufacturing operations which will be in-detail introduced in the following sections.

Surface integrity from the metallurgical point-of-view includes physical, chemical and metallurgical alterations or defects generated by plastic deformation, phase transformation and recrystallisation on the free surface and subsurface of the machined workpiece. Scanning electron microscopy (SEM) has been widely used to examine the microstructural changes of machined surfaces of MMCs, where the grain deformation, voids, particles cracks, protuberances and matrix tearing caused by high plastic deformation on metallic matrix as well 
as particles removal have been found on the workpiece surface and subsurface $[7,8]$. In terms of phase contrast examination, techniques such as Energy-Dispersive Spectroscopy (EDS), Electron Backscatter Diffraction (EBSD), Transmission Electron Microscopy (TEM) and Xray diffraction (XRD) have been employed for the in-depth analysis [32,38,39] (see Figure 6). EBSD is now becoming a popular technique as it has been widely used to provide quantitative information about grain characterisation of the machined workpiece including the grain orientation and phase identification [40-42]. However, to the authors' best knowledge, although EBSD has been employed for characterising some of the advanced materials after machining process, there is no such research on MMCs. TEM has also been employed to reveal the deformation patterns of the work hardening matrix [43] and the dislocation pile-ups closed to the machined surface [44]. Moreover, the selected-area electron diffraction (SAED) pattern of TEM can provide important crystal structure of the phases formed and transformed in a particular area [45] of MMCs which are induced during the machining process. X-ray diffraction (XRD) was used for phase analysis to reveal the chemical composition and its quantitative analysis of machined MMCs based on elements evaluation in the measured workpiece [46].

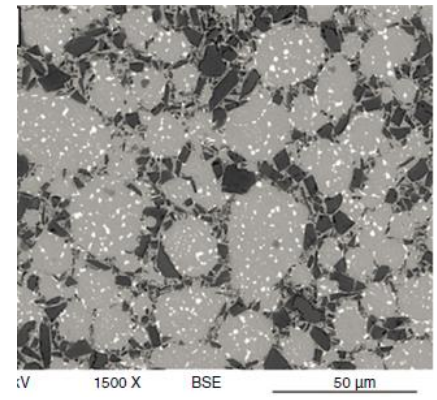

(a)

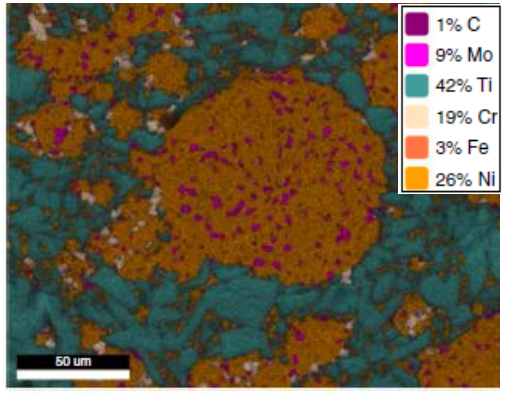

(b)

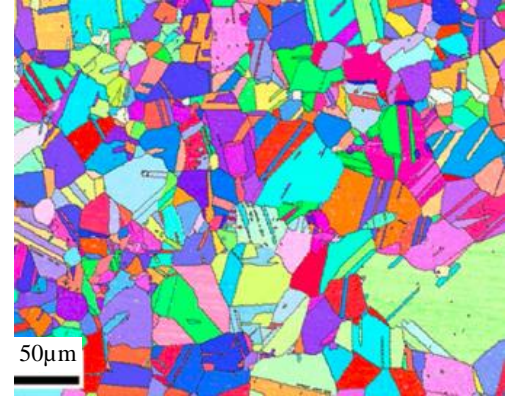

(c)

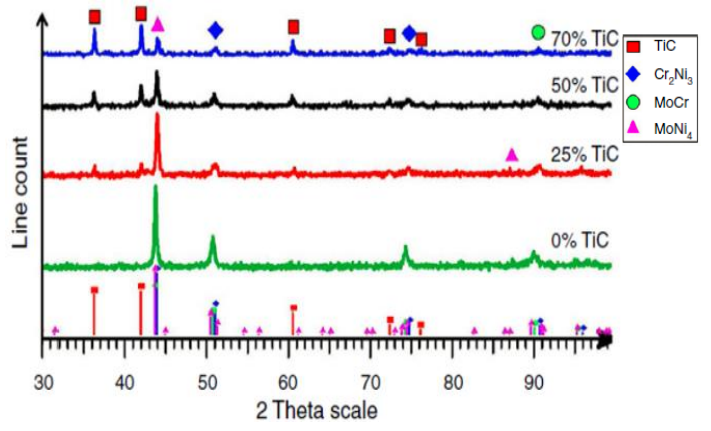

(d)

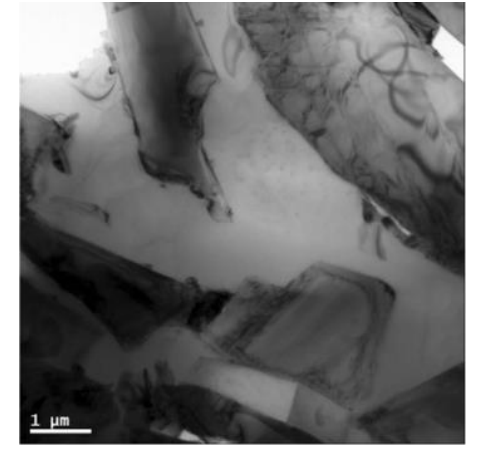

(e)

Figure 6 Surface metallurgical characteristics of MMCs detected by various measurement techniques: microstructural features of the TiCp/Inconel MMCs by SEM (a), elemental distributions of the TiCp/Inconel MMCs by EDS mapping (b), grain characterisation of the TiCp/Inconel MMCs by EBSD (c), Component analysis of the TiCp/Inconel MMCs by XRD (d), and the microstructure of the SiC/Al MMCs by TEM (e) [38,39]

The changes in mechanical characteristics of MMCs after manufacturing operations are mainly contributed by the process induced stresses, deformations and temperatures. As one of 
the main mechanical characteristics, microhardness variations are used as an indicator of the imperfections that could be induced within the machined surface. Owing to the existence of reinforcements, the microhardness of MMCs detected by the micro-indentation tests is highly related to intergranular fractures, dislocation density and porosity distributions as well as the formation of a surface hardening layer. Residual stresses which are retained in the superficial layer of the material after the manufacturing operations are difficult to be modelled, especially for MMCs because of their anisotropic nature. Mechanical/physical measurements, which include non-destructive methods such as X-ray Diffraction, Neutron Diffraction, and Raman spectroscopy, and destructive methods such as hole drilling, slitting, selective etching, are the main approaches to access the residual stresses of machined MMCs [47].

\section{Conventional Machining of Metal Matrix Composites}

Conventional machining operations generally provide high geometrical quality of produced surfaces compared to non-conventional ones. Nevertheless, by involving cutting tools, conventional machining can introduce high levels of plastic deformations and heat generation that lead to subsequent alterations of workpiece surface properties. In the following sections, the fundamentals of material removal and effects on surface integrity of MMC are presented through studying of orthogonal cutting. Then, oblique cutting processes (e.g. turning, drilling, milling and grinding) are considered in the subsequent sections.

\subsection{Orthogonal cutting and turning of MMCs}

As a simplified cutting process, orthogonal cutting provides accessible tool for studying the cutting mechanics and surface integrity, which are not only controlled by process parameters but also by geometry, physical properties and volumetric concentration of the reinforcing constituents.

Generally, in orthogonal cutting of MMCs the geometrical defects like micro-cracks, voids, pits and craters are predominantly formed due to particle fracture, complete pull-out and reinforcement/matrix interfacial debonding with particle left within the matrix, as shown in Figure 7 [48]. These defects are mainly relevant to the reinforcing constituents (e.g. average particle size and volume fraction) as well as selection of cutting parameters, which could lead to excessive cutting forces and temperature. It was found that strain hardening variation and hardened layer depth increased with decreasing cutting speed, increasing undeformed chip thickness and decreasing particle volume fraction. The effect of volume fraction and particle size on the change in microhardness under the free machined surface (Figure 8) was attributed to the tendency of the matrix to plastically flow between the particles that act as deformation barriers. This leads to plastic deformation localization/restraining, thus less work hardening, of the material with increase in particle sizes and/or volume fraction. 


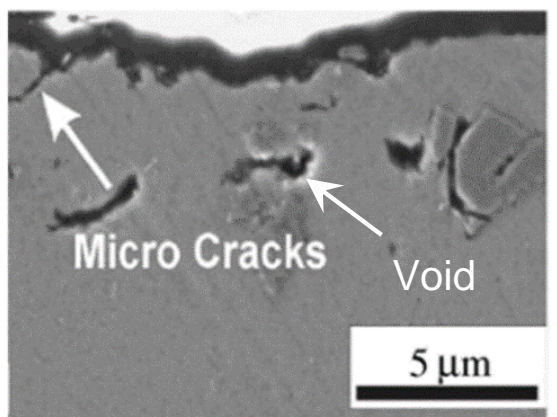

(a)

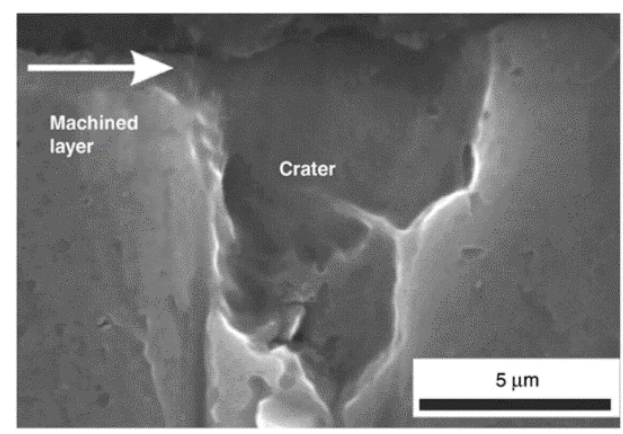

(b)

Figure 7 Typical machined surface/subsurface damage encountered when orthogonal cutting of Alumina reinforced aluminium 6061 matrix composite (cutting speed $\{v\}: 60 \mathrm{~m} / \mathrm{min}$, feed rate $\{f\}: 0.1$ $\mathrm{mm} / \mathrm{rev}$, depth of cut $\{\mathrm{DoC}\}: 3 \mathrm{~mm}$ ): micro cracks and voids (a) and crater (b) [48].

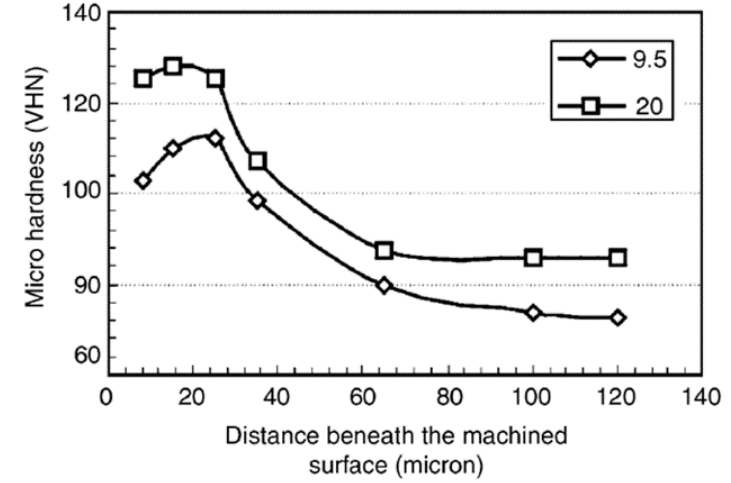

(a)

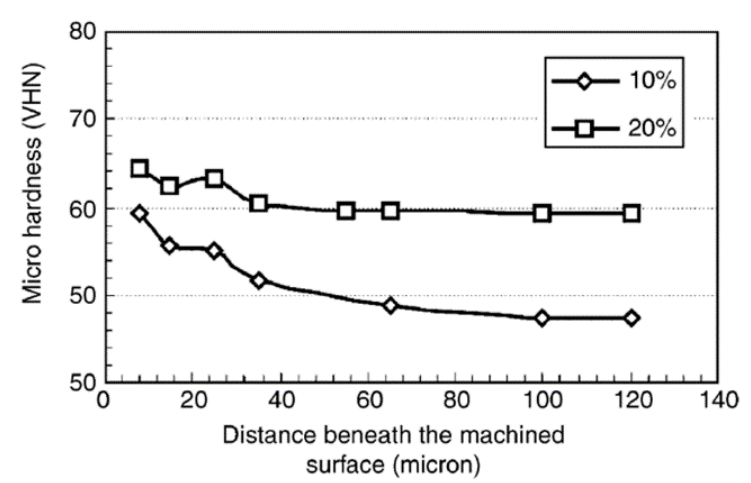

(b)

Figure 8 Effect of Alumina reinforcement properties on 6061 aluminium matrix microhardness under machined surface (v: $60 \mathrm{~m} / \mathrm{min}, \mathrm{f}: 0.1 \mathrm{~mm} / \mathrm{rev}, \mathrm{DoC}: 3 \mathrm{~mm}$ ): Average particle size in $\mu \mathrm{m}(\mathrm{a})$; Volume fraction (b) [48].

This explanation was supported by later findings of Kannan et al. [43] when examining the dislocations within the machined subsurface of Alumina reinforced AA6061 MMC. As depicted in Figure 9, with an increase in reinforcement density or size, the length of dislocation lines increased due to a larger activation energy required to glide past the barriers (i.e. to subsequently deform at the same cutting parameters and tool/workpiece configuration). 


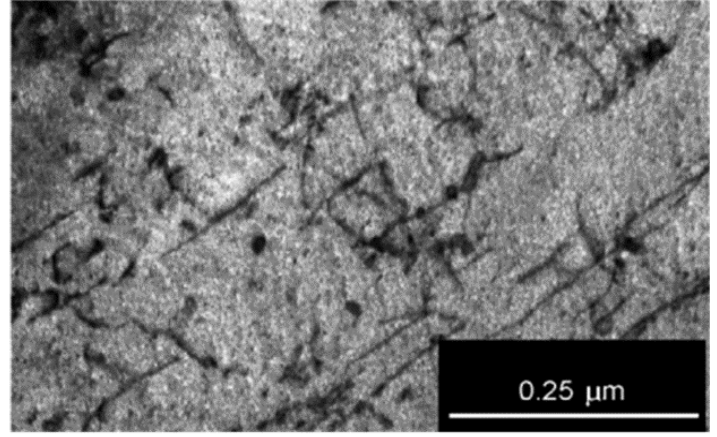

(a)

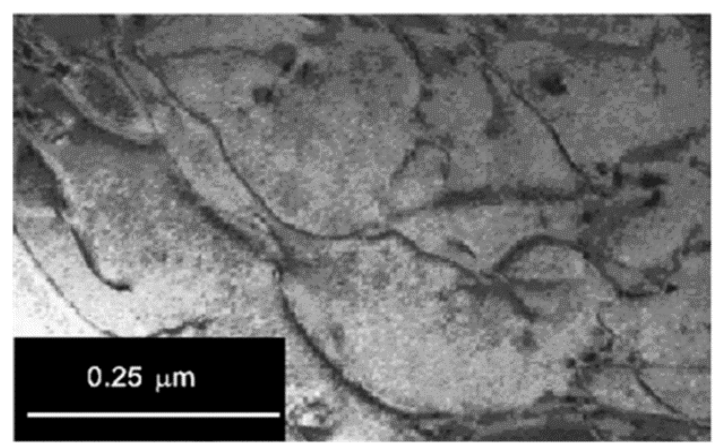

(b)

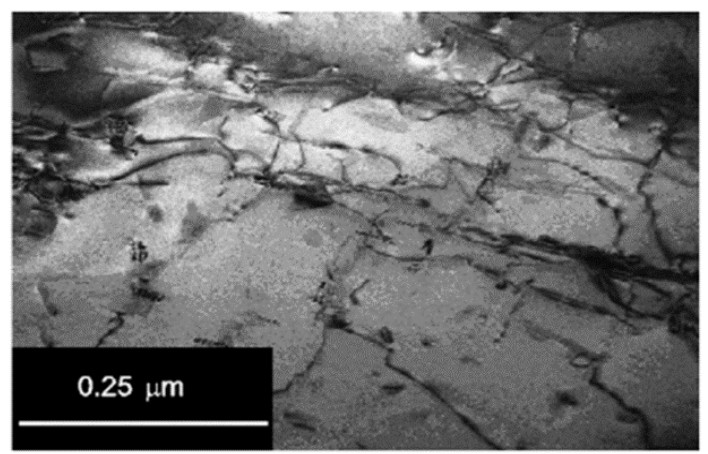

(c)

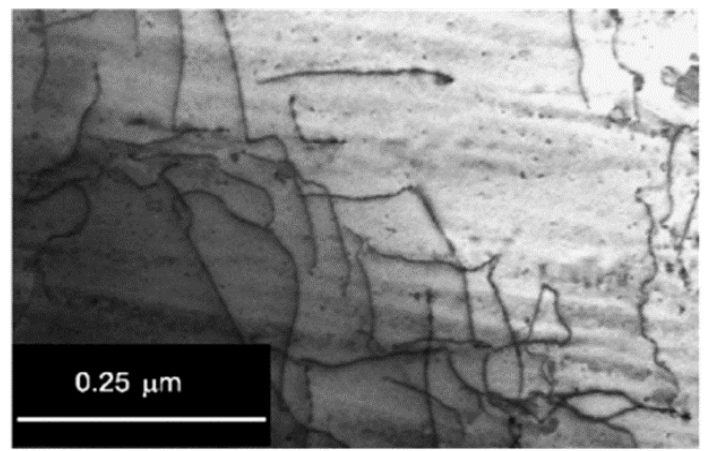

(d)

Figure 9 Line defects/dislocations formation during cutting Alumina reinforced 6061 MMC (v: 30-60 $\mathrm{m} / \mathrm{min}$, uncut chip thickness: $0.1 \mathrm{~mm}, \mathrm{DoC}: 3 \mathrm{~mm}$ ) with particle size $9.5 \mu \mathrm{m}(\mathrm{a}), 25 \mu \mathrm{m}(\mathrm{b})$, volume fraction 10\% Alumina (c) and 20\% Alumina (d) [43].

Considering its heterogeneous structure, the state of the surface integrity of MMCs is also dependent on particle position relative to the cutting edge. By a micro-mechanical finite element analysis, Ghandehariun et al. [49] showed three cases of particle-tool interaction depending on the their position above, below or in the middle of the cutting plane/surface, while the resulted cavities and residual stress has been revelled with completely different observations on these three conditions (Figure 10). In the case of particle above the machining plane, significant cavities and tensile residual stresses would be produced due to the pull-out of the particles from the matrix. Conversely, no cavities were produced for the other two cases due to tool flank pushing the particles into the matrix, which resulted in compressive residual stresses. The relative position of the reinforcing particles with respect to cutting edge also influences the surface roughness as the reinforcement particles could be elongated, sheared or pulled out during the machining process, as exemplified for turning in Figure 10 [50]. Moreover, results also showed that adding Bismuth (Bi) to the alloy ( $\mathrm{Al}-20 \% \mathrm{Mg}_{2} \mathrm{Si}-0.4 \% \mathrm{Bi}$ instead of $\mathrm{Al}-20 \% \mathrm{Mg}_{2} \mathrm{Si} \mathrm{MMC}$ ) could alter the morphology of coarse $\mathrm{Mg}_{2} \mathrm{Si}$ reinforcements with decreasing the mean size of particles by $52 \%$ while increasing the mean density and aspect ratio by $174 \%$ and $4 \%$ respectively. Therefore, relatively small pit holes and voids were observed on the cross sections of the Bi-modified machined surface. Additionally, Bi addition led to lower cutting forces, low tendency to form built-up edge and better surface roughness due to localized melting of Bi during turning [50]. 


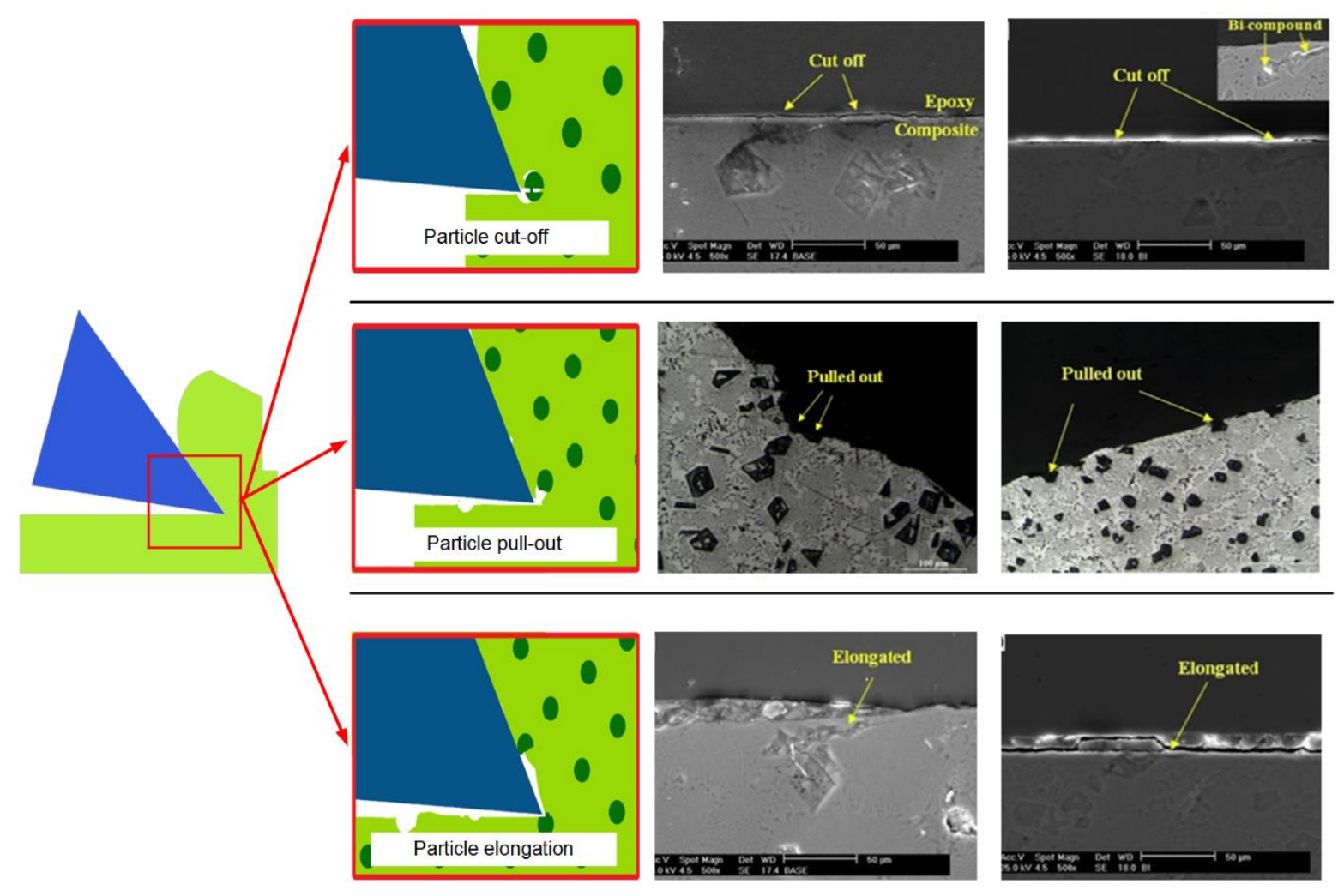

Figure 10 Different scenarios of tool-particle interactions with the corresponding machined surface micrographs featuring particles shearing/ cut-off (top), pull-out (middle) and elongation/deformation (bottom). Micrographs correspond to turning of Al-20\% Mg 2 Si at v: $210 \mathrm{~m} / \mathrm{min}$, f: $0.2 \mathrm{~mm} / \mathrm{rev} \mathrm{[49,}$ $50]$.

Among other conventional cutting process, turning of MMCs is facing the challenge of intense tool wear with inherent alteration of the surface integrity for a given tool life. Ge et al. [51] showed that using of single crystal diamond (SCD) tool led to reduction of particle pullout/cavity formation in the machined surface when turning a SiC/Al MMC. While these results were not explained in-depth, the reason for this might be caused by enhanced tool thermal diffusivity and reduced tool nose radius/ higher sharpness of SCD compared to PCD tools. It was also depicted that increasing the volume fraction of reinforcement would lead to a more deteriorated machined surface as a result of more particles pull-out [51].

Kannan and Kishawy [52] observed that coolant usage detrimentally affected the surface integrity when turning AA7075-10\% Alumina and AA6061-10\% Alumina. From Kannan and Kishawy point of view [52], it was expected that the samples being cut under dry conditions would have higher tensile residual stresses in the aluminium matrix than in wet conditions due to the thermal expansion of affected layer. The introduction of higher tensile residual stresses leads to tearing of the softened material under tool flank and formation of surface cracks in dry conditions, as shown in Figure 11. 


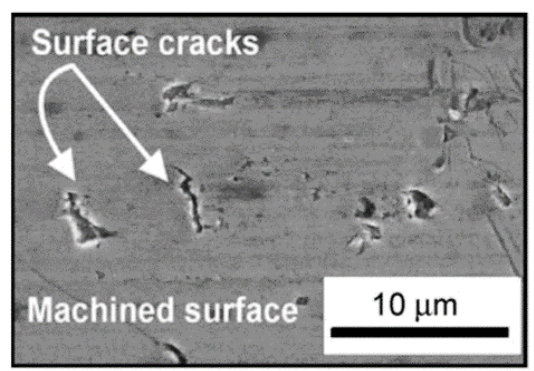

(a)

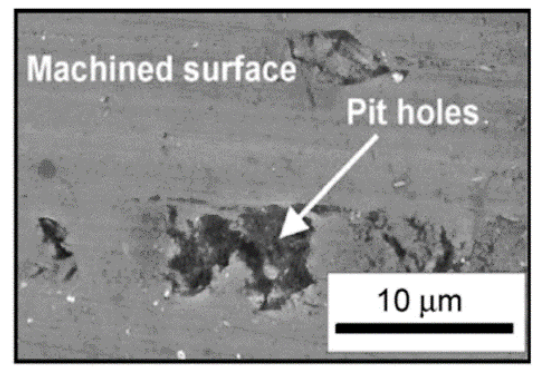

(b)

Figure 11 Influence of coolant on the nature of the defects on the machined surface (7075-Alumina $M M C$ ): Dry cutting (a) and Wet cutting (b) [52].

Considering that the machining and deformation mechanisms of MMCs are more complicated compared with those found for monolithic (non-reinforced) materials, the mechanisms of residual stress generation are likely to be more intricate for the former due to the interaction between matrix and reinforcements. The effects of the machining parameters on the surface residual stress were presented to be different when comparing monolithic material (e.g. AA6061) to MMC (e.g. AA6061-20\% SiC), as shown in Figure 12 [53]. Three main factors control the mechanical deformation and thus, residual stresses during machining of AA6061-20\% SiC MMC: (a) restriction of matrix flow due to the presence of particles, (b) indentation of the particles on the machined surface, as detailed before and observed in Figure 10 , and (c) high compression of the matrix found in between the particles and the tool. At low tool feed rates, these factors become very prominent. Increased percentage of particle fracture and debonding indicates higher tool-particle interaction at low feeds. However, with the increase of the feed rate, indentation effects of particles and work hardening induced by previous passes as well as tool-particle interaction decrease as less cutting passes are needed to remove a certain volume of material. Additionally, the increase of the temperature at toolworkpiece interface with the increment of the feed rate led to lower compressive residual stress values. However, these changes were overall relatively small as seen in Figure 12.

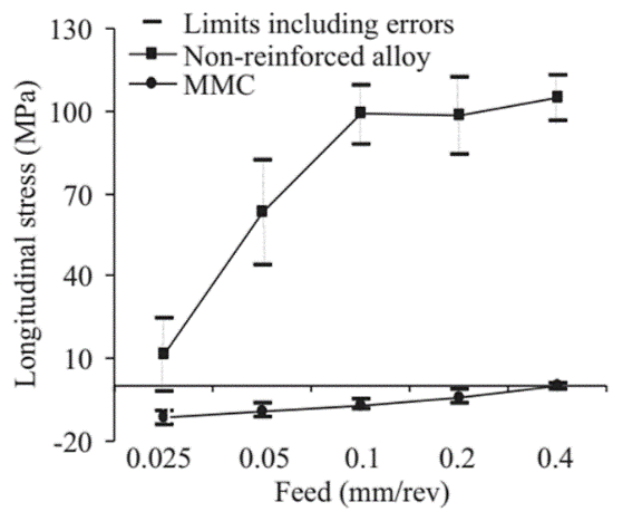

(a)

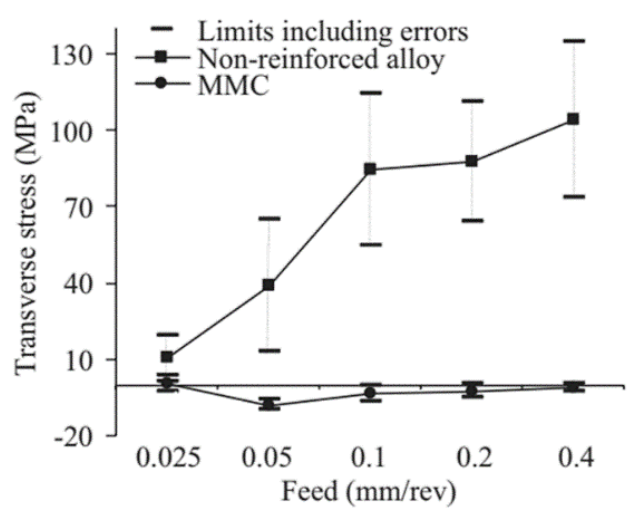

(b)

Figure 12 Effect of feed rate on residual stresses of machined AA6061-20\% SiC MMC at cutting speed $400 \mathrm{~m} / \mathrm{min}$ and depth of cut $1 \mathrm{~mm}$ : longitudinal (a); transverse directions (b) relative to the cutting speed direction [53]. 
From the part geometrical accuracy point of view, the greater thermal loads on the workpieces during the machining process could also be overcompensated by the significantly lower coefficients of thermal expansion of the MMC that is influenced by the reinforcement constituents. These significantly lower coefficients of thermal expansion cause a smaller expansion of the MMC workpiece, despite the greater thermal load. This reduced thermal expansion/distortion would lead to a higher geometrical accuracy for MMCs compared to nonreinforced alloys. It has been reported that the turning of Al-MMC 30/3 was subject to $12.8 \%$ greater thermal load than the workpieces of the non-reinforced alloy however, the coefficient of thermal expansion of the composite is $52.5 \%$ lower [54]. This difference in the coefficients of thermal expansion is sufficient in order to overcompensate the greater thermal load on the workpiece. The reinforcement of aluminium using a particle volume percentage of $17 \%$ (mean of the Al-MMCs 17/0.6 and 17/3) reduces the diameter deviation by $17 \%$ on average compared to non-reinforced alloy over all investigated cutting conditions. The reinforcement phase of 30 volume percent reduces the diameter deviation by $11 \%$. The comparison of the Al-MMCs $17 / 0.6$ and 17/3 reveals that the greater average particle size leads to $13 \%$ lower deviations from the nominal diameter [54] due to the lower tool temperatures, and consequently also lower tool holder temperatures.

\subsection{Drilling, milling and grinding}

Drilling and milling involve multi-cutting edges tools with complex geometrical features and tool move trajectories, whereby built-up of the temperature or dynamic loads could be generated that would affect the surface finish, e.g. tool chattering marks, as well as chip packing in tool flutes and subsequent increased cutting forces and deteriorated surface integrity. These difficulties would complicate the process analysis in general and surface integrity investigation in particular. Rajmohan et al. [55] studied the drilling of Al356/SiC-Mica MMC using WC coated and uncoated drills beside PCD tools. On the one hand, the increased percentage of Mica in the MMC reduced the cutting forces, tool wear and surface roughness significantly due to the probable solid lubrication effect. On the other hand, the increase of feed rate exhibited extensive surface damage due to the increased contact pressure at the tool nose/flank. The later results in surface cracks due to work hardening and heat generation which cause matrixreinforcements interface fracturing under mismatched thermal expansion and subsequent particles pull-out.

Adversely, the presence of hard reinforcement particles deteriorated the machined surface by formation of pits and grooves when end milling at high feed rates. This was evident when

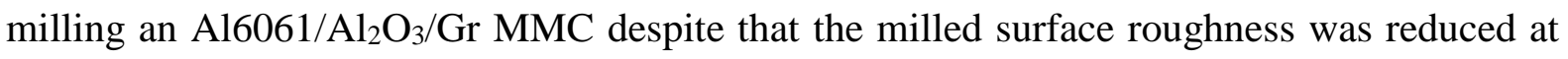
higher cutting speeds and lower feed rates due to the honing effect by the entrapped particles between the cutter and the workpiece surface [32].

Moreover, the material type of the reinforcement (e.g. metal or ceramic) in MMC has the main impact to the machined surface integrity in conventional machining. On one hand, while the usage of ceramic reinforcement constituents would be favourable (e.g. higher hardness, 
strength and low affinity to chemically react with the matrix) for the $\mathrm{MMC}$, the formation of surface pits and subsurface micro cracks are common flaws due to reinforcement partial pullout or interfacial bond fracture. On the other hand, the usage of ductile reinforcements would be required to enhance the mechanical performance of some MMCs via increasing matrixreinforcement interfacial bond strength and depth due to diffusion/alloying of the interface. Nevertheless ductile reinforcements also brings their own difficulties when machining such MMCs. Comparing the performance when milling metallic-metallic (reinforcement-matrix) MMCs to the corresponding performance of ceramic-metallic MMCs, the former would expedite higher surface damage by crack and top burr formations. Such difficulties were observed when micro-slot milling (twin fluted end-mill of $1 \mathrm{~mm}$ diameter) of metallic (Ti) versus ceramic $\left(\mathrm{TiB}_{2}\right)$ reinforcements in $\mathrm{Mg}$-based $\mathrm{MMCs}, \mathrm{Mg} / \mathrm{Ti}$ [56]. This was attributed to the lower thermal diffusivity, high ductility and adhesion of Ti. Meanwhile the thermal softening of both the matrix and reinforcement facilitate the formation of burrs and surface cracks by material adhesion and drag, as shown in Figure 13.

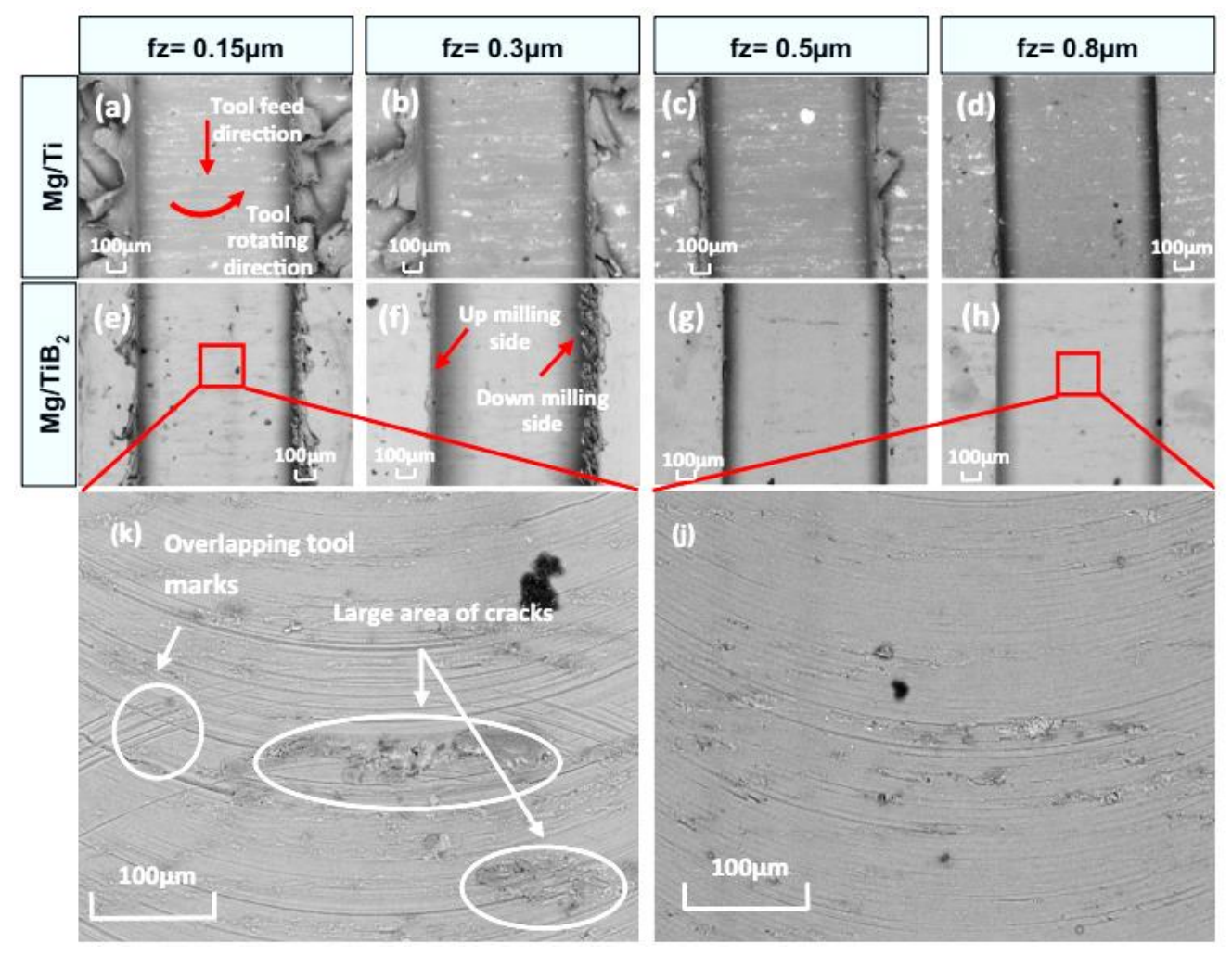

Figure 13 SEM micrographs of micro-milled slots for Mg/TiB2 MMCs and Mg/Ti MMCs at cutting speed of $250 \mathrm{~m} / \mathrm{min}$ and depth of cut of $200 \mu \mathrm{m}$ [56].

Nevertheless, not only the material type of the reinforcement but also the interfacial bond [57] affects the surface integrity. When milling of Al6061/B ${ }_{4} C$ MMC, the majority of $B_{4} C$ particles in the aluminium matrix were separated from the matrix forming voids because of the weak interfacial bond, as shown in Figure 14. Some of $\mathrm{B}_{4} \mathrm{C}$ particles are removed from the matrix and dragged under the cutting edge, thus, damaging the workpiece surface; additionally, several small cavities and crushed $\mathrm{B}_{4} \mathrm{C}$ particles were detected as well. Surprisingly, increasing 
the reinforcement content resulted in better machined surface quality due to less tool/workpiece friction coefficient as well as less heat diffusivity which reduced tool build up edge, matrix melting and subsequently particles pull-out.

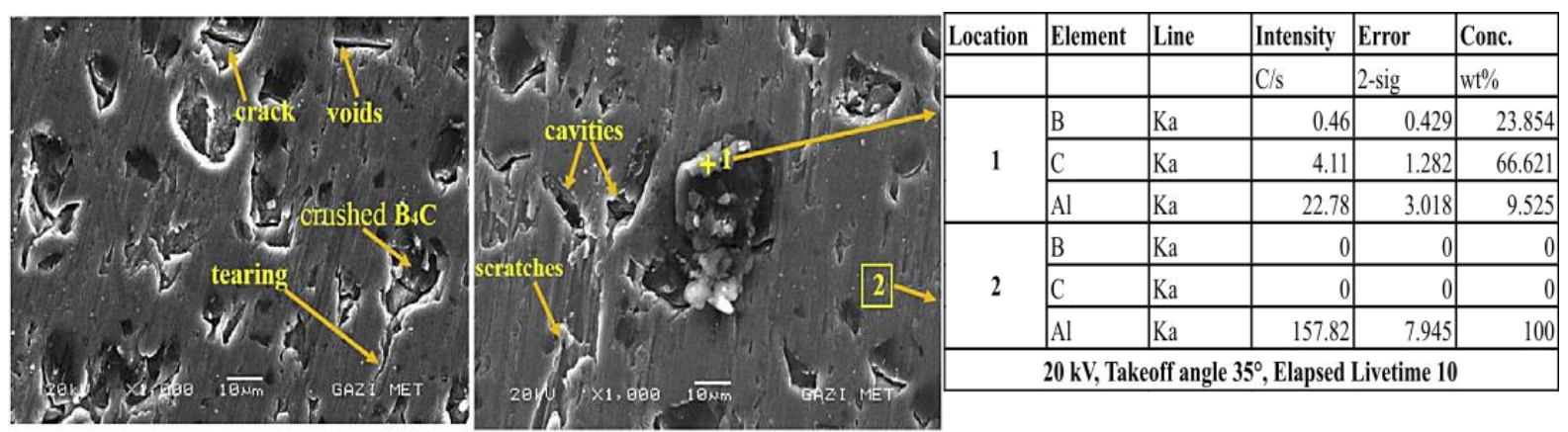

Figure 14 SEM micrograph of machined surface of Al6061/10 wt\% B4C at high magnification showing the anomalies on the surface [57].
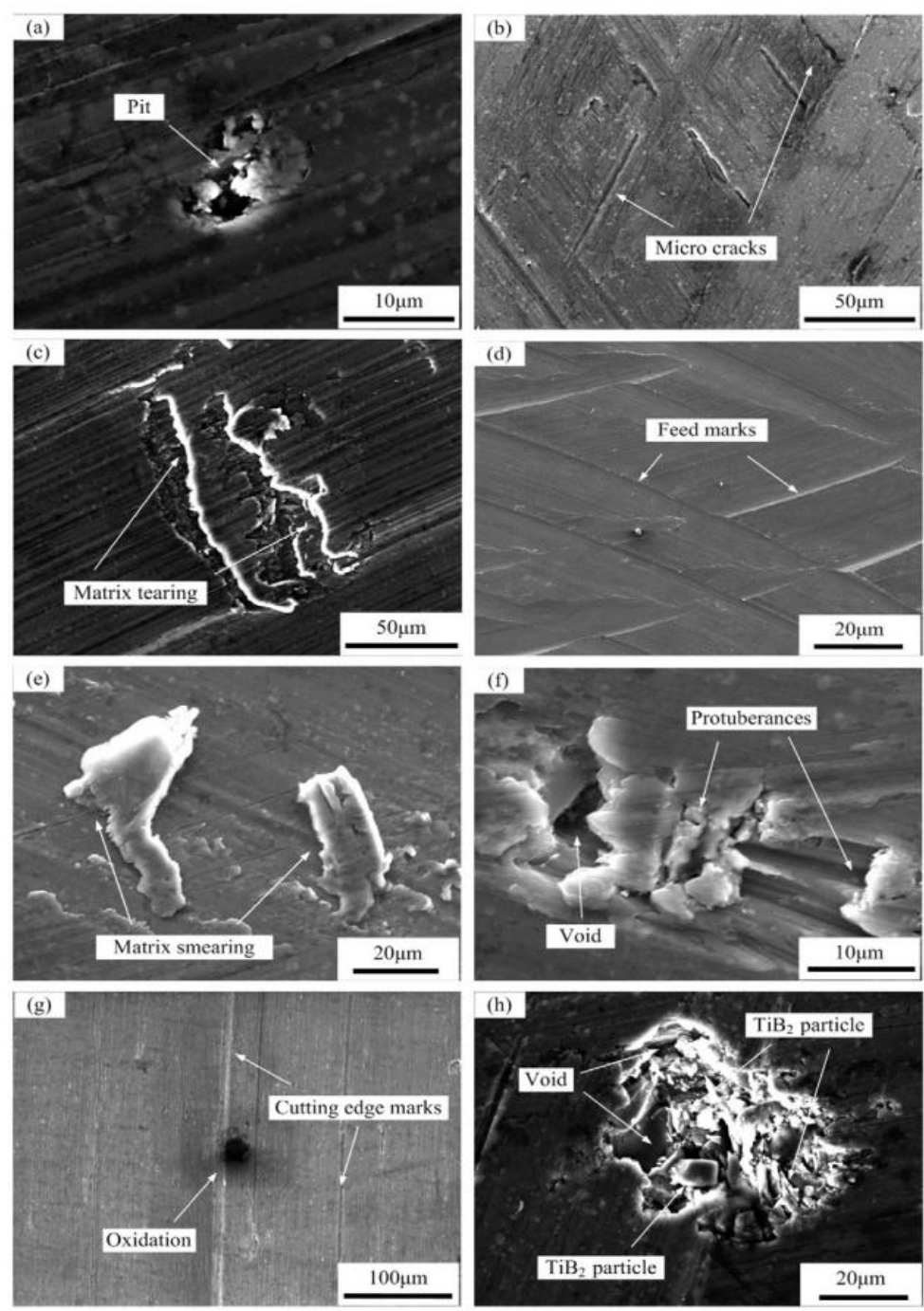

Figure 15 Surface defects when end milling of AA7050 - 6\% TiB 2 MMC: pit (a); micro-cracks (b); matrix tearing $(c)$; feed marks $(d)$; matrix smearing $(e)$; protuberances and void $(f)$; oxidation and cutting edge marks ( $\mathrm{g}$ ); $\mathrm{TiB}_{2}$ particles (h) [58]. 
Similar kind of defects were depicted in other literature [58], as shown in Figure 15. In addition, the formation of oxide spots were detected due to the high transient temperature $\left(700^{\circ} \mathrm{C}\right)$ arising during milling of $\mathrm{Al} 7050 / \mathrm{TiB}_{4} \mathrm{MMC}$. This transient heat, especially at lower feed and higher cutting speed, resulted in tensile residual stresses conversely to the common compressive residual stresses experienced under normal/unaggressive cutting condition.

High dimensional accuracy and surface finish are generally achieved using grinding process. Nevertheless, the dissimilar physical and mechanical properties of reinforcement (hard) versus matrix (soft) of the composites complicates the grinding process of metal matrix composites. In fact, during the grinding process the soft matrix tend to adhere to the grains and close the grinding wheel structure, thus increasing the forces and consequently the temperature of the ground material [59].
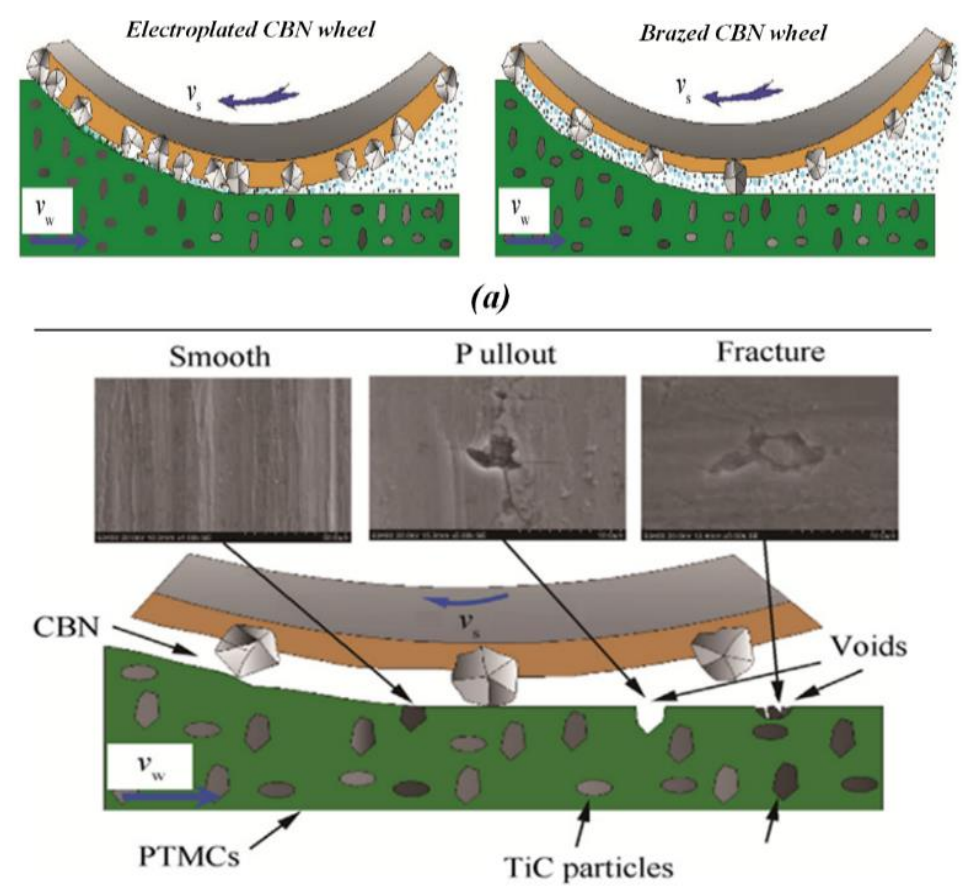

(b)

Figure 16 Tool-workpiece contact zone for electroplated vs. brazed grinding wheels (a) and surface defects encountered (b) when grinding MMCs [61].

Recent studies on grinding of MMC are scarce and mostly focused on comparing different types of grinding wheels with limited analysis of the specifics of the material removal mechanisms and surface integrities. Electroplated wheels are generally used for grinding of MMCs due to their high hardness, low wear rate and high thermal conductivity. Conversely, using resin-bonded abrasive wheels [60] and single-layer brazed wheels [61] has been reported to show better performance in terms of reduced cutting forces, reduced workpiece temperature and enhanced surface finish. This was attributed to the higher grain protrusion of the brazed/ resin-bonded abrasive compared to the electroplated grinding wheels (e.g. protrusion of 20$30 \%$ of abrasive grain size in electroplated vs. 50-70\% in brazed wheels). This led to efficient coolant delivery to the cutting zone and bigger space for chip formation which, overall, lowered the generated heat and force, for MMCs machining, as shown in Figure 16(a) [61]. In general, 
common surface defects when grinding MMCs are reinforcement particles pull-out and/or fracture, micro-cracks and adhesion of abrasive particles on workpiece surface, examples shown in Figure 16(b). These defects generally increased at higher feed and/or depth of cut and low cutting speed [62]. Further in-depth surface integrity research is recommended on this aspect.

\section{Non-Conventional Machining of Metal Matrix Composites}

In contrast with conventional machining of MMCs which would cause rapid tool wear and unavoidable surface damage, nonconventional machining methods which include laser (assisted) machining, abrasive waterjet machining and electro discharge machining (EDM), provide non or less tool wear and lower cost compared to the conventional machining methods. However, due to the different nature and material removal mechanisms, most of these nonconventional machining processes yield relatively severe machining defect and further investigations are needed in order to understand their surface damage mechanisms thus to attain the "optimal" machining results.

\subsection{Laser (assisted) machining}

Laser beam processing delivers a high density energy focused on the workpiece with the ability to soften, melt and vaporise the reinforcement particles and matrix material. This provides the possibility of either assisting the conventional machining process (laser assisted machining) or machining directly using the laser beam (laser cutting/ablation).

\subsubsection{Laser assisted machining}

Laser assisted machining (LAM) is based on the idea of increasing the temperature of the workpiece by laser heating the workpiece in front of the cutting tool, thus, to soften the material and reduce the cutting forces, as shown in Figure 17 [39, 63]. This process has the ability of improving the surface roughness and material removal rates while decreasing the specific cutting energy and tool wear in the machining of difficult-to-cut materials [64-66], where it was reported that the cutting forces could be significantly reduced (ca. 50\%) while the tool life could be improved (ca. 30\%) [67] when compared with conventional machining (e.g. turning, milling). 


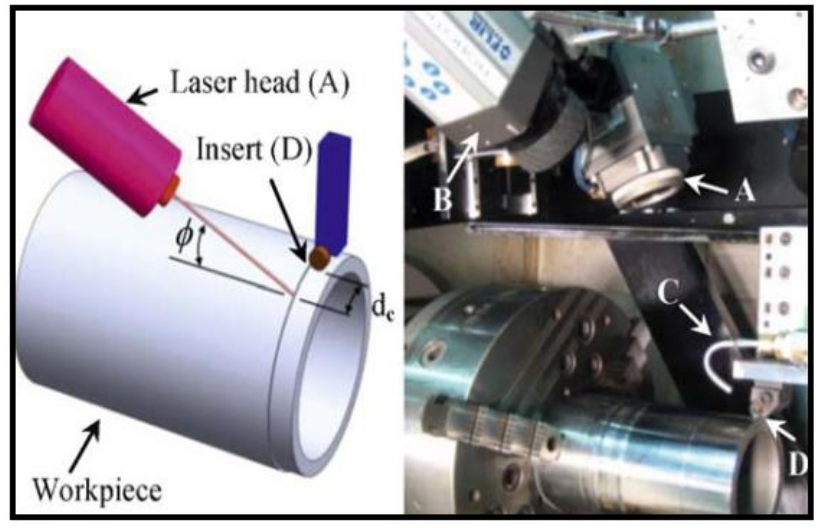

(a)

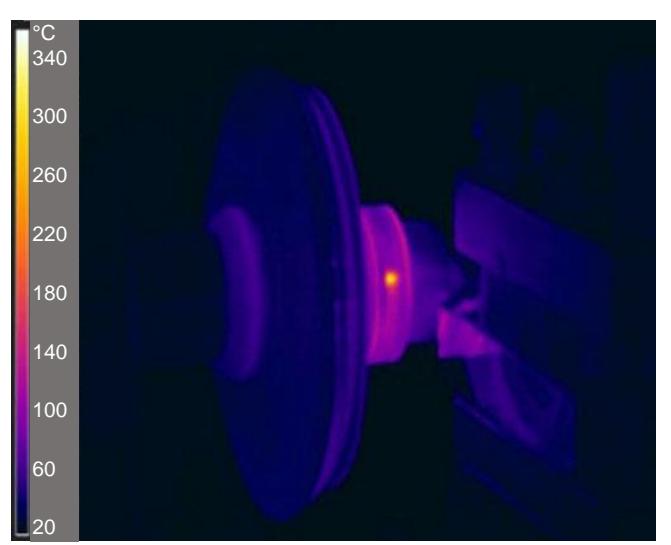

(b)

Figure 17 Laser assisted turning: (a) schematic diagram [63] and (b) temperature map during machining [39]

In MMCs the two components (i.e. matrix and reinforcement) usually have different melting temperatures, which causes different thermal reactions during the LAM process. For instance, in an $\mathrm{A} 359 / 20 \mathrm{SiCp}$ the $\mathrm{SiC}$ particles are melted at $2600^{\circ} \mathrm{C}$ while the $\mathrm{AlSi}{ }_{9} \mathrm{Mg}$ matrix melts at $575-620^{\circ} \mathrm{C}$. Thus, in general during the LAM of MMCs the mechanism happening would be that the matrix material is melted while the reinforcing particles still keep their solid state, which results in the separation of these two components, e.g. particles sinking when the matrix has a lower density or particle ejection when the matrix density is higher. Przestacki et al. [68] showed that in LAM of an A359/20SiCp composite the SiC particles sunk into an overheatedliquid area of the metal matrix, as shown in Figure 18, where two different zones are formed: (A) minor percentage contribution of the reinforcing phase and (B) higher contribution of the $\mathrm{SiC}$ particles.

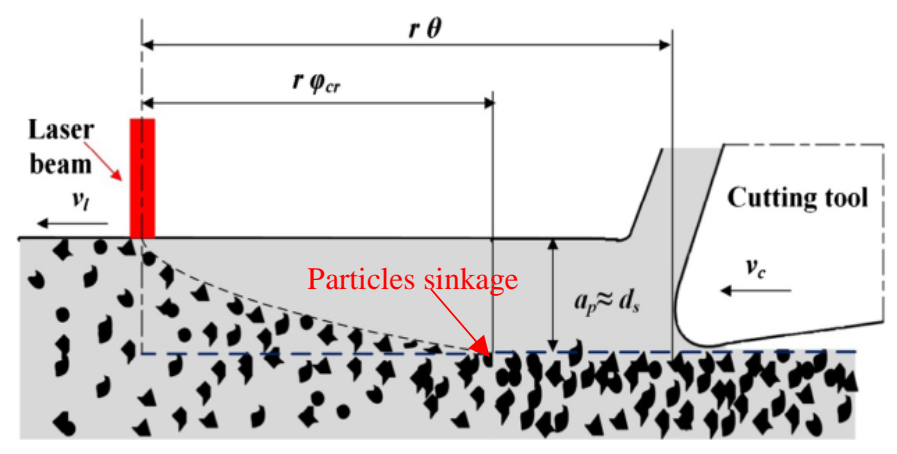

(a)

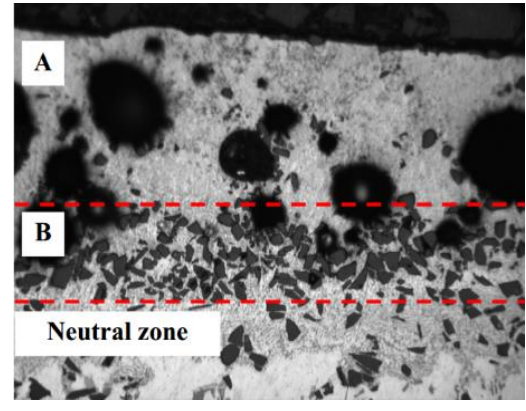

(b)

Figure 18 Schematic of LAM process on A359/20SiCp composite (a) and micrographic section of surface layer after laser heating (b) [68].

Similar to what is was reported in conventional machining, three main surface damages are observed in LAM of particle reinforced MMCs including debonding, particle pull-out and particle fracture. However, all these three damage mechanisms were found less significantly in A359/SiC/20p MMC parts produced by LAM when comparing with the conventional machining results, as shown in Figure 19. This is because the increased cutting temperature by 
laser heating leads to the higher material softening and lower deformation between the matrix material and the particles $[69,70]$. It is also interesting to comment that in the LAM of Titanium MMCs there is no particle debonding but only particle breakage was observed; this was manifested by the broken particles being left inside the matrix (Figure 20a) or being pushed back into the matrix (Figure 20b). Some non-broken particles which are pushed into the matrix (Figure 20c) have also been found [63].

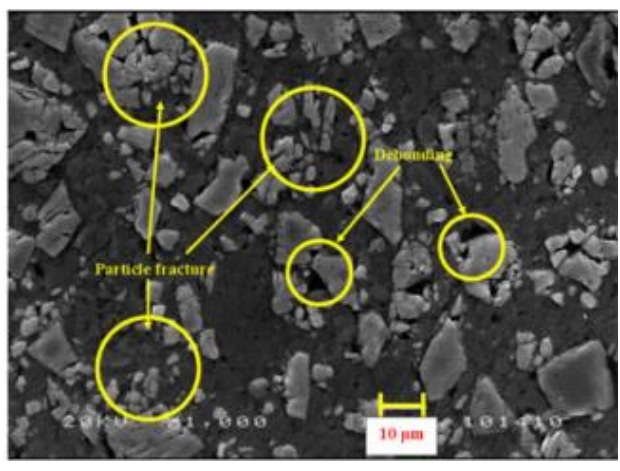

(a) Conventional machining

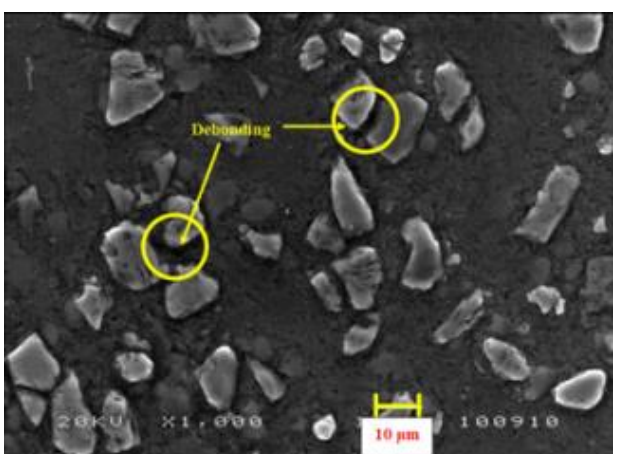

(b) $L A M$

Figure 19 Cross section of (a) conventional machining and (b) LAM of A359/SiC/20p MMC at v: 150 $\mathrm{m} / \mathrm{min}$, DoC: $0.76 \mathrm{~mm}$, and f: $0.05 \mathrm{~mm} / \mathrm{rev}$ [69].

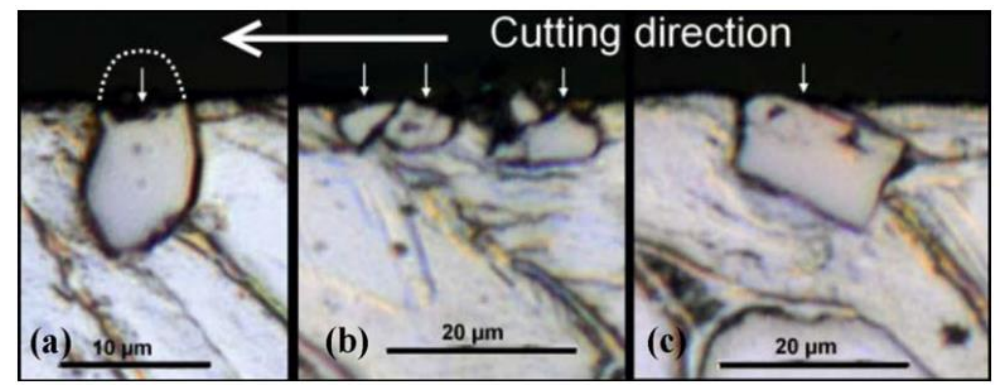

Figure 20 An example of particles behaviour of LAM TiMMCs: (a) particle breakage inside the matrix, (b) broken particles pushed back into the matrix and (c) non-broken particles pushed back into the matrix [63].

Although similar types of surface defects were found in both conventional machining and LAM of MMCs, the magnitudes of these defects and their formation mechanisms are significantly different in these two processes. Kong et al. [39] reported that in LAM of a $\mathrm{SiCp} / \mathrm{Al}$ the strain misfit in the matrix around the particles is relaxed due to the high temperature dynamic recovery happening in the aluminium crystal. This results in a decreased strength of the MMC structure, thus the applied low cutting stress is not enough to break the particles in LAM, while in conventional machining the reduced ductile deformation of the material leads to severe crack damage. A more in-depth analysis of the surface metallurgy with TEM found that, due to the lower plastic deformations in LAM, the dislocation density piling up in the matrix material was decreased compared with conventional machining (Figure 21). Furthermore, as shown in Figure 22, although serrated chips are formed in both LAM and conventional machining of MMCs $[39,71]$, in LAM a secondary crack is generated in the back of the chip due to the higher thermal gradients. 
$\left(22^{\circ} \mathrm{C}\right)$

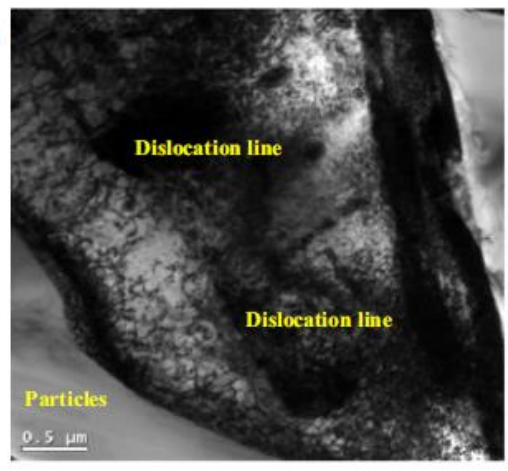

(a) Around particles

$\left(320^{\circ} \mathrm{C}\right)$

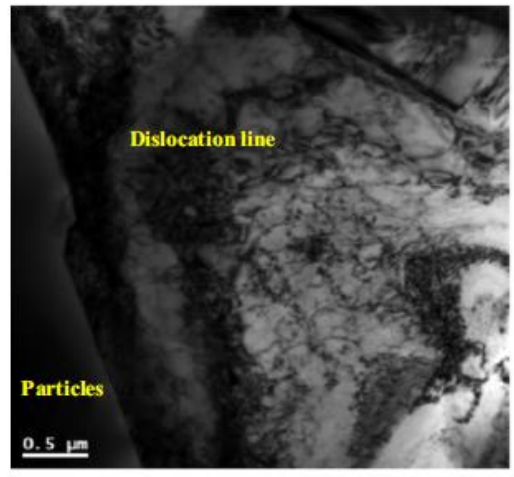

(c) Around particles

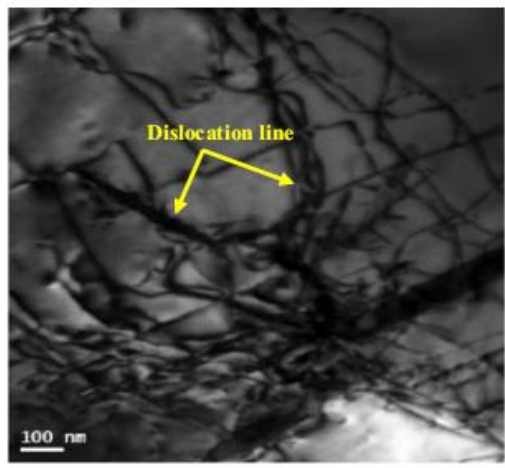

(b) Aluminum matrix

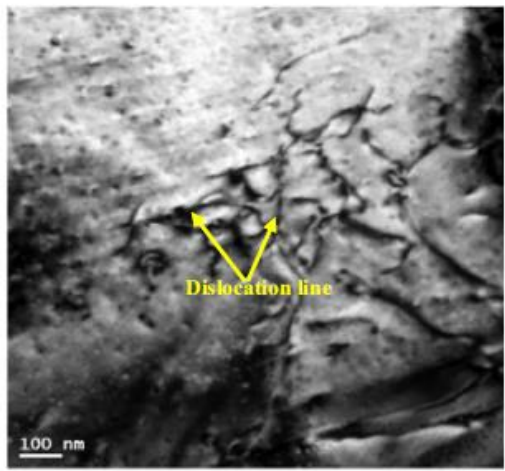

(d) Aluminum matrix

Figure 21 TEM micrographs of cross-sectional samples showing the dislocation sub-structure: (a and c) around particles and ( $b$ and $d$ ) aluminium matrix [39]
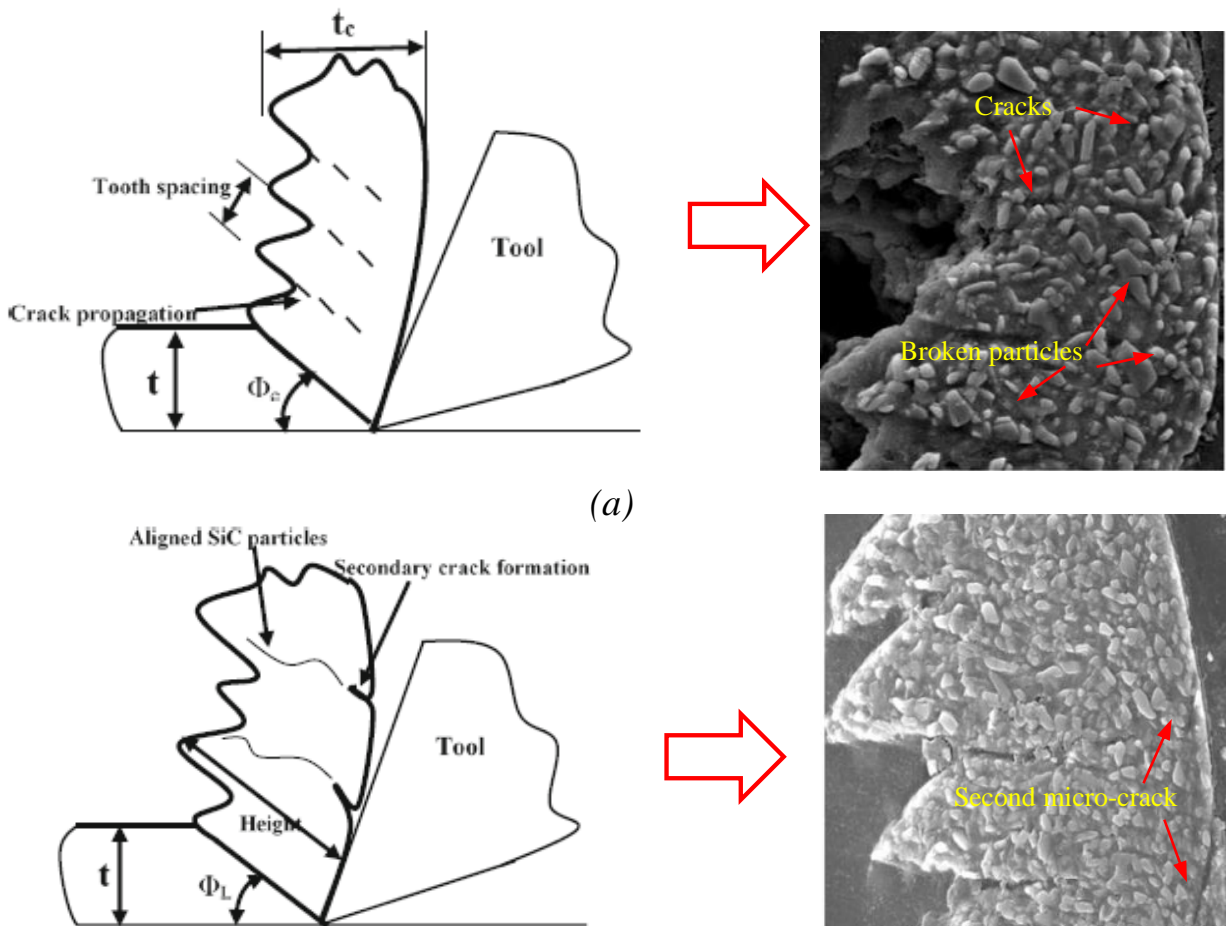

(a)
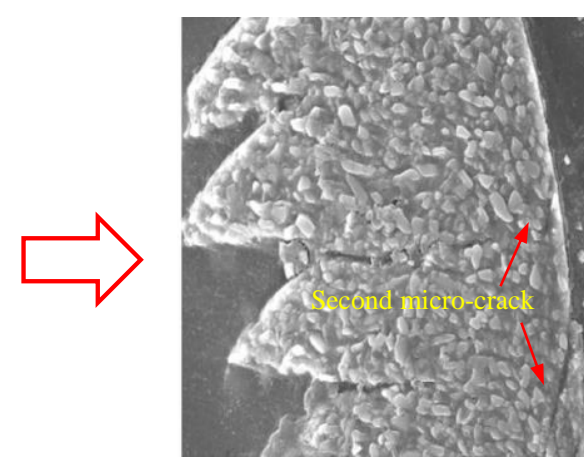

(b)

Figure 22 Chip formation mechanism in conventional machining (a) and LAM (b) of SiCp/Al MMC [39, 71] 


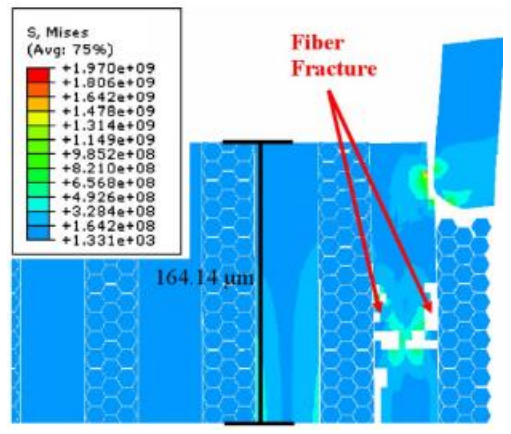

(a)

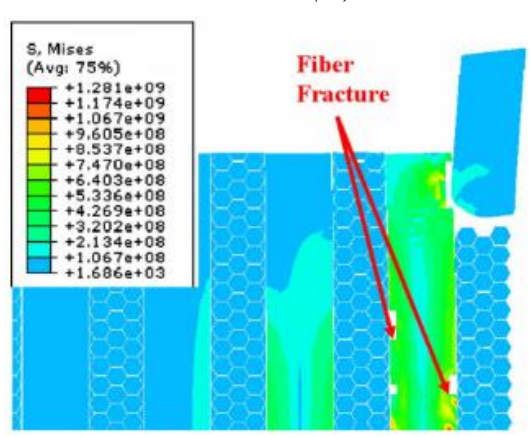

(c)

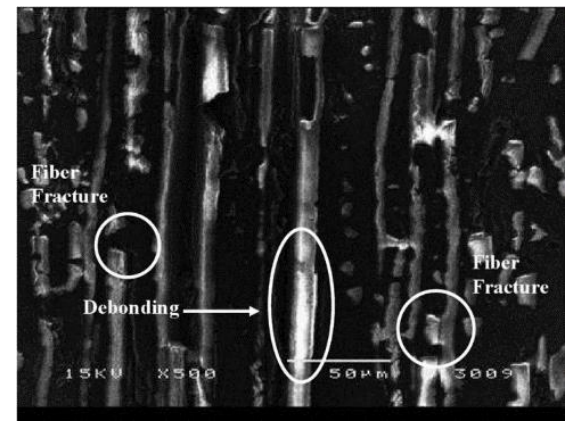

(b)

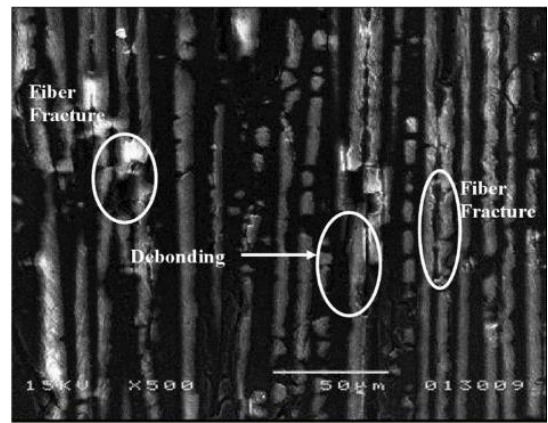

(d)

Figure 23 Simulation and SEM measurement of surface damage of conventional machining (a), $(b)$ and LAM (c) (d) of fibre reinforced MMCs [72].

In contrast to the results found for particle-reinforced MMCs, in conventional machining of fibre-reinforced MMCs it was found that the main surface damage was caused by fibre breakages (e.g. deboning or fibre fracture) below the cutting plane, due to the high cutting force and brittle nature of these fibres. However, these fibre breakages are found significantly decreased in the laser assisted machining of fibre reinforced MMCs due to the material softening effect by the laser heating, as shown in Figure 23 [72]. In particular, this softening effect mainly occurred in the metal matrix as the fibres in general are more difficult to be softened as they have a much higher melting temperature (e.g. $2000^{\circ} \mathrm{C}$ of $\mathrm{Al}_{2} \mathrm{O}_{3}$ fibres) compared with the matrix material (e.g. $\mathrm{Cu}$ with a melting temperature of $1085^{\circ} \mathrm{C}$ ).

The optimization of the LAM process to achieve better surface integrity has mainly focused in studying the influence of the different laser parameters (e.g. laser power, laser beam diameter) and cutting conditions (e.g. feed speed, the cutting speed, depth of cut) by using design of experiments $[39,73]$ or by employing finite element models to predict the sub-surface damage $[70,72]$. Nevertheless, there are very few in-depth studies on analytical modelling as the material removal mechanism in LAM for MMCs has not been proposed in the literature. Przestacki et al [68] developed a model including the effect of gravity, buoyancy, resistive force of liquid matrix and centrifugal force of the rotating work material, in which instantaneous sedimentation speed and the depth of sedimented SiC particles could be calculated. By this model the cutting depth and tool distance from the laser beam could be selected to perform the cutting in the particle free layer to achieve a better surface, as shown in 
Figure 24, where a more homogenous and crack-free surface were observed after the LAM process.

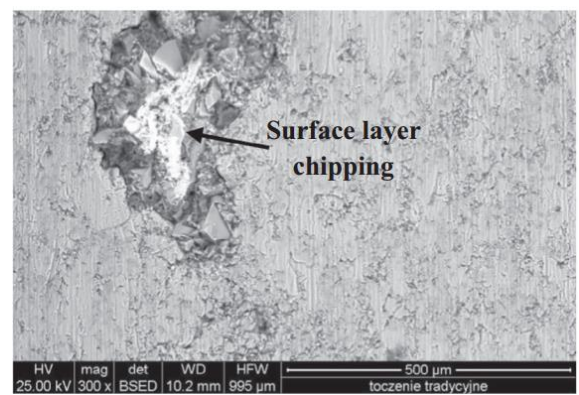

(a)

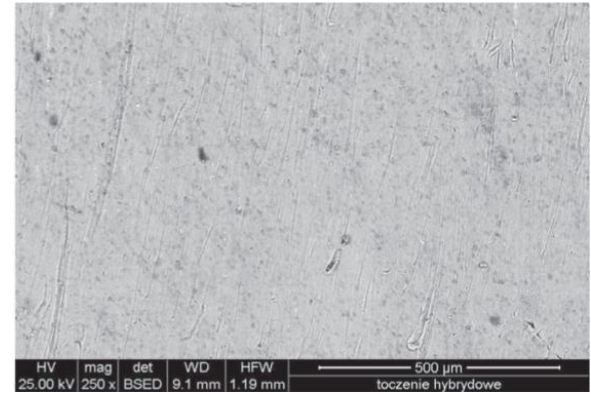

(c)

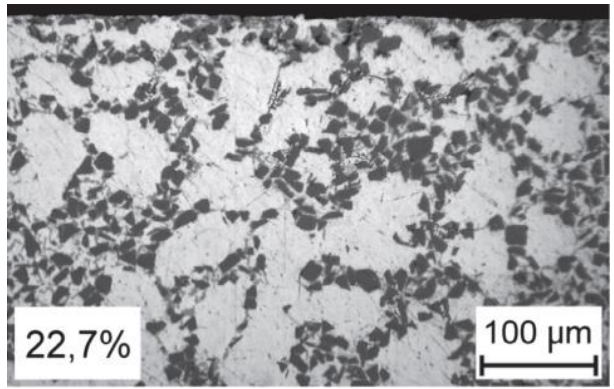

(b)

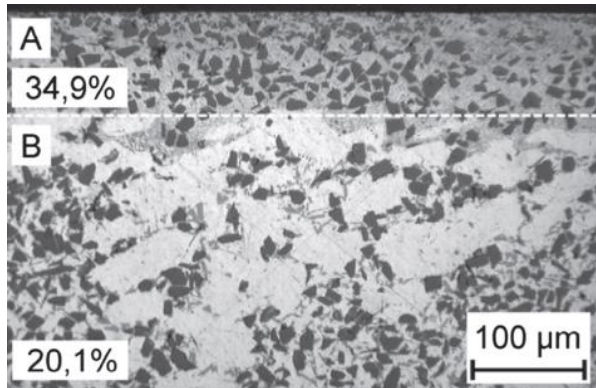

(d)

Figure 24 Examples of machined surface of conventional machining on top surface (a) and cross section (b), and optimized LAM on top surface (c) and cross section (d)[68]

\subsubsection{Laser machining}

While in LAM the laser is mainly employed to soften the material for assisting the material removal by a solid (conventional) cutting tool, in the laser machining of MMCs, the material is removed by the laser ablation and this experiences three different stages: melting, vaporization and chemical degradation. Moreover, with an increase of the laser fluence, instead of material vaporization, a phase explosion (explosive boiling) would happen [74], in which a melting pool will be formed (Figure 25). In this case, by applying a high pressure assistant gas (e.g. $1 \mathrm{MPa} \mathrm{Ar}$ ), the liquid in the melting pool could be blown away thus, to enhance the ablation depth and improve the material removal rate [75]. 


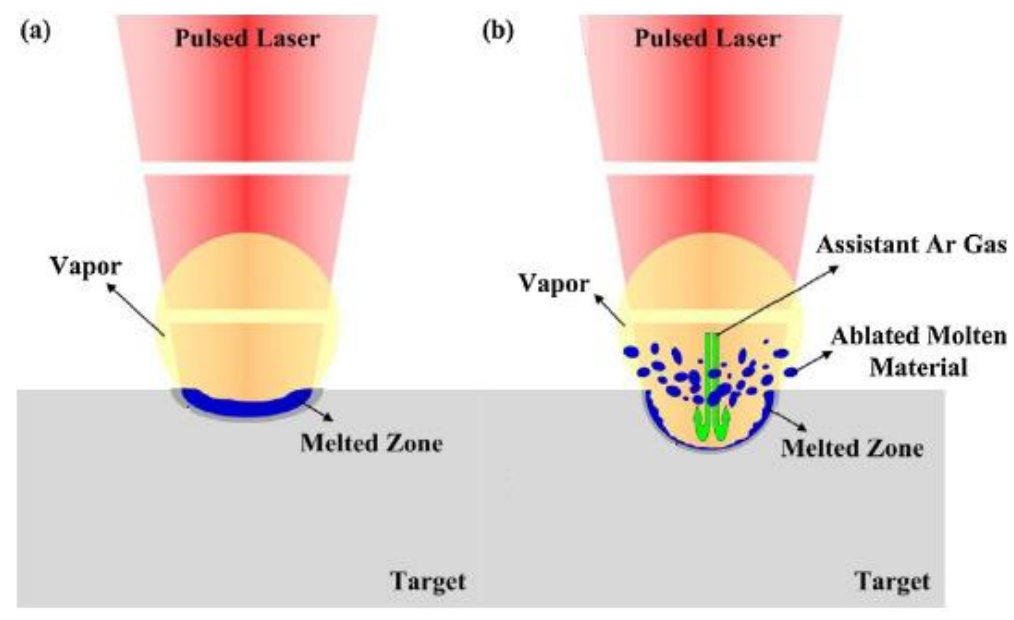

Figure 25 Pulsed laser ablation of materials without (a) and with (b) assistant of gas [75].

In addition, since MMCs consist of reinforcing particles and a metal matrix, the temperature rises on these two components are with different rates (e.g. time reaching melting point, boiling point and ablation state) due to the variation of their thermal properties. For instance, in the laser cutting of an AlSi alloy/SiCp MMC, although the SiC particles heat up faster than the AlSi matrix (due to the higher thermal conductivity and absorptivity), the time needed for melting SiC particles is almost two times longer than that of AlSi matrix due to the higher melting point of $\mathrm{SiC}$ particles (Figure 26) [76].

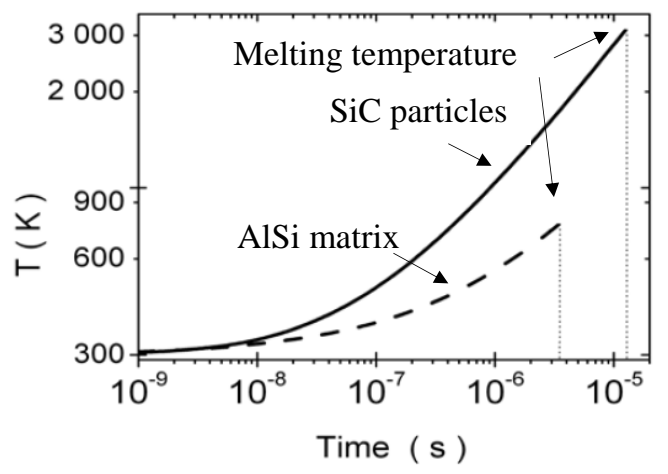

Figure 26 An example indicating the SiC reinforcing particles reach the melting temperature by laser irradiation slower than the AlSi-alloy matrix although it has higher thermal conductivity and absorptivity [76]

Considering above mentioned heterogeneous nature of the MMCs, the laser machined surface yields a comparative poor quality with melting and vaporizing the matrix and reinforcements in differential manners. In general, the machined surface is found with three different types of defects, as shown in Figure 27:

a) Striations and dross: As the embedded particles usually have a higher melting point, small unburned particles would be present at the edge of the surface when high pressure of the protective gas jet forces the molten material towards the bottom of the cut through surface. This makes the expulsion of molten material difficult which results in large striations marks and dross [77, 78]. 
b) Cracks and voids: The stress concentration initiated by the reinforcement particles and the de-bonding between the particles and matrix induced by the high thermal effect results in a large number of voids and cracks [79, 80];

c) Recast layer: Recast layers are usually generated by the high thermal effect of laser beam $[77,80]$ where the surface layer has been recrystallized with fine grain sizes of the matrix.

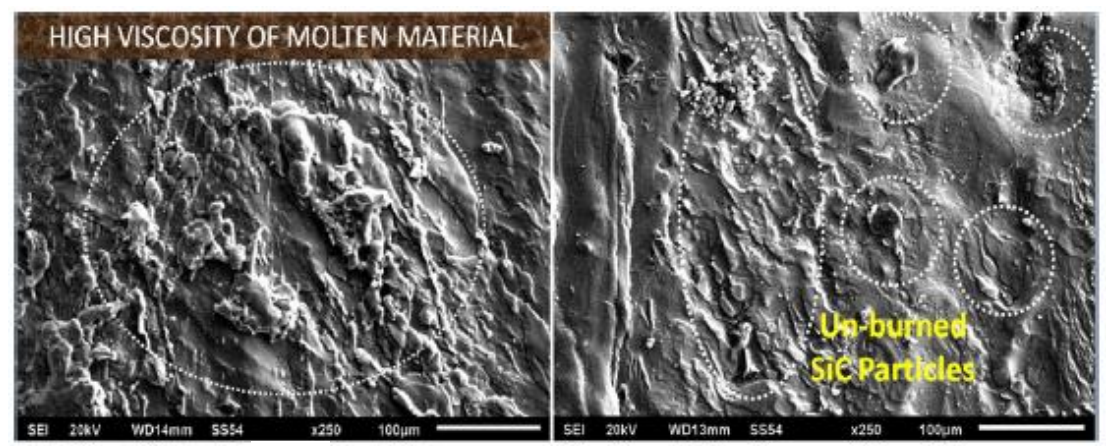

(a)

(b)

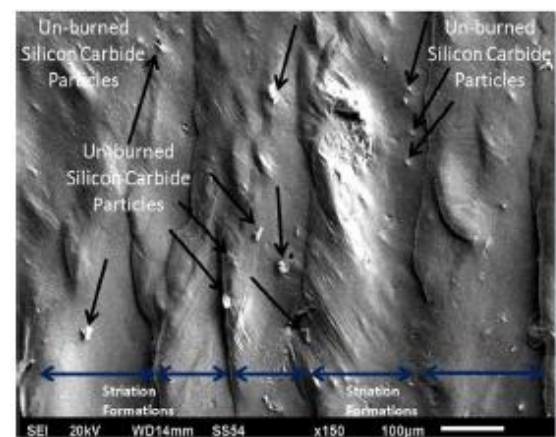

(c)

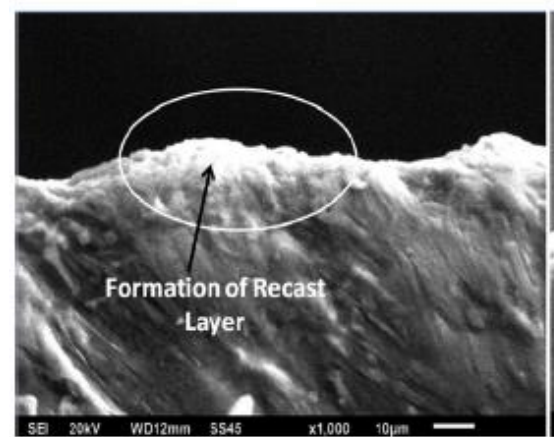

(e)

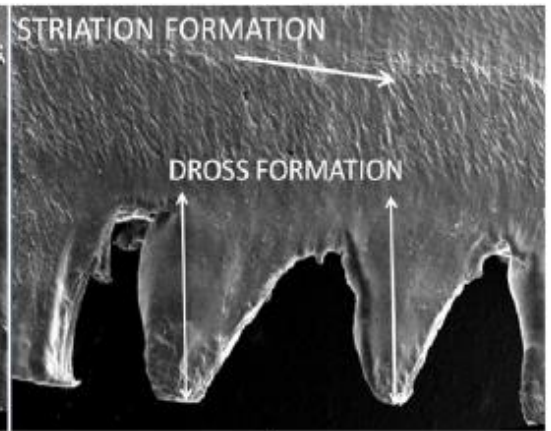

(d)

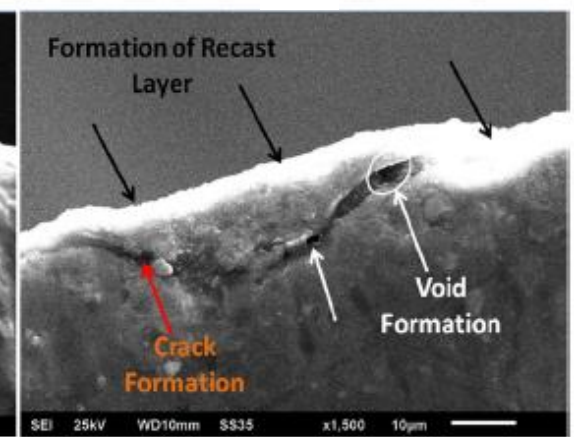

(f)

Figure 27 SEM surface of laser cutting MMCs (AA5052/SiC) shows unburned SiC reinforced particles and restricted flow $(a-c)$, dross and striations formation $(d)$, formation of recast layer $(e)$ and crack initiation $(f)$ [80].

As one of the main contributors to the MMCs performance, the different selection of reinforcement particles results in varying material properties (e.g. strength, hardness, melt temperature, phase explosion threshold etc.) while also leading to diverse workpiece surface damage mechanisms when laser cutting. For example, Sharma and Vinod Kumar [81] investigated the laser beam machining on AA5052 MMCs reinforced with different particles, i.e. $\mathrm{SiC}, \mathrm{Al}_{2} \mathrm{O}_{3}$, and $\mathrm{ZrO}_{2}$. As shown in Figure 28(a), it was found that in the $\mathrm{Al} / \mathrm{SiC} / 0-20 \%$ MMC the primary defects were the striations and dross caused by the liquid flow obstruction 
of the molten material from the remained unburned $\mathrm{SiC}$ particles, while the cracks were also observed which are initiated from unburned and broken $\mathrm{SiC}$ particles. In the $\mathrm{Al} / \mathrm{Al}_{2} \mathrm{O}_{3} / 0-20 \%$ MMC (Figure 28b) higher accumulation of $\mathrm{Al}_{2} \mathrm{O}_{3}$ particles was observed on the machined surface as well as large size of cracks due to the poor bonding energy between $\mathrm{Al}_{2} \mathrm{O}_{3}$ particles and $\mathrm{Al}$ matrix. In $\mathrm{Al} / \mathrm{ZrO}_{2} / 0-20 \% \mathrm{MMCs}$ the observed height of dross was much lower compared to the other two MMCs, which is believed due to the higher rate of agglomeration of the $\mathrm{ZrO}_{2}$ particles and the resulted higher viscosity and surface tension, as shown in Figure $28(\mathrm{c})$.
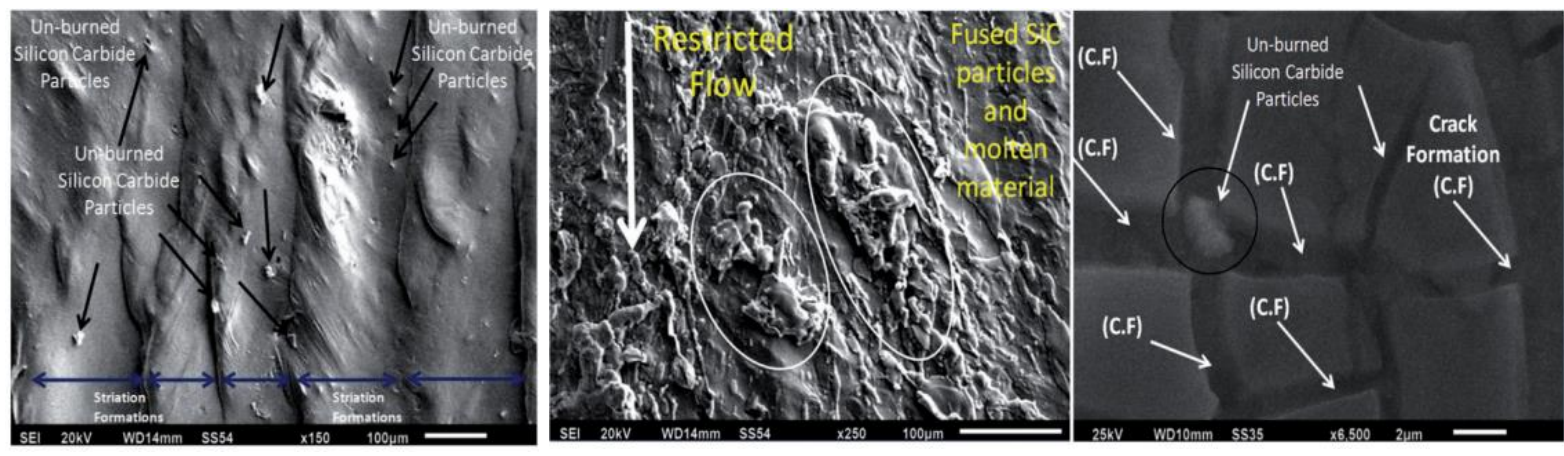

(a)
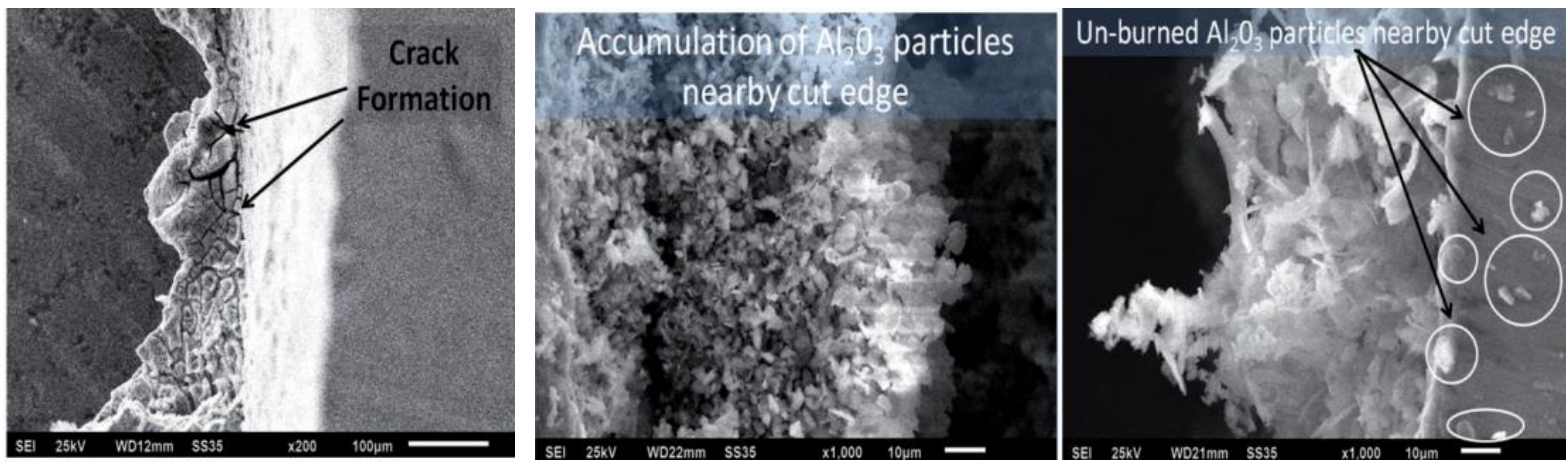

(b)
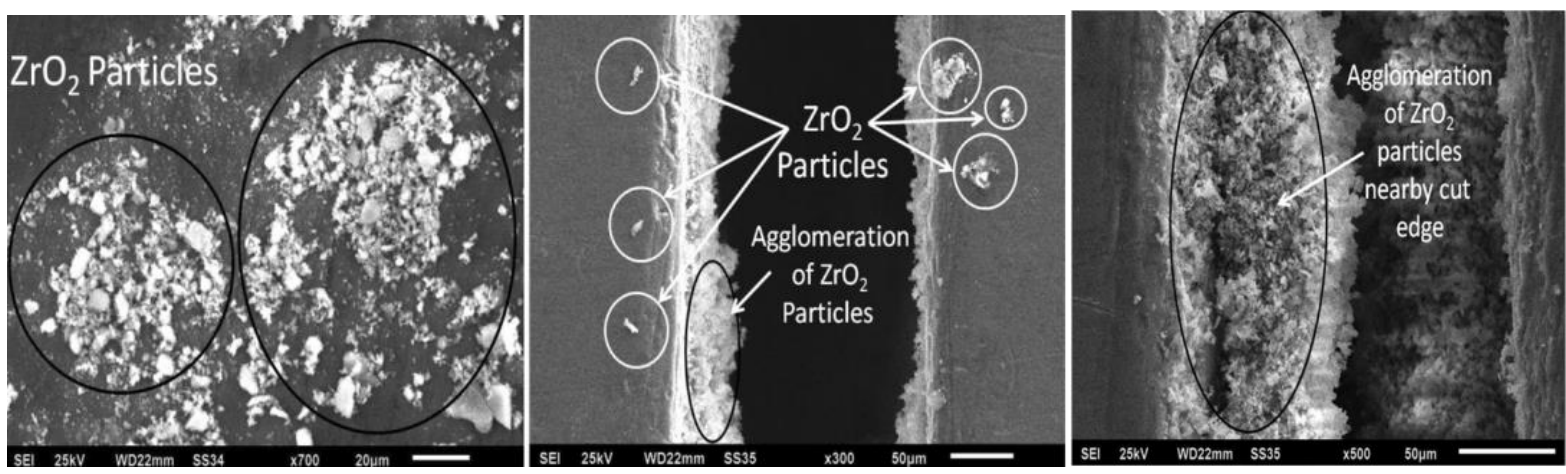

(c)

Figure 28 Laser machined surface of AA5052 metal matrix composites with SiC particles (a), Al2O3 particles (b) and $\mathrm{ZrO} 2$ particles (c) [81].

Furthermore, due to the high temperature incurred during laser cutting of MMCs, in the melting pool, the matrix (e.g. Aluminium) and reinforcing particles (e.g. Silicon) could coexist 
in a liquid state facilitating their chemical interaction. Because high pressures of gases are applied to assist the blowing of molten material, the atmospheric oxygen reacts with the material constituents in melting pool. Figure 29 shows the possible oxygen reaction during the laser machining of $\mathrm{SiC} / \mathrm{Al}$ alloy matrix MMC [75]. Further with XRD measurement ( $2 \theta$ value at $42.1^{\circ}$ and $48.9^{\circ}$, as shown in Figure 30 ) it was also found that the $\mathrm{C}$ reacted with the $\mathrm{Al}$ and formed a new compound (i.e. $\mathrm{Al}_{4} \mathrm{C}_{3}$ ), which would produce a weaken bond between the reinforcement and matrix material [80].

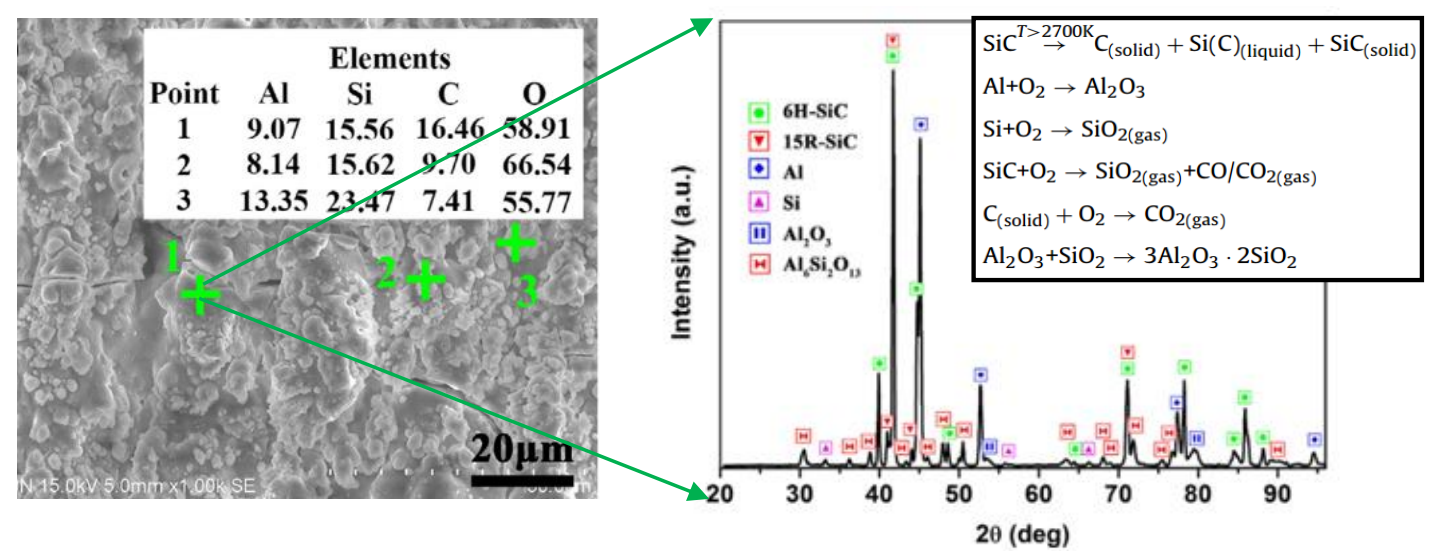

Figure 29 Oxidization of the SiC/Al alloy matrix MMC material during laser machining [75]

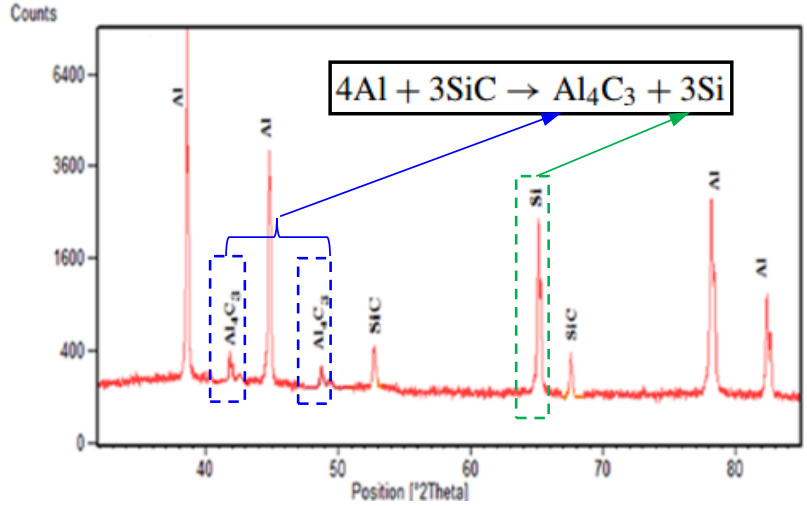

(a)

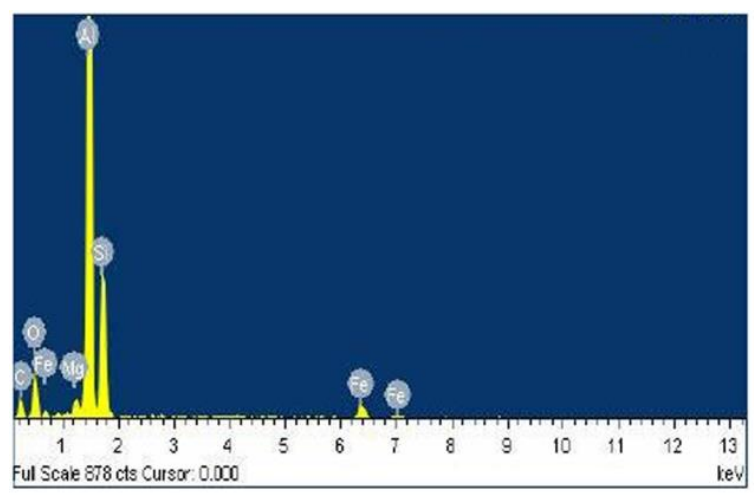

(b)

Figure 30 New phase generation during the laser machining of SiC/Al alloy matrix MMC: (a) XRD plot and (b) EDX analysis of laser machined surface [80]

To optimize the surface quality of MMCs after laser machining, the laser feed speed is the main factor to be concerned, while the laser energetic parameters (e.g. laser power, frequency of pulse laser) also play significant roles [77]. However, due to the complicated physical, chemical and mechanical interaction between the MMCs material and the laser beam, currently the research related to surface quality optimization is still only studied via design of experiments while there is no research on the analytical modelling to enable the understanding of the mechanisms that governs this process. As shown in Figure 31, Sharma and Kumar [80] carried out a series of experiments to identify the thermal effects of laser cutting on AA5052/SiC composite with a $2.5 \mathrm{~kW}$ continuous $\mathrm{CO}_{2}$ wave laser, showing that higher laser 
power (to $2.5 \mathrm{~kW}$ ), cutting speed (to $3000 \mathrm{~mm} / \mathrm{min}$ ) and lower reinforced particle density (to $0 \%$ of $\mathrm{SiC}$ particles) generate a better cut kerf. Moreover, it was commented that the improved surface integrity with higher laser power is due to the sufficient laser energy has been provided for the cutting through the material. The increased particles content initiates more stress concentrations and rises the viscosity of the melt material with resulting in worse surface. However, it is still not clear the how the cutting speed influences the machined surface quality. Thus, without an in-depth understanding of the mechanism governing the laser cutting process in MMCs it is still difficult to predict its surface quality.

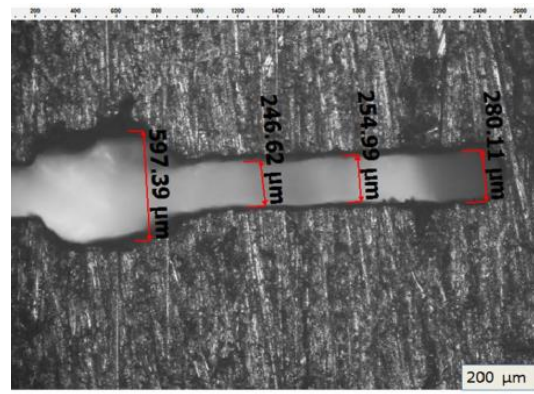

(a)

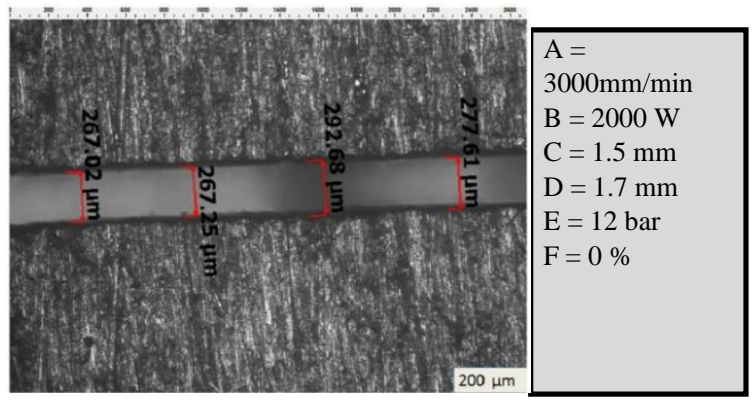

(c)
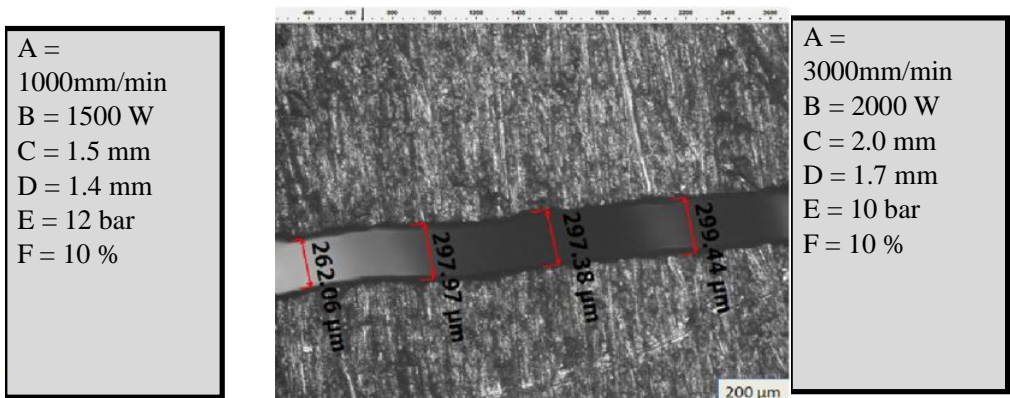

(b)

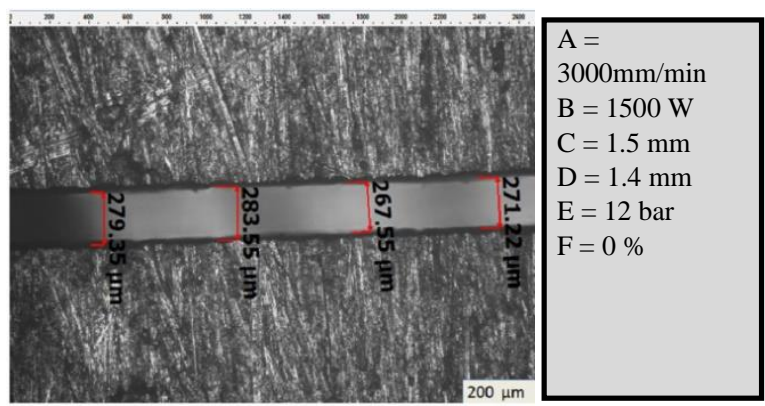

(d)

Figure 31 Deviations of cut kerffor different cutting conditions where: A Cutting speed, B Laser power, C Standoff distance, D Nozzle diameter, E Gas pressure, F Reinforcing particles [80]

\subsection{Abrasive waterjet machining}

Although the laser beam cutting has been applied for cutting different MMCs successfully, the thermal nature of the material removal induces high thermal local damages in the machined surface. Abrasive waterjet (AWJ) machining, with its advantage of low thermal effect and high material removal rate, has received an increasing attention in the machining of a wide range of materials with AWJ turning and AWJ through cutting being the most popular. The key factors of this process that affect the material removal rate and machined surface quality are related to the abrasive type/size, abrasive mass flow rate, jet feed speed, standoff distance, jet pressure as well as its impact angle relative to the target surface [82, 83]. 

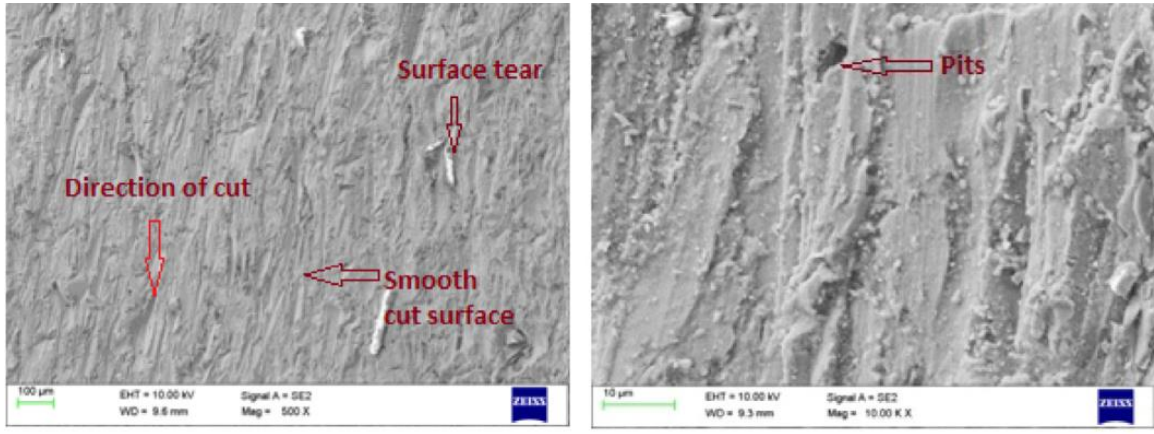

(a) SOD $-4 \mathrm{~mm}, \mathrm{~mm}, \mathrm{TS}-210 \mathrm{~mm} / \mathrm{min}, \% \mathrm{WC}-6$, MRR- $1.005 \mathrm{~mm}^{3} / \mathrm{min}, \mathrm{SR}-4.21 \mu \mathrm{m}$
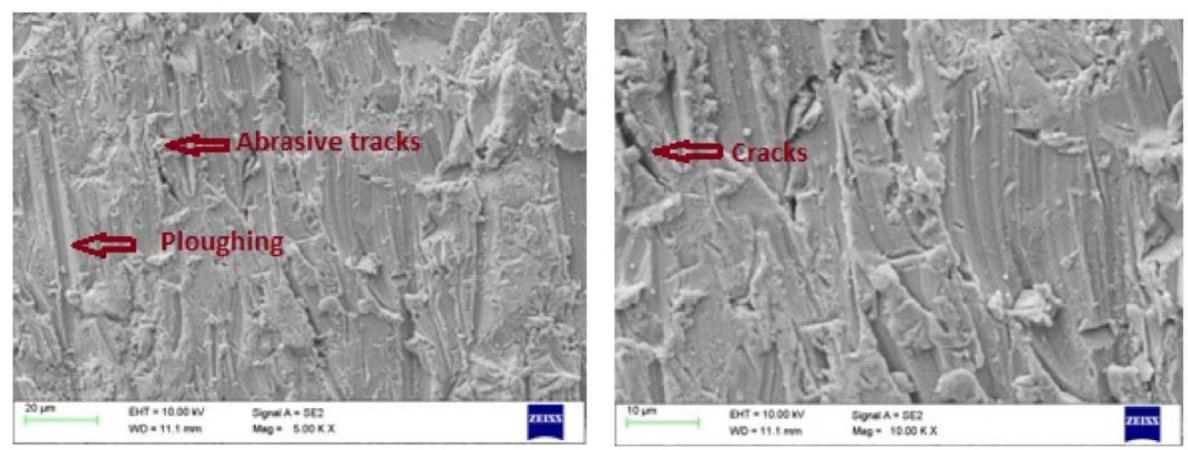

(b) SOD -5 mm, mm, TS - $190 \mathrm{~mm} / \mathrm{min}, \%$ WC- 10 , MRR- $0.912 \mathrm{~mm}^{3} / \mathrm{min}, \mathrm{SR}-4.29 \mu \mathrm{m}$
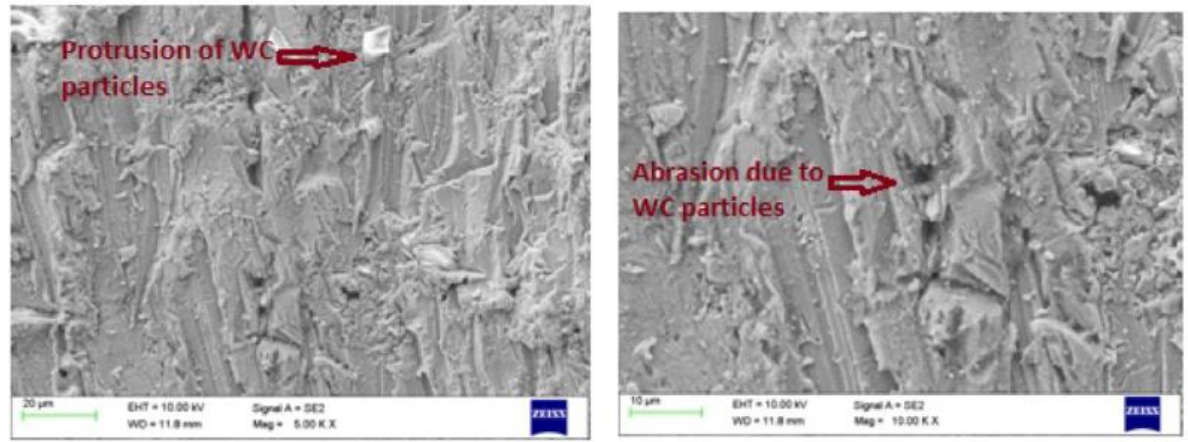

(c) SOD - $3 \mathrm{~mm}, \mathrm{~mm}, \mathrm{TS}-230 \mathrm{~mm} / \mathrm{min}$, \% WC- 8 , MRR- $1.025 \mathrm{~mm}^{3} / \mathrm{min}$, SR- $3.96 \mu \mathrm{m}$
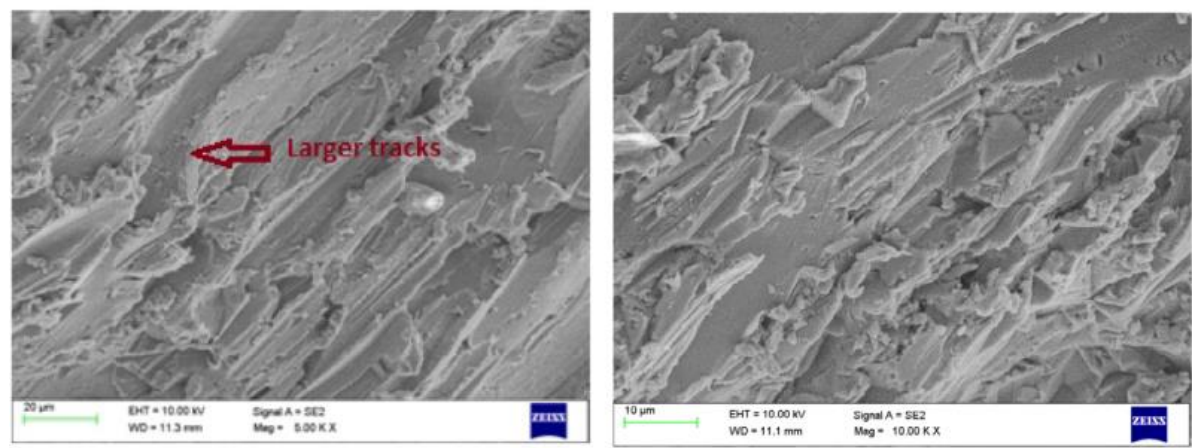

(d) SOD $-5 \mathrm{~mm}, \mathrm{~mm}$, TS $-230 \mathrm{~mm} / \mathrm{min}, \%$ WC- 4 , MRR- $1.085 \mathrm{~mm}^{3} / \mathrm{min}$, SR- $4.92 \mu \mathrm{m}$

Figure 32 SEM micrograph of the AWJ cut Al6082/WC MMC surface showing different surface defects [87]

In this process, since the material is removed by hard abrasives (e.g. garnet and olivine) mixed waterjet, the resulted surface consists of a large number of scratches/cutting traces left by abrasive grains [85]. Moreover, since the abrasion (wear) cutting is the phenomena 
accompanying the material removal process, as shown in Figure 32-Figure 34 [85-87], the surface could be mainly damaged as: a) plastic deformations of the matrix due to the ploughing action of the particles; b) cracking of reinforcing particles due to their brittle nature; c) protrusion of the reinforcing particles due to the preferential erosion of the matrix; d) pits and voids due to the removal of reinforcement particles from matrix by the high energy impact; e) abrasive embedment due to the impact of the hard abrasive into the relatively soft matrix; f) micro-melting of the matrix due to the localized high temperature from impingement of abrasive particles on the workpiece surface when the matrix is a metal with high affinity on oxygen, e.g. Ti or Mg based MMC [87].

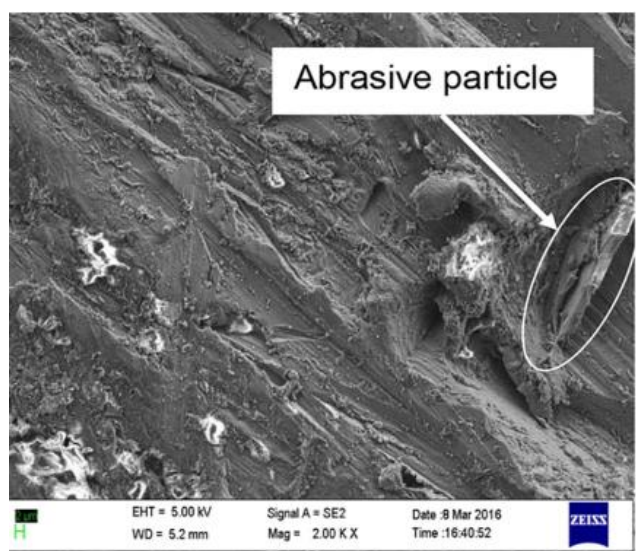

(a)

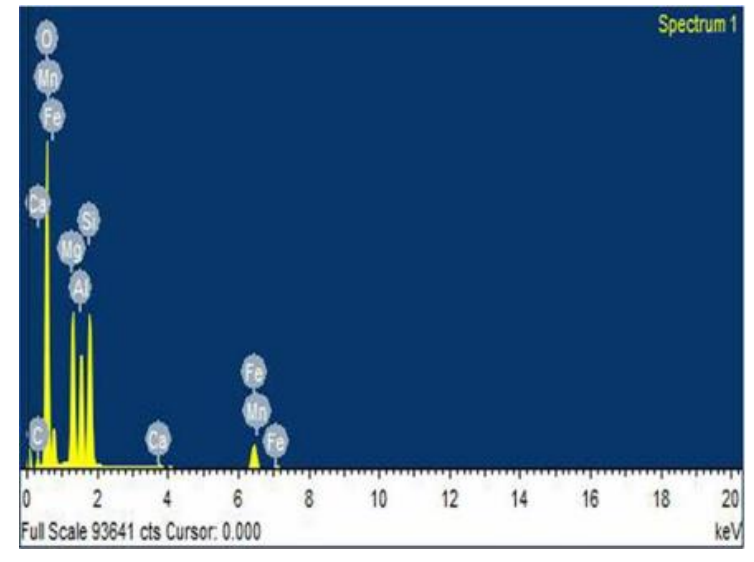

(b)

Figure $33 \mathrm{SEM}(\mathrm{a})$ and $\mathrm{EDS}(\mathrm{b})$ of $\mathrm{AWJ}$ cut $\mathrm{Mg}-6 \mathrm{Al} / 0.66 \% \mathrm{Al}_{2} \mathrm{O}_{3} \mathrm{MMC}$ surface showing abrasive particle embedment [87]

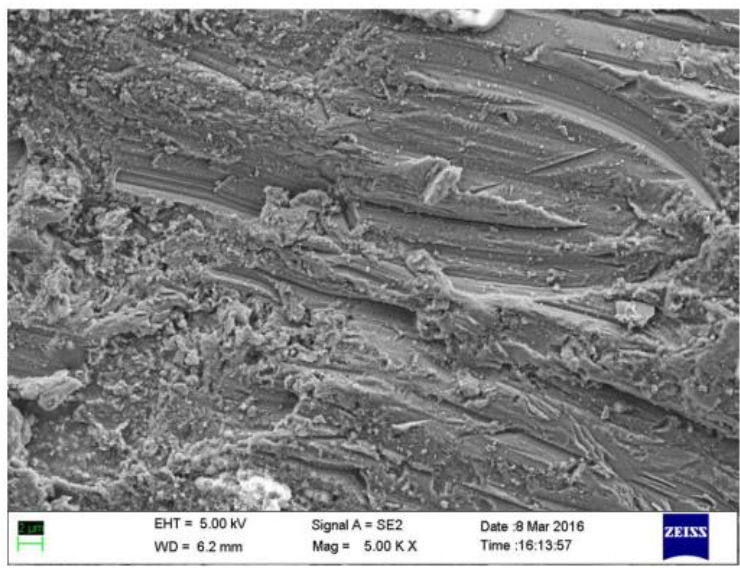

Figure 34 Micro-melting of matrix material after AWJ cutting of $\mathrm{Mg}-6 \mathrm{Al} / 0.66 \% \mathrm{Al}_{2} \mathrm{O}_{3} \mathrm{MMC}$ at a high cutting speed [87]

By adding an additional degree of freedom in the rotational direction of the workpiece, the AWJ process can also resemble the turning operation which combines the advantages of AWJ cutting with the kinematics of a conventional turning process, as shown in Figure 35 [84]. This allows the use of abrasive waterjet as a 'universal tool' to achieve various cylindrical shapes while keeping the advantage of high material removal rate as well as low thermal influence for the machining of MMCs. Moreover, in contrast to conventional turning, in AWJ turning the 
depth of cut is highly dependent on the water pressure, impact angle as well as the transverse speed, enabling the achievement of different levels of surface integrity and material removal rate by varying the combination of these parameters.

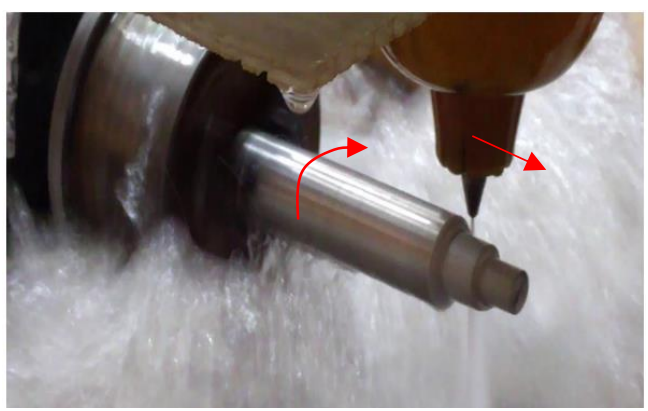

(a)

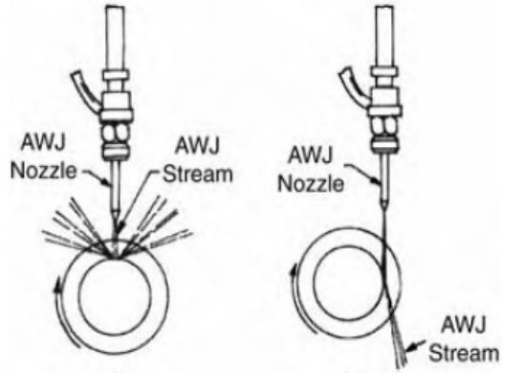

(b)

Figure 35 Abrasive water jet turning of MMCs specimen: machining setup (a) and different impact angle of jet to the workpiece (b) [82, 84]

Since the AWJ turning has the same material removal mechanism of that AWJ through cutting, similar surface damages, e.g. pits, cracks, craters and ploughing, can be found in this operation [88], as shown in Figure 36. Moreover, the plastic deformations observed on the machined surface from the impingement of the abrasives can also induce high residual stresses. As shown in Figure 37 [88], when machining an $\mathrm{A} 359 / \mathrm{B}_{4} \mathrm{C} / \mathrm{Al}_{2} \mathrm{O}_{3} \mathrm{MMC}$, compressive residual stresses were observed due to the high impact of abrasive waterjet, which reached peak values at the subsurface about $50 \mu \mathrm{m}$ below the machined surface. The compressive residual stresses decrease with the increase of jet transverse speed due to the reduction of the dwell time of AWJ impact upon the workpiece which leads to reduced number of abrasives hitting the material at a certain area. The influence of microhardness in the machined $A 359 / \mathrm{B}_{4} \mathrm{C} / \mathrm{Al}_{2} \mathrm{O}_{3} \mathrm{MMCs}$ subsurface shows the same tendency as the residual stresses but only with a small variation (9\%) due to the non-significant microstructural changes during AWJ process which makes it a more effective method of MMCs machining preferable over other techniques (e.g. conventional machining).
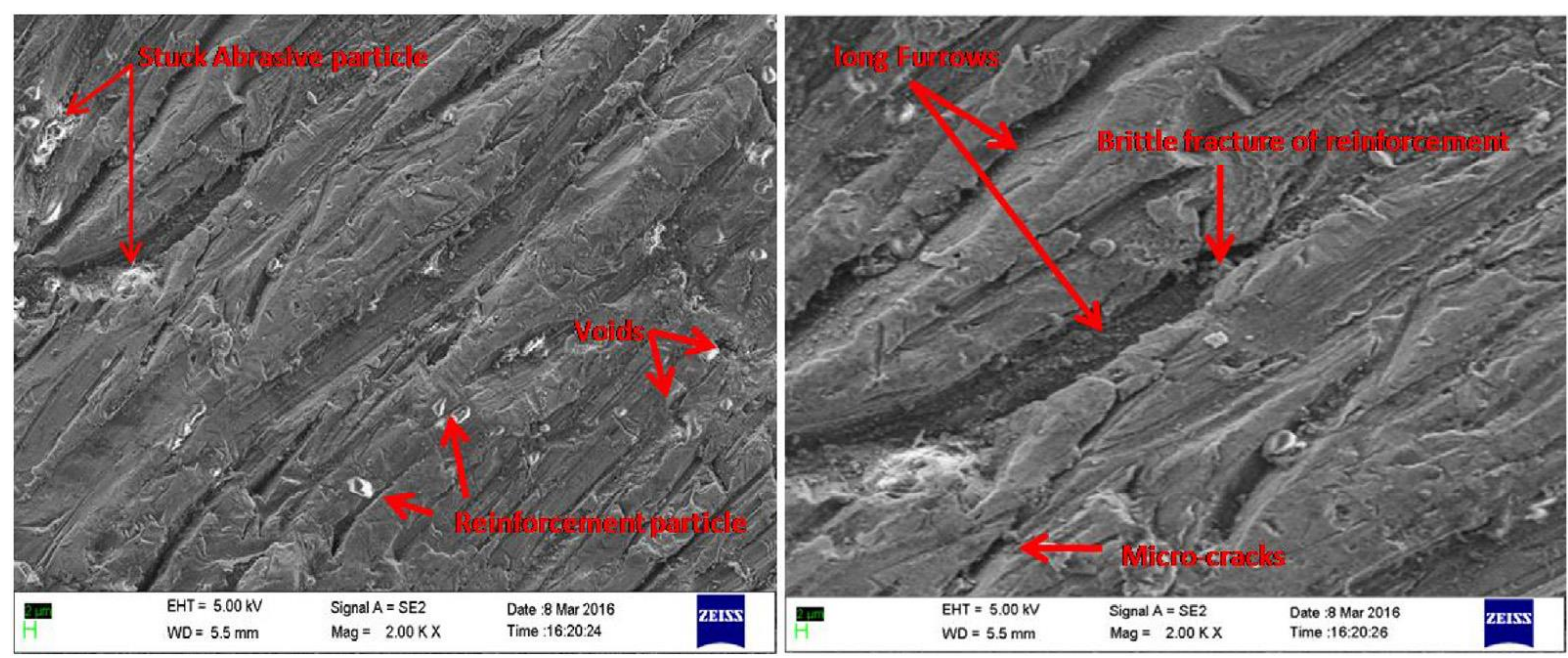

Figure 36 SEM micrograph of the AWJ turning surface on $\mathrm{A359/B}{ }_{4} \mathrm{C} / \mathrm{Al}_{2} \mathrm{O}_{3} \mathrm{MMC}$ [88] 


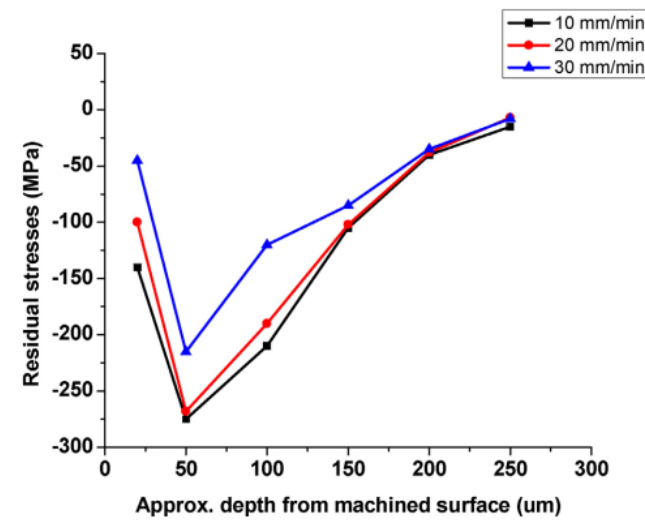

(a)

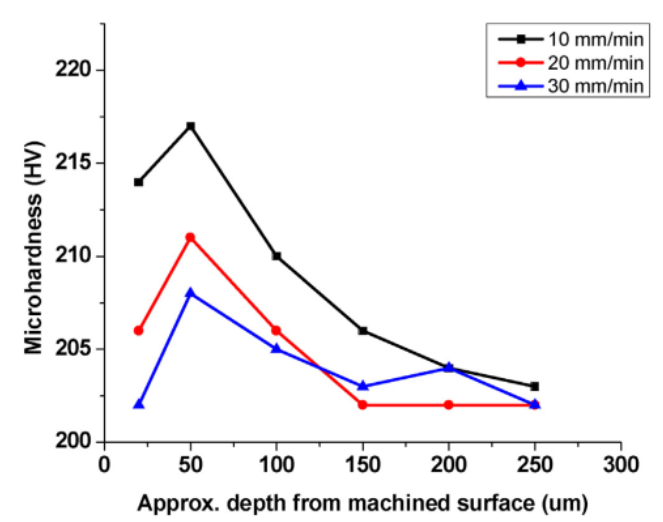

(b)

Figure 37 Residual stresses (a) and microhardness (b) for AWJ turning surfaces of $\mathrm{A359/B}{ }_{4} \mathrm{C} / \mathrm{Al}_{2} \mathrm{O}_{3}$ $M M C$ under different jet transverse speeds [88].

On the other hand, in AWJ turning the workpiece is kept rotating during the jet impacting and moving along the length of the workpiece. This leads to tilted trajectories of the abrasive traces relative to the direction of the sample rotation due to the deflection of the moving jet in contact with the machined surface with combining the energy loss (speed loss) of the jet. An average angle around $15^{\circ}$ to $25^{\circ}$ between the cutting traces and the direction of the rotation were observed in [84] with a jet transverse speed of $10 \mathrm{~mm} / \mathrm{min}$ and a rotation speed of 400 rpm at a $14.5 \mathrm{~mm}$ diameter $\mathrm{A} 359 / \mathrm{B}_{4} \mathrm{C} / \mathrm{Al}_{2} \mathrm{O}_{3} \mathrm{MMC}$ workpiece, as shown in Figure 38, where the bottom and sides of the traces contain fine parallel grooves, oriented parallel to the traces.

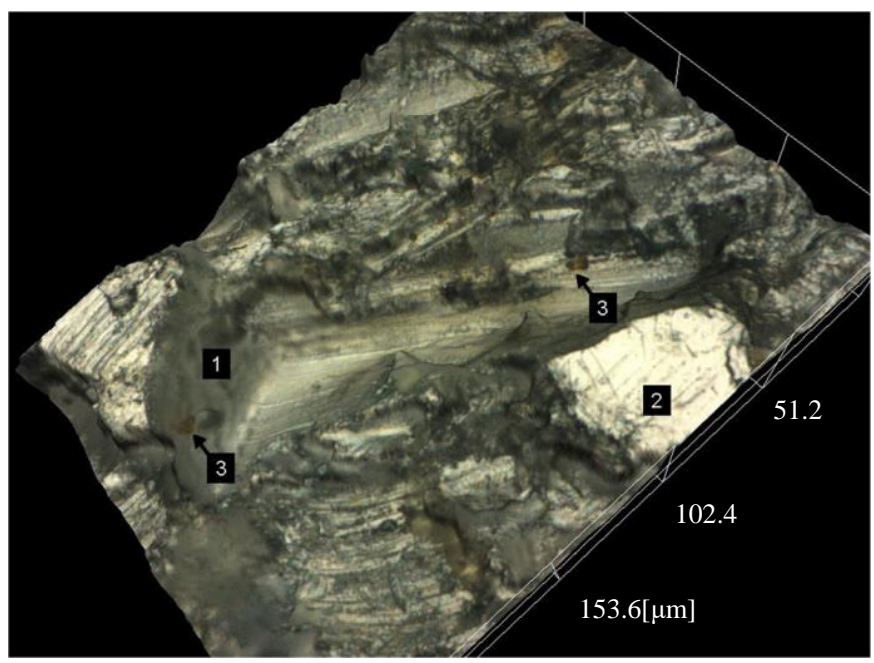

Figure 38 Surface defects generated by AWJ turning showing: 1) front of a cutting trace, 2) smooth glossy flat, and 3) small grains of abrasives stuck in the surface [84]

\subsection{Electro-discharge machining}

Electro-Discharge Machining (EDM) is one of the most widely-used non-conventional machining processes [89] that relies on thermal erosion (vaporization) of the material due to a series of discrete electric discharges between electrode and workpiece while immersed in dielectric fluid. EDM is mainly set on two different configurations: wire EDM (Figure 39a) 
which is preponderantly used to cut through metals to produce prismatic geometries while die sinking EDM (Figure 39b) is mainly used in the production of parts with complex geometries of inverse shape to that of the electrode (e.g. cavity and core) [90]. Due to the non-contact nature, EDM machining enjoys some advantages in comparison with conventional machining including [91,92]: independent tool-wear from workpiece materials hardness; negligible machining forces; ability to machine complicated shapes at high aspect ratios and accuracies. The above advantages might also explain why EDM has attracted increasing attentions recently as a promising method for machining of MMCs.

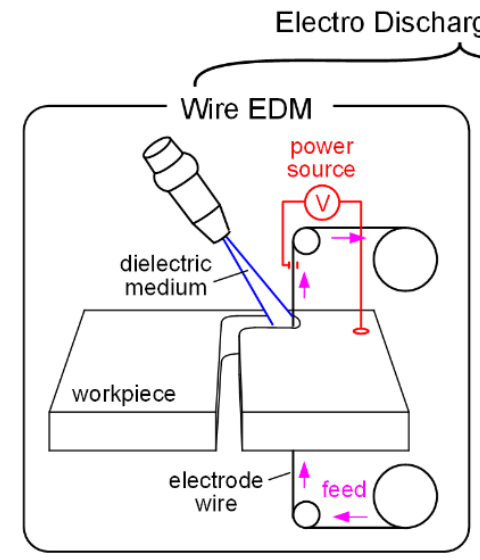

(a)

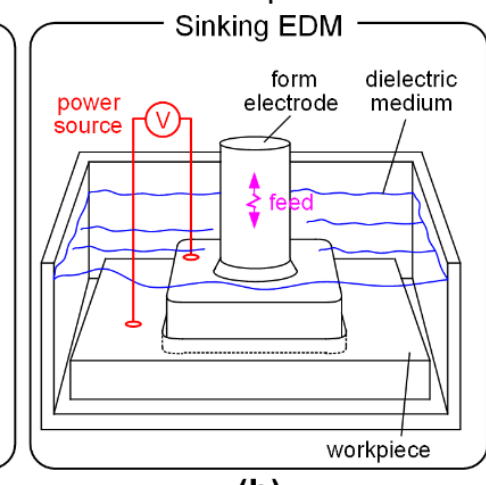

(b)

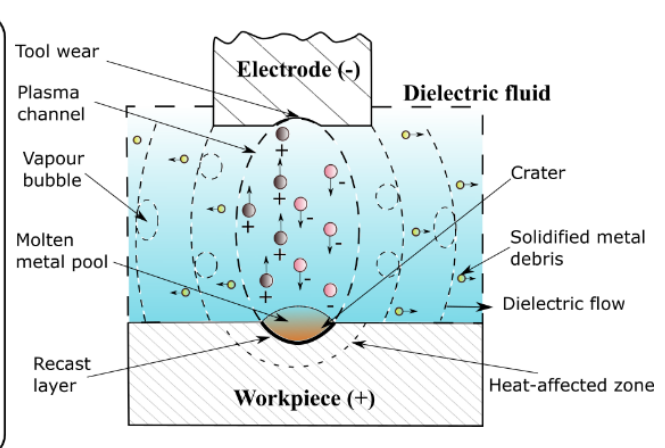

(c)

Figure 39 Schematics of Electro-Discharge Machining (EDM) mainly including (a) wire EDM and

(b) sinking EDM and (c) the working principle during the EDM of monolithic materials

The working principle of EDM (Figure 39c), regardless of the nature of the workpiece material (monolithic, composite, etc.), could be summarised as below:

- Pulsed voltage difference between the tool (normally cathode) and the electrically conductive workpiece (normally anode) within the spark gap is developed beyond the breakdown voltage of the dielectric medium around them.

- As a result, small-scale electric discharge happens in the short-term near the workpiece surface, generating local ultra-high temperature (as high as $20000^{\circ} \mathrm{C}$ [93]) which can, at micro-scale, melt or even vaporise the workpiece forming small debris.

- Finally, the solidified debris are removed by dielectric flushing the cutting area.

Because of employing pulsed voltage, typical material removal rate of EDM is $10^{-6}$ to $10^{-4}$ $\mathrm{mm}^{3}$ per discharge and generally can achieve a machined surface roughness Ra of around 0.01$0.1 \mu \mathrm{m}$ using sophisticated techniques. The EDM mechanism in MMCs is in general similar to that of monolithic materials, however, some specific aspects of the process depend on elevated hardness and thermal stability of particle or fibre reinforcements. Surprisingly, EDM mechanism of MMCs with fibre/whisker reinforcements has been occasionally reported.

Considering that reinforcement particles size is usually 10 times smaller than the EDM wire diameter, particles material removal modes are, generally, different of the corresponding 
removal modes of matrix phase in MMCs. The removal modes of particles in wire EDM is detailed below:

(i) Two distinct zones in the cut slot during wire EDM of MMCs can be distinguished; zone 1 (width equal to wire diameter) which is formed due to spark erosion in the feed direction, and zone 2 (equivalent to kerf slot) which is formed due to spark erosion in the lateral-tofeed direction and/or due to wire deflection/vibration.

(ii) For zone 1 (Figure 40a), when the wire is fed with the breakdown action of the dielectric between wire and workpiece, both the metallic matrix and the reinforcements can be properly removed, in theory. However, substantial experiments proved that wire breakage would happen within this zone (zone 1). The explanation can be that, the particle reinforcement was gradually exposed from the matrix when the wire is fed and hence, it makes it exposed to the sharp edges of the particles leading to the wire damage. Other researchers thought the electrode failure could be attributed to the delay of the plasma formation induced by the melting process of the metallic matrix, leading to an insufficient flushing effect and an ineffective removal of the melted debris which could scratch the electrode surfaces.

(iii) For zone 2, the interaction between the particle reinforcement and the electrode is quite similar to the one in zone 1 . However, instead of being removed, part of the particles in zone 2 are probably held by the matrix while the other part is exposed to the sparks. This difference was believed to be related with the sudden variance of the cutting path and the cross-section profile shift of the machined workpiece, because the protruded particles could micro-deviate the electrode from its planned paths (straight moving path) of the electrode. However, the opposite opinion stated that zone 2 might not exist because in most cases the spark gaps were larger than the particle reinforcement size and therefore no halfexposed half-held reinforcement particles can contact the electrode [94].

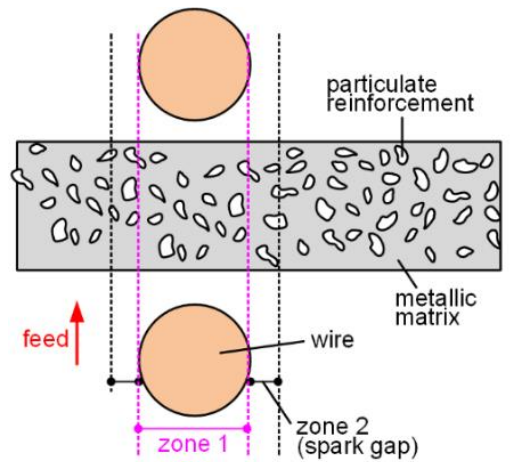

(a)

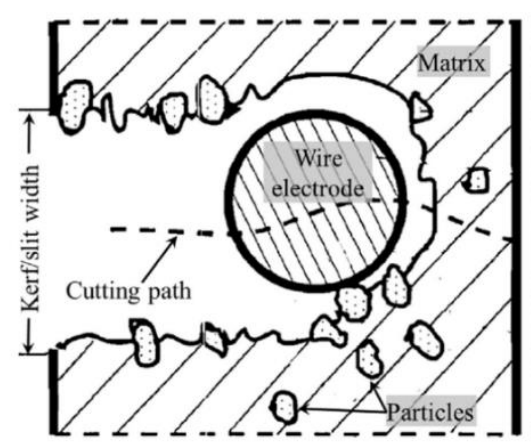

(b)

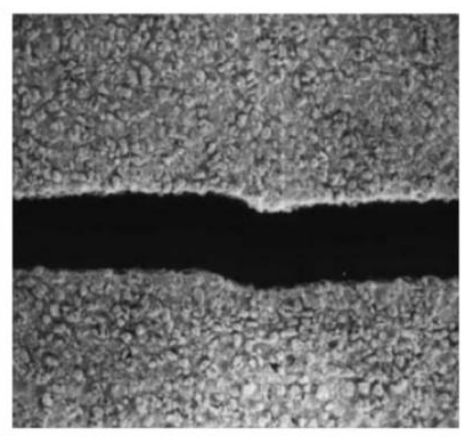

(c)

Figure 40 Working principle during the EDM of MMCs with particle reinforcements (a), and theoretical (b) [94] and deviation of cut profile when wire EDM of $\mathrm{Al}_{2} \mathrm{O}_{3} / 6061 \mathrm{Al} M M C$ (c) [95]

The material of the reinforcement employed on MMCs was reported to be the most influential factor when referring to the machined surface integrity. One typical evidence [96] is the decrease of the machined surface roughness $\mathrm{Ra}$ (around 50\%) induced by the $\mathrm{SiC}$ 
reinforcements when compared to $\mathrm{Al}_{2} \mathrm{O}_{3}$ particles (see Figure 41a). This could be because [96]: the good electric conductivity of the $\mathrm{SiC}$ particles exposed in the spark gap lower the fluidity of the melt and the spreading of the discharge channel, and therefore, shallower melting depth and smaller craters are created, leading to lower Ra values. On the contrary, as seen in Figure $41 \mathrm{~b}$, the poor conductivity of the $\mathrm{Al}_{2} \mathrm{O}_{3}$ reinforcements facilitates the concentration of the plasma energy induced by the dielectric medium breakdown, leads to obviously large pits on the machined surface and therefore, poor surface finish [96].

In addition to the material of the reinforcement, its proportion/volume ratio can also influence the machined surface quality. It was reported that in EDM of Al6061-B 4 C MMCs the weight ratio of the $\mathrm{B}_{4} \mathrm{C}$ reinforcement contributed by $80 \%$ to the enhanced surface quality in comparison with peak current and spark gap voltage in EDM [97].

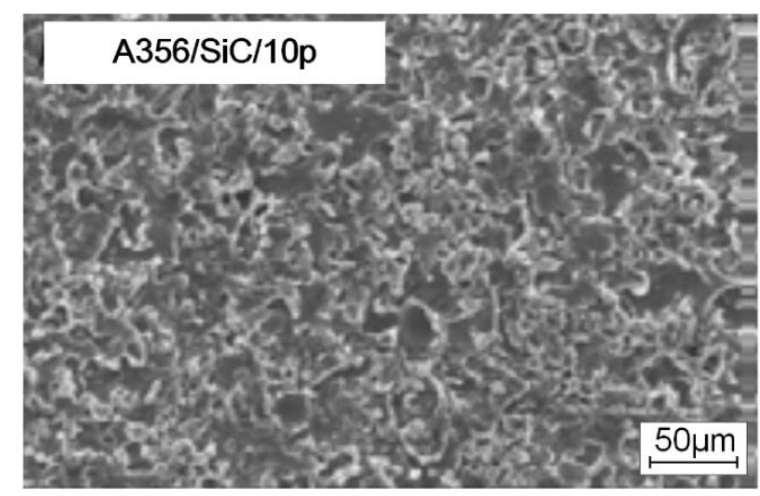

(a)

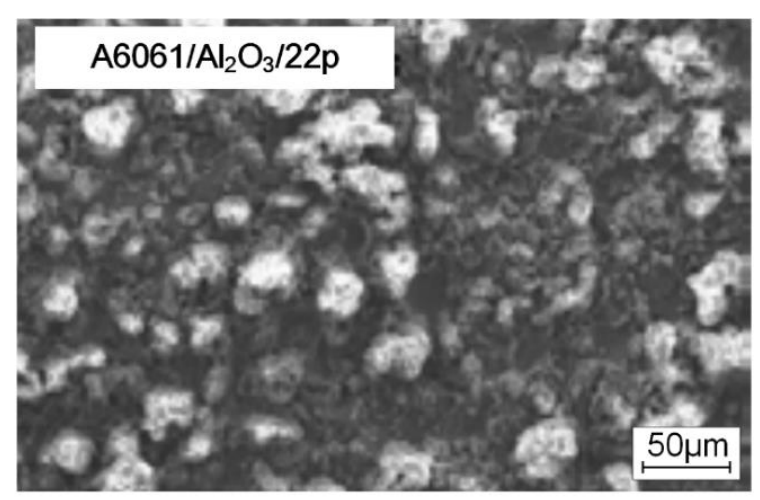

(b)

Figure 41 SEM micrographs of surface morphology after EDM: the Al/SiC composite (a) and the Al/Al2O3 composite (b) [95,96]

Because the material removal mechanism in EDM relies on the electric sparks, the process parameters (voltage and current signal characteristics) were also found dominant to the machined surface integrity. As seen in Figure 42, the recast layer was found thicker when increasing the pulse-on time and the peak current in EDM of Al/SiC MMC [98]. 


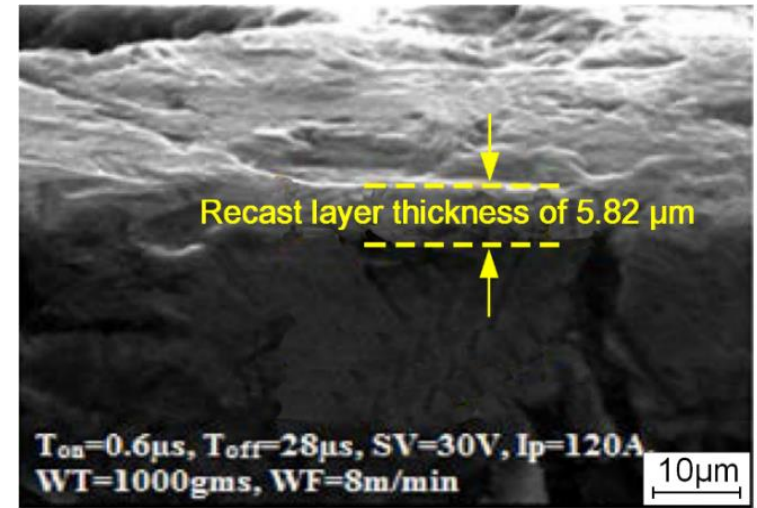

(a)

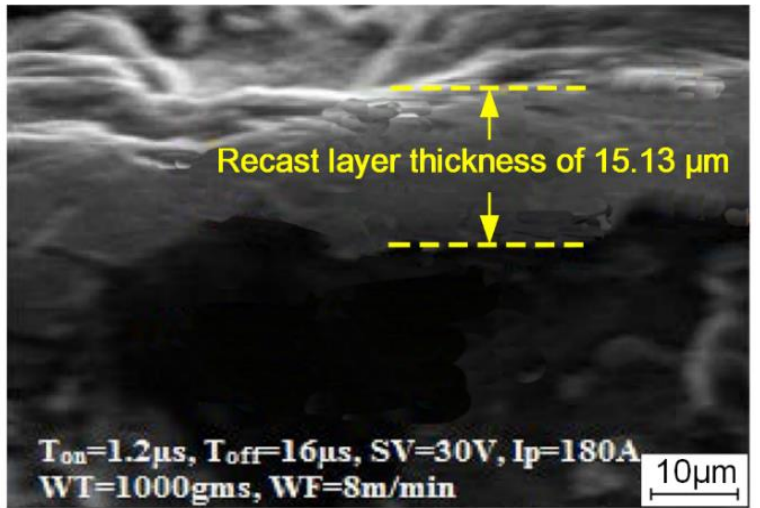

(b)

Figure 42 Comparison of recast layer of machined surfaces (material: Al/SiC-MMC) with different discharge duty cycle and peak current: $2.1 \%, 120 \mathrm{~A}(\mathrm{a})$ and $7.5 \%, 180 \mathrm{~A}(\mathrm{~b})$ [98]

Apart from recast layers, other types of surface defects induced by wire EDM were also reported, including:

(i) Microcracks (see Figure 43a) on/beneath the machined surface [98] - resulted from the high tensile stresses on the machined surface exceeding the matrix cohesion limit when using the higher value of pulse-on time and peak current, which might lead to the deterioration of the machined surface topography and morphology;

(ii) Black spots (see Figure 43b) upon the machined surface [98] - resulted from either the wire failure induced by the abnormal arcing (e.g. continuous discharge of energy) or the contamination of the spark gap due to the melted debris; black spots could be related to unwanted material phase transformations;

(iii) Wire shifting marks (see Figure 43c) on the machined surface [98] - resulted from either the wire feed direction shift due to the exposed reinforcement particles in the theoretical trajectory of the wire motion, or the wire deflection caused by the plasmainduced pressure generated in the dielectric fluid during EDM [98], and might decrease both the geometrical and morphological qualities of the machined surface.

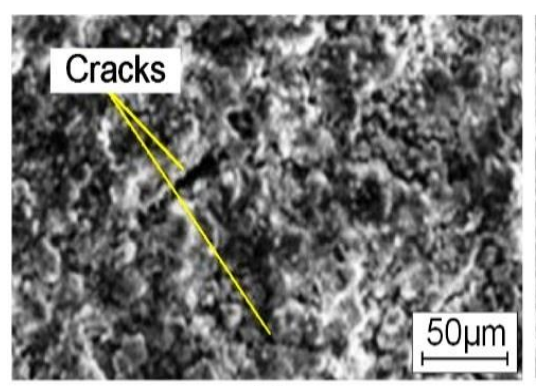

(a)

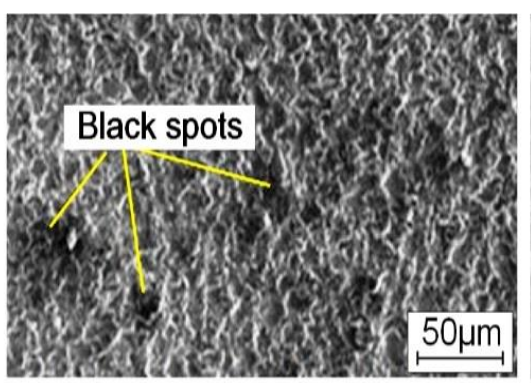

(b)

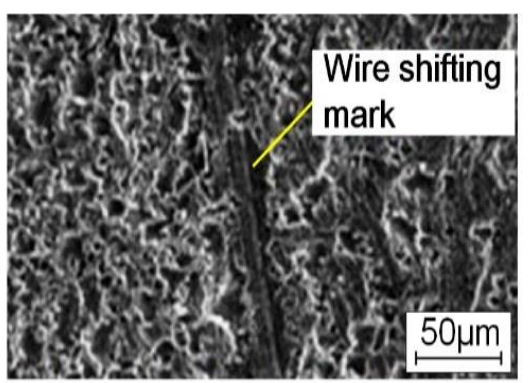

(c)

Figure 43 Other types of EDM-induced surface defects (material: Al/SiC-MMC): crack defects on the machined surface (a), black spots defects on the machined surface (b), and wire shifting marks on the machined surface (c) [98] 
When it comes to microscale, as seen in Figure 44, different defects were also observed in the micro wire EDM process of Al alloy 2024-based matrix composite with SiCp reinforcement, including:

(i) Micro-pores and globules of debris-resulted from the gas bubbles in the raw MMCs, or the escape of bubbles during micro wire EDM process [99];

(ii) Micro-cracking - resulted from the thermal stress generated by the sharp temperature drop on the machined surface when the dielectric medium contacts the workpiece [99];

(iii) Shallow craters - resulted from the insufficient support to the reinforcement particles due to the removal of the molten metal matrix in micro wire EDM [99].

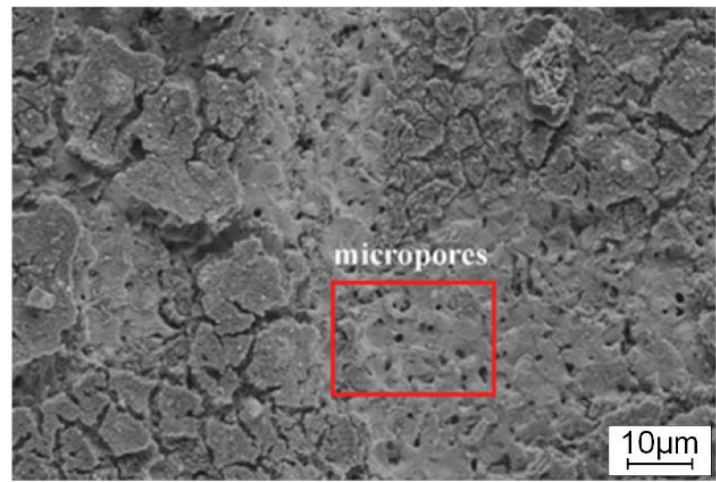

(a)

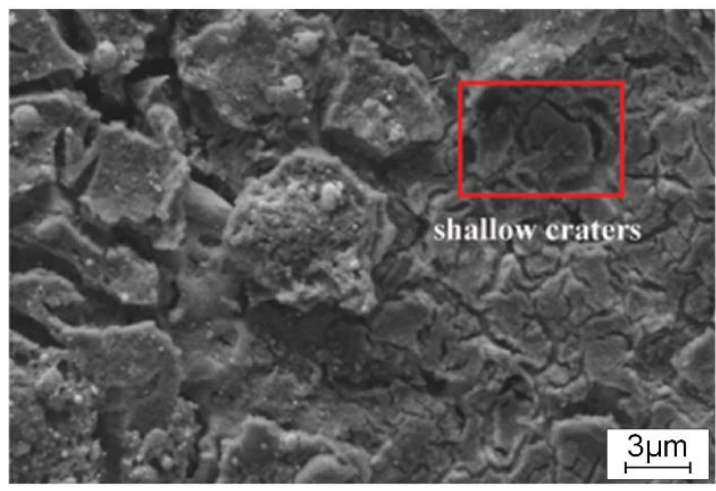

(c)

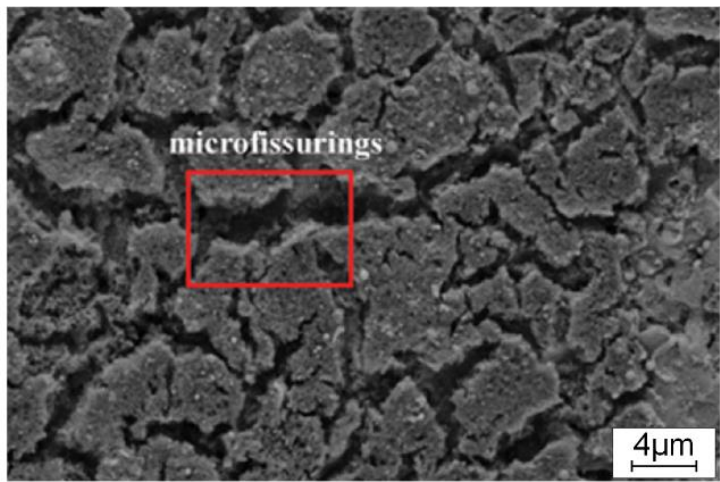

(b)

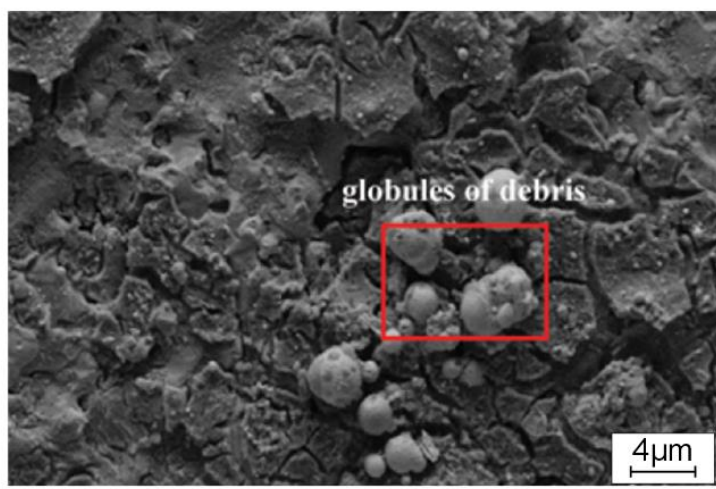

(d)

Figure 44 Micro-WEDMed surface microtopography of SiCp/Al2024 MMC: micropores (a), micro cracking (b), shallow craters (c), and globules of debris (d) [99]

On the sinking EDM process front (macro scale), the effects of the process parameters on the workpiece surface integrity were also reported to give similar effects. Rough machined surface with the sign of large-sized craters was found in the Al6351 matrix composites with a $5 \mathrm{wt} \% \mathrm{SiC}$ and a $5 \mathrm{wt} \% \mathrm{~B}_{4} \mathrm{C}$ reinforcements when the high current was employed (see Figure 45) [100]. This was explained by the fact that, an increased current generated a substantial amount of energy and therefore, molten more material which formed larger pits on the machined surface. Similar outcome was also found for the $\mathrm{Al} 7075$ matrix composite with $\mathrm{B}_{4} \mathrm{C}$ reinforcements [101], as shown in Figure 46. 


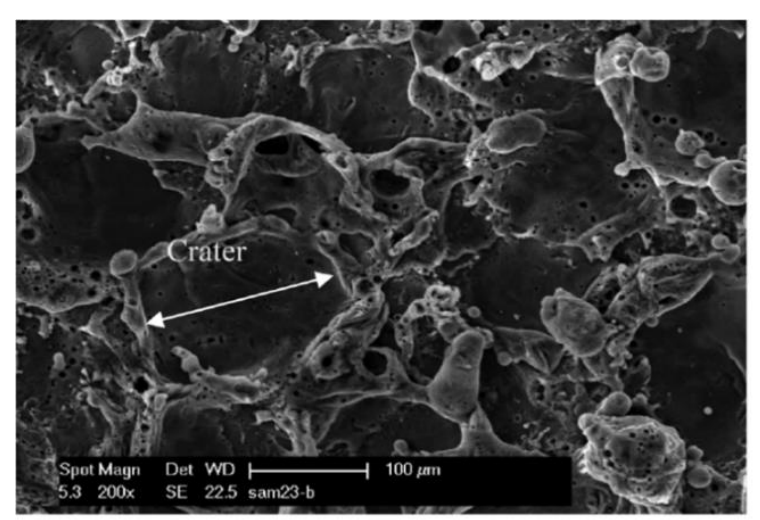

(a)

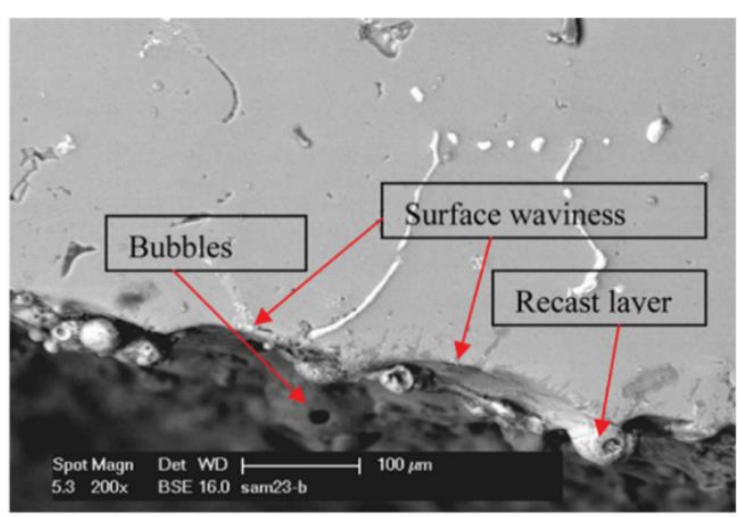

(b)

Figure 45 Craters on the machined surface of Al(6351)-SiC-B4C MMC when the high current was employed (a), and the cross section morphology when the low current was employed on which recast layers and bubbles can be observed (b) [100].

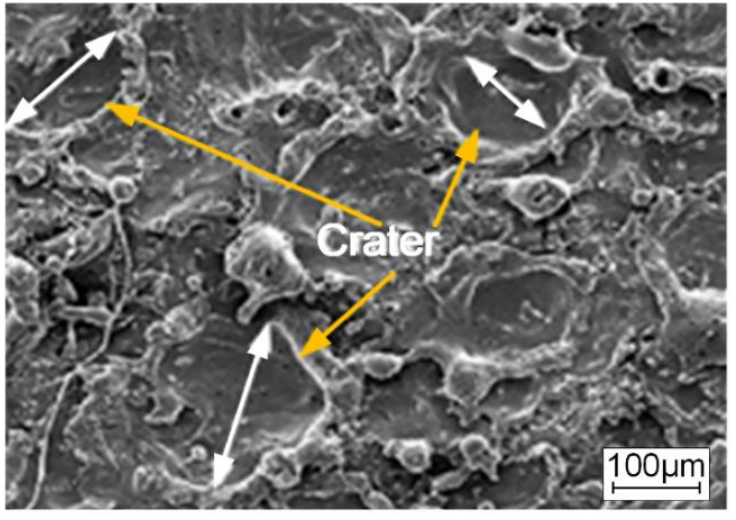

(a)

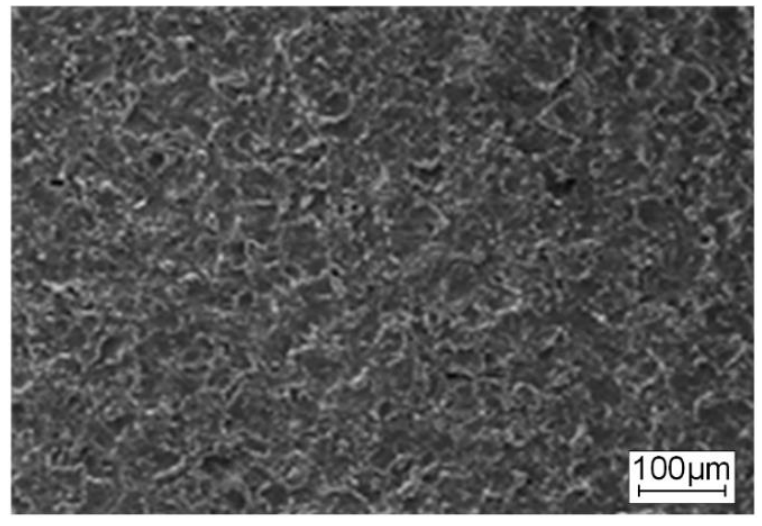

(b)

Figure 46 Machined surface topography showing craters formed due to impact with plasma channels during sinking EDM when the pulse voltage is $60 \mathrm{~V}$, the current is $12 \mathrm{~A}$, the pulse on time is $8 \mu$ s and the pulse off time is $8 \mu \mathrm{s}(\mathrm{a})$, and the pulse voltage is $40 \mathrm{~V}$, the current is $6 \mathrm{~A}$, the pulse on time is $4 \mu$ s and the pulse off time is $8 \mu$ s (b) [101].

\section{Effect of surface integrity on the functional performance of MMCs}

As previously mentioned, the MMCs, with their lightweight and high strength and stiffness, have been widely applied for the aerospace and ground transportation industries in which structural integrity of the components under cycled thermal and mechanical loads [2,3] is of high importance. The harsh applications of MMCs could results in the occurrence of fatigue failure which is linked with quality/integrity of machined surfaces (i.e. residual stress, surface topography and defects) [102,103]. Thus, the effect of machined surface integrity on fabricating MMCs specimens subjected to fatigue is of importance to the community. Although there are quite a few researches on the fatigue performance of the MMCs, most of them were performed with polished surface for eliminating the surface defect effect thus to reach the fatigue perforce of the bulk material [104-106], while only few papers have focused on the influence of the surface integrity on the fatigue life. 
As for other metallic materials, the residual stresses have a significant influence on the fatigue performance of the machined MMCs components where the compressive stress would favour the extension of fatigue life while the tensile stress have the opposite effect $[107,108]$. However, differently from monolithic metallic materials, fatigue cracks of MMCs do not follow the traces left by conventional machining process, which means surface roughness has limited effects on fatigue life (Figure 47) [102,109]. Instead, the propagation of fatigue crack is usually arrested or deflected by reinforced particles towards an easy debonding direction and this effect becomes more evident with the increase of reinforcement particles size. More interestingly, when it comes to non-conventional machining (e.g. EDM) the surface roughness then makes a difference on the fatigue life, i.e. better surface roughness results in longer fatigue life (Figure 48), as less surface defects are caused by the recast layer of the matrix and pull-out of the reinforcement particles in this machining process [110].
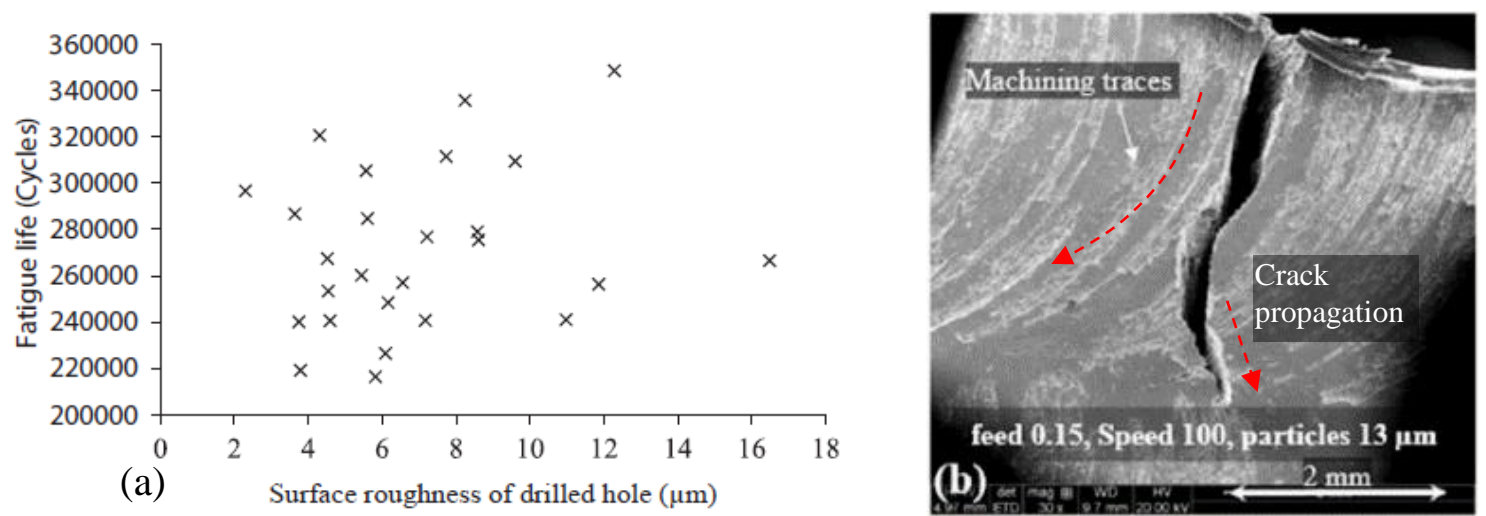

Figure 47 Fatigue test of milled Al6061/SiC/10p MMCs at displacement amplitude of 0.58mm showing that there is no conclusive evidence to prove the effects of surface roughness on fatigue life of drilled holes (a) and the fatigue crack propagation on specimens does not follow the machining traces (b) [102].

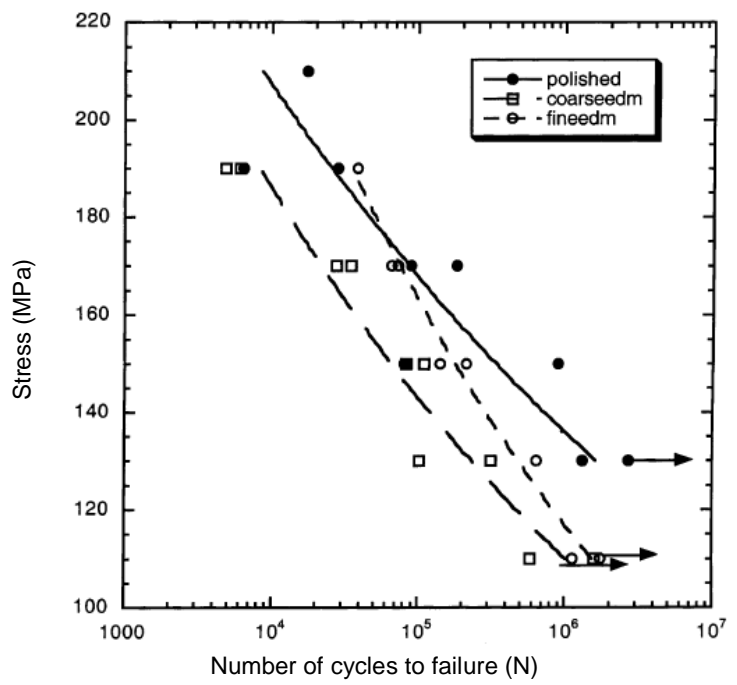

\begin{tabular}{|l|l|}
\hline $\begin{array}{l}\text { Surface } \\
\text { condition }\end{array}$ & $\begin{array}{l}\text { Surface roughness } \\
\mathbf{R a}(\boldsymbol{\mu m})\end{array}$ \\
\hline Polished & 0.28 \\
\hline Fine Sparked & 3.71 \\
\hline Coarse Sparked & 14.5 \\
\hline
\end{tabular}

Figure 48 Stress vs fatigue life of polished and coarse and fine EDM samples of A356/SiC/15p MMC [110] 
In general the fatigue failure of MMCs occurs with an initial damage induced by voids nucleation in the material, while these voids will then grow and subsequently coalesce in the matrix materials or separate the particle/matrix interface, as shown in Figure 49. Particularly, the specific surface defects of MMCs generated during machining process, such as microcrack, recast layer, pits and voids, which cause variation in stress concentration at localised regions (especially in the interface of matrix and reinforcement particles [109]), can also be the initial damage when in fatigue application, leading to deleterious effect for fatigue life. As shown in Figure 50, where the fracture morphologies after fatigue testing of machined Al6061/SiC/10p are presented, the fracture has predominantly a ductile nature which started from microscopic cracks caused by fracture and debonding of reinforcements at particle-matrix interfaces [102]. It is also found the fatigue life of MMCs are much shorter than that of corresponding matrix material due to the fracture and detachment of reinforcing particles from the matrix.
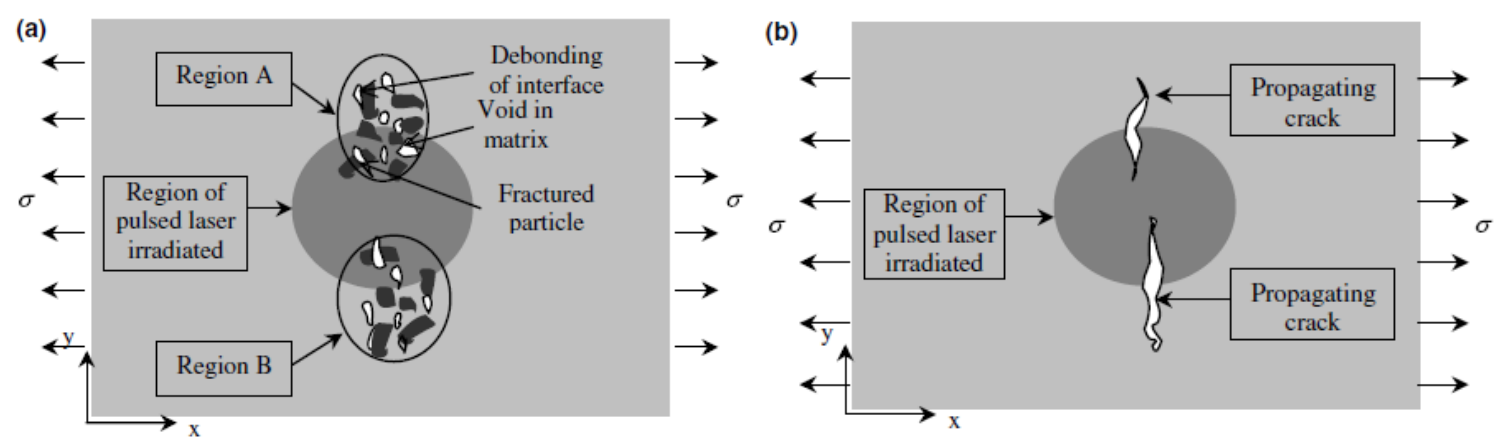

Figure 49 Schematic fatigue of Al6061/SiC/15p MMC induced by repetition-pulsed laser and mechanical load, fatigue damage initial position and damage models (a), fatigue crack propagation

(b) [111]
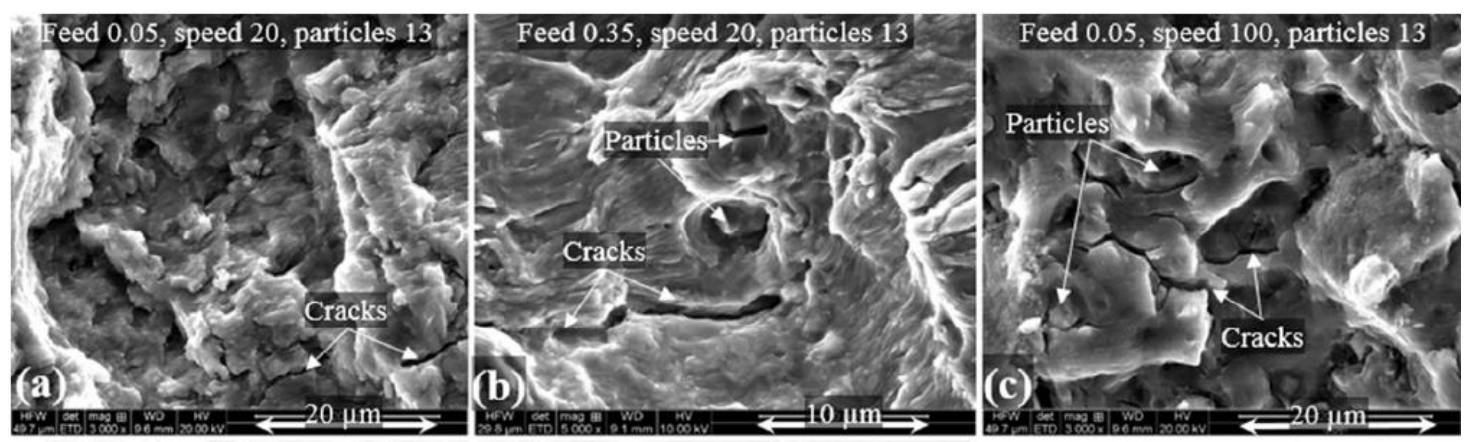

Figure 50 Fracture morphology of flexural fatigue testing on machined Al6061/SiC/10p under different cutting conditions [102]

\section{Summary and Outlook}

With their enhanced properties (e.g. high strength, wear resistance), MMCs are emerging as substitutes of monolithic metal materials while, in the same time, pose significant challenges in terms of low machinability and severe workpiece surface damage. As they are used for highend applications, the surface integrity of MMCs is highly influential on the functional 
performance and service life of the machined components. Thus, understanding the machining process and the resulting surface integrity is important to the community.

Based on the mapping of the existing published literature related to machining and surface integrity of MMCs (Figure 51), it can be seen that, on one hand, the amount of published research publications in the field of machining MMCs has considerably grown during the last five years, particularly for mechanical/conventional machining processes. On the other hand, it can be observed that the MMCs attracting more interest for the machining research are the $\mathrm{Al} / \mathrm{Al}_{2} \mathrm{O}_{3}$ followed by the $\mathrm{Al} / \mathrm{SiC}$, which are widely used in the automobile, aerospace and electricity industries due to their advantages of light weight, high wear resistance, strength and durability, etc.

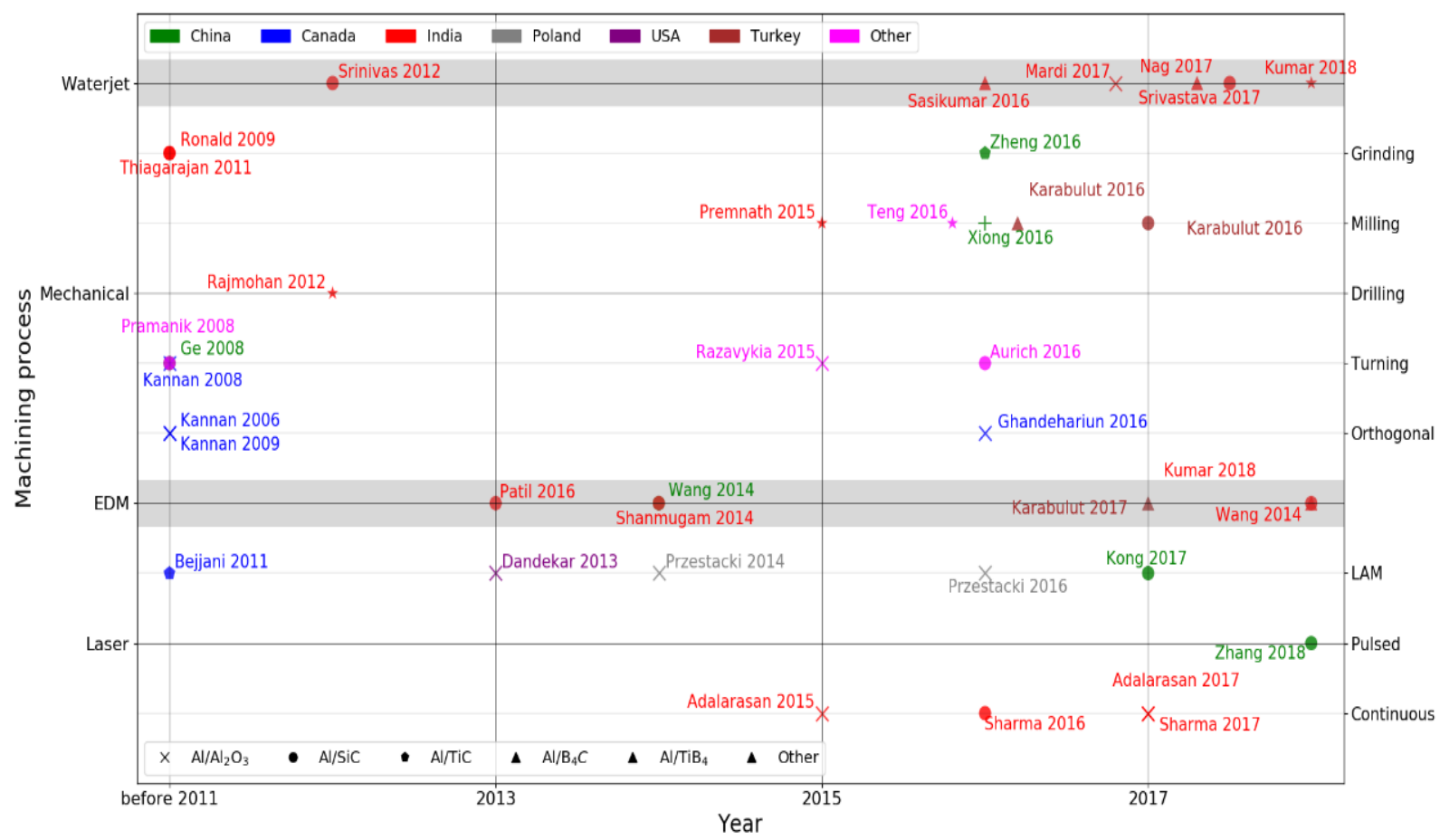

Figure 51 An overview of published papers over the last 10 years in relation to conventional and nonconventional machining of MMCs, classified by MMCs type and country.

Thus, based on the in-depth review on conventional and non-conventional machining of MMCs, it can be concluded that the surface integrity of MMCs machining is drawing an increasing attention. Moreover, the major conclusions of the previous work and the future directions could be summarised:

- Conventional machining is the leading technology for MMCs when dimensional and geometrical accuracy of machined surfaces functionality is essential. Nevertheless, the tool/workpiece mechanical contact could lead to rapid tool wear and unfavourable surface integrity issues especially. Besides the increased tool wear, the presence of particle phase in the workpiece promotes some particular surface defects namely, but not exclusively, particles pull-out, pits, grooves, craters and micro-cracks. The reinforcement particles also affect the strain hardening sensitivity of the material by acting as a barriers in front of the 
material dislocations flow and/or restraining the material flow in between the particles. The latter led to less subsurface deformation during machining hence, reduced residual stresses. The presence of particles also helped in obtaining finer surface topology/roughness (at high cutting speed and lower feed rates).

- Laser assisted machining has been applied for both turning and milling process of MMCs. Because of the lower melting temperatures of the matrix compared to reinforcement particles, in LAM of MMCs the matrix softening effect leads to low cutting force and sinking of reinforcement particles into the matrix. This leads to different surface damage mechanism when compared with conventional machining. Although similar surface damage modes such as debonding, particle pull-out and particle fracture were observed, all these damages were found less significant than in conventional machining. Different from conventional machining and LAM, in laser machining of MMCs the surface damage is predominately affected by the melting and vaporizing of the matrix and reinforcement particles under different rates. These result in striations and dross, recast layer as well as cracks and voids. Moreover, due to the high temperature effect some chemical reactions such as oxidation, or carbonization could be observed. In addition, it could be commented that the laser cutting yields a lower material removal rate as well as surface integrity on MMCs when compared with other process, thus more effort needs to be paid to improve the process before it can be widely applied in industry.

- In AWJ machining of MMCs the main operations are through cutting and turning. The affected surface is formed by pronounced cutting traces of various lengths and widths left by abrasive grains. Moreover, considering that mechanical erosion occurs during the AWJ machining, the main surface defects are found as plastic deformations, cracking pits and voids, abrasive embedment and micro-melting. It is also found that the impinging of abrasive particles could induce compressive residual stresses which would be beneficial to its fatigue life.

- In EDM, the surface damage is mainly formed with recast layer, microcracks, black spots and wire shifting marks. The constitution of reinforcement is the most influential factor for the quality of the machined surfaces. High conductivity reinforcement (e.g. SiC) leads to smooth surface while low conductivity reinforcement (e.g. $\mathrm{Al}_{2} \mathrm{O}_{3}$ ) leads to severe surface damage due to the concentration of the plasma energy. With the variation of reinforcement proportion the surface quality (e.g. surface roughness, recast layer and microcrack) is also changed.

- The fatigue performance of MMCs is significantly influenced by the present of reinforcement components compared with the corresponding monolithic metallic materials. However, most researches reported only on the fatigue performance of the bulk MMCs with well-polished surface (i.e. surface defect effect free) while the understanding the influence of the surface integrity on their fatigue life is rare. As most MMCs components are machined to achieve the desired dimension and geometry accuracy in which condition the surface damage may be induced, more work should be focused on 
deeply understand the relationship between the surface integrity and fatigue performance under different machining processes.

\section{References}

[1] Metal Matrix Composite Market by Type (Aluminum MMC, Magnesium MMC, Refractory MMC), Production Technology, Reinforcement (Continuous, Discontinuous, Particle), End Use Industry, and Region - Global Forecast to 2021. Market Research Report, May, 2017

[2] J.W. Kaczmar, K. Pietrzak, W. Włosiński, The production and application of metal matrix composite materials, Journal of Materials Processing Technology, 106 (1) (2000) 58-67.

[3] T. Barrett, The Future of Metal is in Matrix Composites https://www.machinedesign.com/materials/future-metal-matrix-composites $\quad$ Jun $\quad 01,2017$ (accessed in 22nd Nov. 2018)

[4] Z. Liao, D.A. Axinte, D. Gao, On modelling of cutting force and temperature in bone milling, Journal of Materials Processing Technology, 266 (2019) 627-638

[5] F. Saba, S.A. Sajjadi, M. Haddad-Sabzevar, F. Zhang, TiC-modified carbon nanotubes, TiC nanotubes and TiC nanorods: Synthesis and characterization, Ceramics International, 44 (7) (2018) 7949-7954.

[6] C. Liu, W. Ding, T. Yu, C. Yang, Materials removal mechanism in high-speed grinding of particulate reinforced titanium matrix composites, Precision Engineering, 51 (2018) 68-77.

[7] A. Pramanik, Developments in the non-traditional machining of particle reinforced metal matrix composites. International Journal of Machine Tools and Manufacture 86 (2014): 44-61.

[8] Liu, J., Li, J., \& Xu, C. Interaction of the cutting tools and the ceramic-reinforced metal matrix composites during micro-machining: a review. CIRP Journal of Manufacturing Science and Technology, 7(2), (2014): 55-70.

[9] Srivastava, A. K., Dixit, A. R., \& Tiwari, S. A review on the intensification of metal matrix composites and its nonconventional machining. Science and Engineering of Composite Materials, 25(2), (2018): 213-228.

[10] Bains, P. S., Sidhu, S. S., \& Payal, H. S. Fabrication and machining of metal matrix composites: a review. Materials and Manufacturing Processes, 31(5), (2016): 553-573.

[11] Sekhar, R., \& Singh, T. P. Mechanisms in turning of metal matrix composites: a review. Journal of Materials Research and Technology, 4(2), (2015): 197-207.

[12] A. Muthuchamy, G.D.J. Ram, V.S. Sarma, Spark plasma consolidation of continuous fiber reinforced titanium matrix composites, Materials Science and Engineering: A, 703 (2017) 461469.

[13] Z. Li, W. Ding, L. Shen, X. Xi, Y. Fu, Comparative investigation on high-speed grinding of $\mathrm{TiCp} / \mathrm{Ti}-6 \mathrm{Al}-4 \mathrm{~V}$ particulate reinforced titanium matrix composites with single-layer electroplated and brazed CBN wheels, Chinese Journal of Aeronautics, 29 (5) (2016) 1414-1424. 
[14] K. Chu, F. Wang, X.-h. Wang, Y.-b. Li, Z.-r. Geng, D.-j. Huang, H. Zhang, Interface design of graphene/copper composites by matrix alloying with titanium, Materials \& Design, 144 (2018) 290-303.

[15] Dinaharan, S. Saravanakumar, K. Kalaiselvan, S. Gopalakrishnan, Microstructure and sliding wear characterization of $\mathrm{Cu} / \mathrm{TiB} 2$ copper matrix composites fabricated via friction stir processing, Journal of Asian Ceramic Societies, 5 (3) (2017) 295-303.

[16] Y.J. Mai, F.X. Chen, W.Q. Lian, L.Y. Zhang, C.S. Liu, X.H. Jie, Preparation and tribological behavior of copper matrix composites reinforced with nickel nanoparticles anchored graphene nanosheets, Journal of Alloys and Compounds, 756 (2018) 1-7.

[17] M. Balakrishnan, I. Dinaharan, R. Palanivel, R. Sivaprakasam, Synthesize of AZ31/TiC magnesium matrix composites using friction stir processing, Journal of Magnesium and Alloys, 3 (1) (2015) 76-78.

[18] L.G. Hou, R.Z. Wu, X.D. Wang, J.H. Zhang, M.L. Zhang, A.P. Dong, B.D. Sun, Microstructure, mechanical properties and thermal conductivity of the short carbon fiber reinforced magnesium matrix composites, Journal of Alloys and Compounds, 695 (2017) 2820-2826.

[19] H. Li, L. Cheng, X. Sun, Y. Li, B. Li, C. Liang, H. Wang, J. Fan, Fabrication and properties of magnesium matrix composite reinforced by urchin-like carbon nanotube-alumina in situ composite structure, Journal of Alloys and Compounds, 746 (2018) 320-327.

[20] S.-J. Huang, A.N. Ali, Effects of heat treatment on the microstructure and microplastic deformation behavior of $\mathrm{SiC}$ particles reinforced AZ61 magnesium metal matrix composite, Materials Science and Engineering: A, 711 (2018) 670-682.

[21] K. Shirvanimoghaddam, S.U. Hamim, M. Karbalaei Akbari, S.M. Fakhrhoseini, H. Khayyam, A.H. Pakseresht, E. Ghasali, M. Zabet, K.S. Munir, S. Jia, J.P. Davim, M. Naebe, Carbon fiber reinforced metal matrix composites: Fabrication processes and properties, Composites Part A: Applied Science and Manufacturing, 92 (2017) 70-96.

[22] D. Hashiguchi, D. Tricker, A. Tarrant, J. Campbell, C. Pokross, Discontinuously reinforced aluminum MMC extrusions, Metal Powder Report, 72 (4) (2017) 252-258.

[23] R. Jiang, X. Chen, R. Ge, W. Wang, G. Song, Influence of TiB 2 particles on machinability and machining parameter optimization of TiB 2 /Al MMCs, Chinese Journal of Aeronautics, 31 (1) (2018) 187-196.

[24] S.M.Y. Kaku, A.K. Khanra, M.J. Davidson, Effect of deformation on properties of Al/Al-alloy ZrB 2 powder metallurgy composite, Journal of Alloys and Compounds, 747 (2018) 666-675.

[25] Attar, Hooyar, Shima Ehtemam-Haghighi, Damon Kent, and Matthew S. Dargusch. Recent developments and opportunities in additive manufacturing of titanium-based matrix composites: A review. International Journal of Machine Tools and Manufacture 133 (2018): 85-102.

[26] Gu, Dongdong, Mujian Xia, and Donghua Dai. On the role of powder flow behavior in fluid thermodynamics and laser processability of Ni-based composites by selective laser melting. International Journal of Machine Tools and Manufacture 137 (2019): 67-78 
[27] P. Shiva Shanker, A review on properties of conventional and metal matrix composite materials in manufacturing of disc brake, Mater. Today Proc. 5 (2018) 5864-5869.

[28] D. Ulutan, T. Ozel, Machining induced surface integrity in titanium and nickel alloys: A review, Int. J. Mach. Tools Manuf. 51 (2011) 250-280.

[29] Diaz, O.G., Luna, G.G., Liao, Z. and Axinte, D., 2019. The new challenges of machining Ceramic Matrix Composites (CMCs): review of surface integrity. International Journal of Machine Tools and Manufacture.

[30] A. Thakur, S. Gangopadhyay, State-of-the-art in surface integrity in machining of nickel-based super alloys, Int. J. Mach. Tools Manuf. 100 (2016) 25-54.

[31] K. Lin, S.D. Pang, The influence of thermal residual stresses and thermal generated dislocation on the mechanical response of particulate-reinforced metal matrix nanocomposites, Compos. Part B Eng. 83 (2015) 105-116.

[32] A. Arun Premnath, Studies on machining parameters while milling particle reinforced hybrid (Al6061/Al2O3/Gr) MMC, Part. Sci. Technol. 33 (2015) 682-692

[33] V. Anandakrishnan, A. Mahamani, Investigations of flank wear, cutting force, and surface roughness in the machining of Al-6061-TiB 2 in situ metal matrix composites produced by fluxassisted synthesis. The International Journal of Advanced Manufacturing Technology, 55(1-4) (2011) 65-73.

[34] Y. Wang, Y. Liu, X. Chu, Y. He, W. Zhang, Calculation model for surface roughness of face gears by disc wheel grinding. International Journal of Machine Tools and Manufacture, 123 (2017) 76-88.

[35] Z. Liao, D.A. Axinte, D. Gao, A novel cutting tool design to avoid surface damage in bone machining. International Journal of Machine Tools and Manufacture, 116 (2017) 52-59.

[36] C.L. He, W. J. Zong, J.J. Zhang, Influencing factors and theoretical modeling methods of surface roughness in turning process: State-of-the-art. International Journal of Machine Tools and Manufacture. 29 (2018) 15-26

[37] Z. Liao, D.A. Axinte, On chip formation mechanism in orthogonal cutting of bone. International Journal of Machine Tools and Manufacture, 102 (2016) 41-55.

[38] A. Bakkar, M.M.Z. Ahmed, N.A. Alsaleh, M.M.E.S. Seleman, S. Ataya, Microstructure, wear, and corrosion characterization of high TiC content Inconel 625 matrix composites, J. Mater. Res. Technol. (2018) 1-9.

[39] Kong, X., Yang, L., Zhang, H., Chi, G., \& Wang, Y. Optimization of surface roughness in laserassisted machining of metal matrix composites using Taguchi method. The International Journal of Advanced Manufacturing Technology, 89(1-4), (2017), 529-542.

[40] J. Guo, S. Amira, P. Gougeon, X.G. Chen, Effect of the surface preparation techniques on the EBSD analysis of a friction stir welded AA1100-B4C metal matrix composite, Mater. Charact. 62 (2011) 865-877. 
[41] W. Li, Y. Yang, M. Li, J. Liu, D. Cai, Q. Wei, C. Yan, Y. Shi, Enhanced mechanical property with refined microstructure of a novel $\gamma$-TiAl/TiB2metal matrix composite (MMC) processed via hot isostatic press, Mater. Des. 141 (2018) 57-66.

[42] Z. Liao, D. Axinte, M. Mieszala, R. M'Saoubi, J. Michler, M. Hardy, On the influence of gamma prime upon machining of advanced nickel based superalloy. CIRP Annals. 67 (2018): 109-112.

[43] S. Kannan, H.A. Kishawy, I. Deiab, Cutting forces and TEM analysis of the generated surface during machining metal matrix composites, J Mater Process Technol, 209 (2009): 2260-2269

[44] M. El-gallab, M. Sklad, Machining of Al / SiC particulate metal-matrix composites Part I : Tool performance, 83 (1998) 151-158.

[45] C. Zhao, Y. Zhou, X. Xing, S. Liu, X. Ren, Q. Yang, Precipitation stability and micro-property of (Nb, Ti)C carbides in MMC coating, J. Alloys Compd. 763 (2018) 670-678.

[46] M.S. Selamat, L.M. Watson, T.N. Baker, XRD and XPS studies on surface MMC layer of SiC reinforced Ti-6Al-4V alloy, J. Mater. Process. Technol. 142 (2003) 725-737.

[47] P.J. Withers, M.J. Roy, Residual stressesin metal matrix composites, Compr. Compos. Mater. II. 4-8 (2018) 275-286.

[48] S. Kannan, H.A. Kishawy, Surface characteristics of machined aluminium metal matrix composites, International Journal of Machine Tools \& Manufacture 46 (2006) 2017-2025.

[49] A. Ghandehariun, H. A. Kishawy, U. Umer. H.M. Hussein, Analysis of tool-particle interactions during cutting process of metal matrix composites, Int J Adv Manuf Technol (2016) 82:143-152.

[50] A. Razavykia, S. Farahany, N.M. Yusof, Evaluation of cutting force and surface roughness in the dry turning of $\mathrm{Al}-\mathrm{Mg} 2 \mathrm{Si}$ in-situ metal matrix composite inoculated with bismuth using DOE approach, Measurement 76 (2015) 170-182.

[51] Y.F. Ge, J.H. Xu, H. Yang, S.B. Luo, Y.C. Fu, Workpiece surface quality when ultra-precision turning of SiCp/Al composites, journal of materials processing technology 203 ( 2008 ) 166-175.

[52] S. Kannan, H.A. Kishawy, Tribological aspects of machining aluminium metal matrix composites, journal of materials processing technology, 198(2008) 399-406.

[53] A. Pramanik, L.C. Zhang, J.A. Arsecularatne, Machining of metal matrix composites: Effect of ceramic particles on residual stress, surface roughness and chip formation, International Journal of Machine Tools \& Manufacture 48 (2008) 1613-1625.

[54] J.C. Aurich, M. Zimmermann, S. Schindler, P. Steinmann, Effect of the cutting condition and the reinforcement phase on the thermal load of the workpiece when dry turning aluminum metal matrix composites, Int J Adv Manuf Technol (2016) 82:1317-1334.

[55] T. Rajmohan, K. Palanikumar, M. Kathirvel, Optimization of machining parameters in drilling hybrid aluminium metal matrix composites, Trans. Nonferrous Met. Soc. China 22 (2012) 12861297.

[56] X. Teng, D. Huo, E. Wong, G. Meenashisundaram, M. Gupta, Micro-machinability of nanoparticle-reinforced Mg-based MMCs: an experimental investigation, Int J Adv Manuf Technol (2016) 87:2165-2178. 
[57] S. Karabulut, H. Karakoç, R. Çıtak, Influence of B4C particle reinforcement on mechanical and machining properties of Al6061/B4C composites, Composites Part B (2016) 101:87:98.

[58] Y. Xiong, W. Wang, R. Jiang, K. Lin, G. Song, Surface integrity of milling in-situ TiB2 particle reinforced Al matrix composites, Int. Journal of Refractory Metals and Hard Materials 54 (2016) 407-416.

[59] A. Di Ilio, A. Paoletti, A comparison between conventional abrasives and superabrasives in grinding of SiC-aluminium composites. International Journal of Machine Tools and Manufacture, 40(2) (2000): 173-184.

[60] B. Anand Ronald, L. Vijayaraghavan, R. Krishnamurthy, Studies on the influence of grinding wheel bond material on the grindability of metal matrix composites. Materials and Design 30 (2009) 679-686.

[61] L. Zheng, D. Wenfeng, S. Long, X. Xinxin, F. Yucan, Comparative investigation on high-speed grinding of TiCp/Ti-6Al-4V particulate reinforced titanium matrix composites with single-layer electroplated and brazed CBN wheels. Chinese Journal of Aeronautics, (2016), 29(5): 14141424.

[62] C. Thiagarajan, R. Sivaramakrishnan, S. Somasundaram. Experimental evaluation of grinding forces and surface finish in cylindrical grinding of $\mathrm{Al} / \mathrm{SiC}$ metal matrix composites. Proc. IMechE Part B: J. Engineering Manufacture 225:1606-1614.

[63] Bejjani, R., B. Shi, H. Attia, and M. Balazinski. Laser assisted turning of titanium metal matrix composite. CIRP Annals-Manufacturing Technology 60, no. 1 (2011): 61-64.

[64] Z. Shang, Z. Liao, J.A. Sarasua, J. Billingham, D. Axinte. On modelling of laser assisted machining: Forward and inverse problems for heat placement control. International Journal of Machine Tools and Manufacture, 2019, 138, 36-50.

[65] Przestacki, Damian. "Conventional and laser assisted machining of composite A359/20SiCp." Procedia CIRP 14 (2014): 229-233.

[66] Garcí, V., Arriola, I., Gonzalo, O., \& Leunda, J. (2013). Mechanisms involved in the imrovement of Inconel 718 machinability by laser assisted machining (LAM). International journal of machine tools and manufacture, 74, 19-28.

[67] Wang, Yang, L. J. Yang, and N. J. Wang. "An investigation of laser-assisted machining of A12O3 particle reinforced aluminum matrix composite." Journal of materials processing technology 129.1-3 (2002): 268-272.

[68] Przestacki, D., P. Szymanski, and S. Wojciechowski. "Formation of surface layer in metal matrix composite A359/20SiCP during laser assisted turning." Composites Part A: Applied Science and Manufacturing 91 (2016): 370-379.

[69] Dandekar, Chinmaya R., and Yung C. Shin. "Experimental evaluation of laser-assisted machining of silicon carbide particle-reinforced aluminum matrix composites." The International Journal of Advanced Manufacturing Technology 66.9-12 (2013): 1603-1610. 
[70] Dandekar, Chinmaya R., and Yung C. Shin. "Multi-scale modeling to predict sub-surface damage applied to laser-assisted machining of a particulate reinforced metal matrix composite." Journal of Materials Processing Technology 213.2 (2013): 153-160.

[71] Zhang, H., Kong, X., Yang, L., Wang, Y., \& Chi, G. (2015). High temperature deformation mechanisms and constitutive modeling for $\mathrm{Al} / \mathrm{SiCp} / 45$ metal matrix composites undergoing laser-assisted machining. Materials Science and Engineering: A, 642, 330-339.

[72] Dandekar, Chinmaya R., and Yung C. Shin. Laser-assisted machining of a fiber reinforced metal matrix composite. Journal of manufacturing science and engineering 132.6 (2010): 061004.

[73] Przestacki, D., and M. Jankowiak. "Surface roughness analysis after laser assisted machining of hard to cut materials." Journal of Physics: Conference Series. 483(1) (2014) 1-7.

[74] Bulgakova NM, Bulgakov AV. Pulsed laser ablation of solids: transition from normal vaporization to phase explosion. Appl Phys A 2001;73:199-208

[75] Zhang, H. Z., T. Huang, Z. Liu, X. Zhang, J. L. Lu, and R. S. Xiao. "High fluence nanosecond laser machining of $\mathrm{SiC}$ p/AA2024 composite with high pressure assistant gas." Journal of Manufacturing Processes 31 (2018): 560-567.

[76] Grabowski A, Nowak M, Sleiziona, J. Laser cutting of an AlSi alloy/SiC composites: theory and experiments. J Achiev Mater Manuf Eng 2006;17:61-4

[77] Adalarasan, R., M. Santhanakumar, and M. Rajmohan. "Optimization of laser cutting parameters for $\mathrm{Al} 6061 / \mathrm{SiCp} / \mathrm{Al} 2 \mathrm{O} 3$ composite using grey based response surface methodology (GRSM)." Measurement 73 (2015): 596-606.

[78] Mardi, Kumari Bimla, A. R. Dixit, and Ashis Mallick. "Studies on Non-traditional Machining of Metal Matrix Composites." Materials Today: Proceedings 4.8 (2017): 8226-8239.

[79] Adalarasan, R., M. Santhanakumar, and S. Thileepan. "Selection of optimal machining parameters in pulsed CO2 laser cutting of Al6061/A12O3 composite using Taguchi-based response surface methodology (T-RSM)." The International Journal of Advanced Manufacturing Technology 93.1-4 (2017): 305-317.

[80] Sharma, Vikas, Vinod Kumar. Multi-objective optimization of laser curve cutting of aluminium metal matrix composites using desirability function approach. Journal of the Brazilian Society of Mechanical Sciences and Engineering 38.4 (2016): 1221-1238.

[81] Sharma, V., Kumar, V. Comparison of machining characteristics of metal matrix composites using $\mathrm{CO} 2$ laser curve cutting process. Proceedings of the Institution of Mechanical Engineers, Part E: Journal of Process Mechanical Engineering, 232(3) (2018) 349-368.

[82] Patel, Rajesh, and S. Srinivas. "Abrasive Water Jet Turning of Aluminum-silicon Carbide Metal Matrix Composites." Proceedings of 10th international conference on precision, meso, micro and nano engineering, 2017

[83] Srinivas, S., \& Babu, N. R. (2012). Penetration ability of abrasive waterjets in cutting of aluminum-silicon carbide particulate metal matrix composites. Machining Science and Technology, 16(3), 337-354. 
[84] Nag, Akash, Jiří Ščučka, Petr Hlavacek, Dagmar Klichová, Ashish Kr Srivastava, Sergej Hloch, Amit Rai Dixit, Josef Foldyna, and Michal Zelenak. "Hybrid aluminium matrix composite AWJ turning using olivine and Barton garnet." The International Journal of Advanced Manufacturing Technology94, no. 5-8 (2018): 2293-2300.

[85] Kumar, K. Ravi, V. S. Sreebalaji, and T. Pridhar. "Characterization and optimization of Abrasive Water Jet Machining parameters of aluminium/tungsten carbide composites." Measurement 117 (2018): 57-66.

[86] Sasikumar, K. S. K., K. P. Arulshri, K. Ponappa, and M. Uthayakumar. "A study on kerf characteristics of hybrid aluminium 7075 metal matrix composites machined using abrasive water jet machining technology." Proceedings of the Institution of Mechanical Engineers, Part B: Journal of Engineering Manufacture (2016): 0954405416654085.

[87] Mardi, K. Bimla, A. R. Dixit, A. Mallick, Alokesh Pramanik, Beata Ballokova, Pavol Hvizdos, Josef Foldyna, Jiri Scucka, Petr Hlavacek, and Michal Zelenak. "Surface integrity of Mg-based nanocomposite produced by Abrasive Water Jet Machining (AWJM)." Materials and Manufacturing Processes 32, no. 15 (2017): 1707-1714.

[88] Srivastava, Ashish Kumar, Akash Nag, Amit Rai Dixit, Sandeep Tiwari, Jiri Scucka, Michel Zelenak, Sergej Hloch, and Peter Hlavacek. "Surface integrity in tangential turning of hybrid MMC A359/B4C/A12O3 by abrasive waterjet." Journal of Manufacturing Processes 28 (2017): $11-20$.

[89] T. Singh, A. Dvivedi, Developments in electrochemical discharge machining: A review on electrochemical discharge machining, process variants and their hybrid methods, International Journal of Machine Tools and Manufacture, 105 (2016) 1-13.

[90] K.H. Ho, S.T. Newman, State of the art electrical discharge machining (EDM), International Journal of Machine Tools and Manufacture, 43 (13) (2003) 1287-1300.

[91] N. Mohd Abbas, D.G. Solomon, M. Fuad Bahari, A review on current research trends in electrical discharge machining (EDM), International Journal of Machine Tools and Manufacture, 47 (7) (2007) 1214-1228.

[92] K.H. Ho, S.T. Newman, S. Rahimifard, R.D. Allen, State of the art in wire electrical discharge machining (WEDM), International Journal of Machine Tools and Manufacture, 44 (12) (2004) 1247-1259.

[93] E.C. Jameson, Electrical Discharge Machining. UK: Society of Manufacturing Engineers.

[94] T. M. Yue, Y. Dai, W. S. Lau, An examination of wire electrical discharge machining (WEDM) of Al2O3 particulate reinforced aluminum based composites, Materials and Manufacturing Processes, 11 (3) (1996) 341-350.

[95] B. Hwa Yan, H.C. Tsai, F. Yuan Huang, L. Chorng Lee, Examination of wire electrical discharge machining of Al2O3p/6061Al composites, International Journal of Machine Tools and Manufacture, 45 (3) (2005) 251-259. 
[96] N.G. Patil, P.K. Brahmankar, Semi-empirical Modeling of Surface Roughness in Wire Electrodischarge Machining of Ceramic Particulate Reinforced Al Matrix Composites, Procedia CIRP, 42 (2016) 280-285

[97] Ş. Karabulut, H. Karakoç, R. Citak, Effect of the B4C reinforcement ratio on surface roughness of A16061 based metal matrix composite in wire-EDM machining, Proceedings of International Conference on Mechanical and Aerospace Engineering, (2017) 812-815.

[98] H. Kumar, A. Manna, R. Kumar, Modeling of process parameters for surface roughness and analysis of machined surface in WEDM of Al/SiC-MMC, Transactions of the Indian Institute of Metals, 71 (1) (2018) 231-244.

[99] W. Zhenlong, G. Xuesong, C. Guanxin, W. Yukui, Surface integrity associated with SiC/A1 particulate composite by micro-wire electrical discharge machining, Materials and Manufacturing Processes, 29 (5) (2014) 532-539.

[100] S.K. Shanmugam, M. Uthayakumar, T. Kumaran, P. Pad, Electrical discharge machining of $\mathrm{Al}(6351)-\mathrm{SiC}-\mathrm{B} 4 \mathrm{C}$ hybrid composite, Materials and Manufacturing Processes, 29 (11-12) (2014) 1395-1400.

[101] S. Mahanta, M. Chandrasekaran, S. Samanta, R.M. Arunachalam, EDM investigation of Al 7075 alloy reinforced with B4C and fly ash nanoparticles and parametric optimization for sustainable production, Journal of the Brazilian Society of Mechanical Sciences and Engineering, 40 (5) (2018) 263.

[102] A. Pramanik, A.K. Basak, Fracture and fatigue life of Al-based MMCs machined at different conditions, Eng. Fract. Mech. 191 (2018) 33-45.

[103] R. Fernández, S. Cabeza, T. Mishurova, P. Fernández-Castrillo, G. González-Doncel, G. Bruno, Residual stress and yield strength evolution with annealing treatments in an age-hardenable aluminum alloy matrix composite, Mater. Sci. Eng. A. 731 (2018) 344-350.

[104] Gabb, T. P., Gayda, J., \& MacKay, R. A. Isothermal and nonisothermal fatigue behavior of a metal matrix composite. Journal of Composite Materials, 24(6) (1990) 667-686.

[105] Logsdon, W. A., \& Liaw, P. K. Tensile, fracture toughness and fatigue crack growth rate properties of silicon carbide whisker and particulate reinforced aluminum metal matrix composites. Engineering Fracture Mechanics, 24(5) (1986) 737-751.

[106] Ceschini, L., Minak, G., \& Morri, A. Tensile and fatigue properties of the AA6061/20 vol\% Al2O3p and AA7005/10 vol\% Al2O3p composites. Composites Science and Technology, 66(2), (2006) 333-342.

[107] S. Fudger, D. Sediako, P. Karandikar, C. Ni, Residual stress induced mechanical property enhancement in steel encapsulated light metal matrix composites, Mater. Sci. Eng. A. 699 (2017) $10-17$.

[108] D. Novovic, R.C. Dewes, D.K. Aspinwall, W. Voice, P. Bowen, The effect of machined topography and integrity on fatigue life, Int. J. Mach. Tools Manuf. 44 (2004) 125-134. 
[109] A. Pramanik, M.N. Islam, I.J. Davies, B. Boswell, Y. Dong, A.K. Basak, M.S. Uddin, A.R. Dixit, S. Chattopadhyaya, Contribution of machining to the fatigue behaviour of metal matrix composites (MMCs) of varying reinforcement size, Int. J. Fatigue. 102 (2017) 9-17.

[110] M. Ramulu, G. Paul, J. Patel. EDM surface effects on the fatigue strength of a $15 \mathrm{vol} \% \mathrm{SiCp} / \mathrm{Al}$ metal matrix composite material. Composite structures 54.1 (2001) 79-86.

[111] S.G. Long, and Y.C. Zhou. Thermal fatigue of particle reinforced metal-matrix composite induced by laser heating and mechanical load. Composites Science and Technology 65.9 (2005): 1391-1400. 